\title{
GGLL - Um gerador de analisadores sintáticos para gramáticas gráficas LL(1)
}

\author{
Tasso Tirapani Silva Pinto
}

\author{
DISSERTAÇÃO APRESENTADA \\ $A O$ \\ INSTITUTO DE MATEMÁTICA E ESTATÍSTICA \\ $D A$ \\ UNIVERSIDADE DE SÃo PAULO \\ PARA \\ OBTENÇÃO DO TÍTULO \\ $\mathrm{DE}$ \\ Mestre em CiÊnCIAS
}

Programa: Ciência da Computação

Orientador: Prof. Dr. Valdemar W. Setzer 


\section{GGLL - Um gerador de analisadores sintáticos para gramáticas gráficas LL(1)}

\footnotetext{
Esta versão da dissertação contém as correções e alterações sugeridas pela Comissão Julgadora durante a defesa da versão original do trabalho, realizada em 19/11/2014. Uma cópia da versão original está disponível no Instituto de Matemática e Estatística da Universidade de São Paulo.
}

Comissão Julgadora:

- Prof. Dr. Valdemar W. Setzer (orientador) - IME-USP

- Prof. Dr. José Remo Ferreira Brega - UNESP

- Prof. Dr. Tomasz Kowaltowski - UNICAMP 


\section{Agradecimentos}

Ao meu orientador, Valdemar W. Setzer, por confiar em mim e me guiar durante o desenvolvimento desta dissertação com seu conhecimento, paciência e experiência.

Aos meus pais, Edson da Silva Pinto e Maria Aparecida Tirapani Pinto, por sempre me apoiar e me ajudar a chegar onde estou hoje, me ensinando seus valores e crenças.

A minha esposa Katarina Barcellos Tirapani, pelo apoio, afeto e paciência nesses últimos meses em que tenho me dedicado a dissertação. E Hector Kikuchi Martins e Ígor Bonadio pela ajuda que me deram ao testar o sistema desenvolvido e ajudar a aprimorá-lo. 


\section{Resumo}

SILVA PINTO, T. T. GGLL - An gerador de analisadores sintáticos para gramáticas gráficas LL(1). 2014. 120 f. Dissertação (Mestrado) - Instituto de Matemática e Estatística, Universidade de São Paulo, São Paulo, 2010.

Este trabalho tem como fulcro o desenvolvimento de um gerador de analisadores sintáticos do tipo top-down para gramáticas LL(1) com entrada gráfica da gramática, bem como uma comparação do mesmo com outros geradores em uso no mercado. Como resultado foi obtido um gerador totalmente funcional, e foi mostrado como ele é superior aos outros analisadores. São descritos detalhes da implementação e foi elaborado um manual de uso do sistema implementado em Java independente de ambientes de programação.

Palavras-chave: analisador sintático, gramática, LL(1), compilador, gerador de analisadores sintáticos. 


\section{Abstract}

SILVA PINTO, T. T. GGLL - An parser generator for graph grammars LL(1). 2014. 120 f. Dissertação (Mestrado) - Instituto de Matemática e Estatística, Universidade de São Paulo, São Paulo, 2010.

This thesis has as its main goal the development a parser generator using top-down syntax analysis for $\mathrm{LL}(1)$ grammars. Its input is a graph grammar. A comparison with available parser generators is also presented. As a result a fully executable generator, and the fact that it is superior to the other generators was demonstrated. This work contains details of the implementation, and presents a user's manual of the system, which was implemented in Java. The system is independent of programming environments.

Keywords: syntax analyzer, grammar, LL(1), compiler, parser generator. 


\section{Sumário}

$\begin{array}{ll}\text { Lista de Abreviaturas } & \mathbf{x i}\end{array}$

Lista de Figuras $\quad$ xiii

Lista de Tabelas $\quad$ xv

Lista de Quadros $\quad$ xvii

1 Introdução 1

1.1 Motivação . . . . . . . . . . . . . . . . . . . . 2

1.2 Caracterização da Pesquisa . . . . . . . . . . . . . . . . . . 3

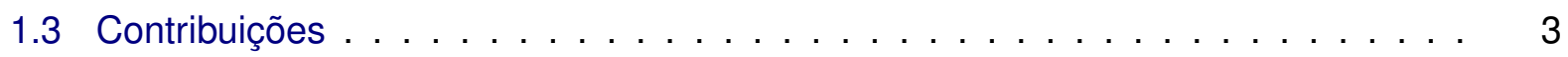

1.4 Divisão do Trabalho . . . . . . . . . . . . . . . . . . . . . . 4

2 Linguagens e Gramáticas $\quad 5$

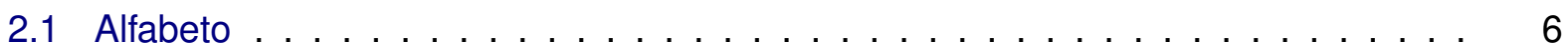

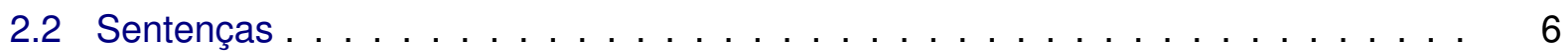

2.3 Linguagem . . . . . . . . . . . . . . . . . . . . . . . . . . 6

2.4 Gramática . . . . . . . . . . . . . . . . . . . . . . . . . . . . . . . 7

2.5 Derivação . . . . . . . . . . . . . . . . . . . . . . . . . 7

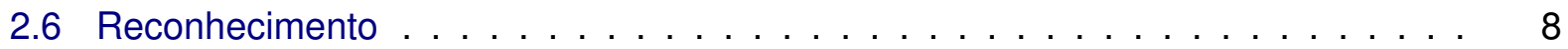

2.7 Tamanho de uma cadeia . . . . . . . . . . . . . . . . . . . . . 8

2.8 Gramáticas equivalentes . . . . . . . . . . . . . . . . . . . . . . . 8

2.9 Árvore de derivação ou árvore sintática . . . . . . . . . . . . . . . . . 8

2.10 Gramáticas ambíguas . . . . . . . . . . . . . . . . . . . . . . . 9

2.11 Tipos de gramáticas . . . . . . . . . . . . . . . . . . . 9

2.11 .1 Gramáticas regulares ou do tipo $3 \ldots \ldots$. . . . . . . . . . . . 10

2.11 .2 Gramáticas livres de contexto ou do tipo 2 . . . . . . . . . . . . . . . . . . . 10

2.11.3 Gramáticas sensíveis ao contexto ou do tipo 1 . . . . . . . . . . . . . . . . 11

2.11 .4 Gramáticas irrestritas ou do tipo $0 \ldots \ldots$. . . . . . . . . . . . . 11

2.11 .5 Gramáticas gráficas . . . . . . . . . . . . . . . . . . . . . . . . . 11

3 Estrutura de um Compilador $\quad 15$

3.1 Análise léxica . . . . . . . . . . . . . . . . . . . . . . . . . . . 15

3.1 .1 Tokens . . . . . . . . . . . . . . . . . . . . . 16

3.1 .2 Lexemas . . . . . . . . . . . . . . . . . . . . 16 
3.1 .3 Padrões . . . . . . . . . . . . . . . . . . . . . . 16

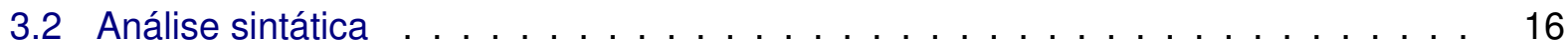

3.3 Análise semântica . . . . . . . . . . . . . . . . . . . . . . . . . 17

3.3 .1 Análise de contexto . . . . . . . . . . . . . . . . . 17

3.3 .2 Geração de código . . . . . . . . . . . . . . . . . . . . . . . . . . . . 18

4 Análise Sintática $r$

4.1 Métodos ascendentes ou bottom-up . . . . . . . . . . . . . . . . . . . . . . . . 19

4.2 Métodos descendentes ou top-down . . . . . . . . . . . . . . . . . . . . 20

4.3 Gramáticas LL(k) . . . . . . . . . . . . . . . . . . . . . . . . . . . . . . 21

4.3 .1 Recursão à esquerda . . . . . . . . . . . . . . . . . . . . 22

4.3 .2 Fatoração à esquerda . . . . . . . . . . . . . . . . . . . . 22

5 Geradores de Analisadores Sintáticos em Uso 23

5.1 Yacc/Lex e Bison/Flex . . . . . . . . . . . . . . . . . . . . . . . . . . 23

5.1 .1 Entrada . . . . . . . . . . . . . . . . . . . . 23

5.1 .2 Saída . . . . . . . . . . . . . . . . . . . . . . . 26

5.1 .3 Recuperação de erros . . . . . . . . . . . . . . . . . . . . . . . 26

5.1 .4 Bison/Flex . . . . . . . . . . . . . . . . . . . . 26

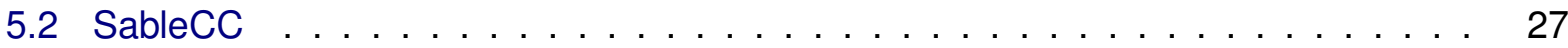

5.2 .1 Entrada . . . . . . . . . . . . . . . . . . . . . . 27

5.2 .2 Saída . . . . . . . . . . . . . . . . . . . . 28

5.2 .3 Recuperação de erros . . . . . . . . . . . . . . . . . . . . . . . . 28

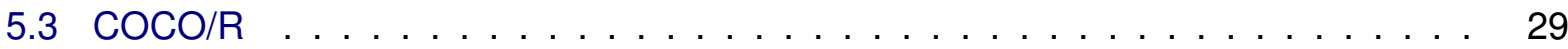

5.3 .1 Entrada . . . . . . . . . . . . . . . . . . . . . . . . . 29

5.3 .2 Saída . . . . . . . . . . . . . . . . . . . . . . . . 30

5.3 .3 Recuperação de erros . . . . . . . . . . . . . . . . . . . . . 30



5.4 .1 Entrada . . . . . . . . . . . . . . . . . . . . . 30

5.4 .2 Saída . . . . . . . . . . . . . . . . . . . . . 31

5.4 .3 Recuperação de erro . . . . . . . . . . . . . . . . . . . . . . 31

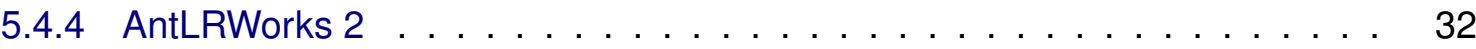

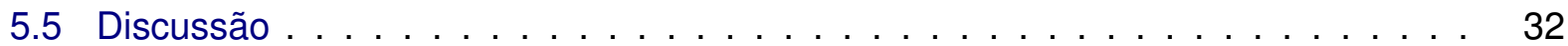

6 O Sistema GGLL 33

6.1 Funcionamento do GGLL . . . . . . . . . . . . . . . . . . . . . . 33

6.2 Interface do GGLL . . . . . . . . . . . . . . . . . . . . . . . . . . 35

6.3 Estrutura do GGLL . . . . . . . . . . . . . . . . . . . . . . . . . . . . . 38

6.4 Utilização do GGLL . . . . . . . . . . . . . . . . . . . . . . . . . . 38

6.5 Algoritmos . . . . . . . . . . . . . . . . . . . . . . . 39

6.5 .1 Tabelas . . . . . . . . . . . . . . . . . . . 39

6.5 .2 Pilhas . . . . . . . . . . . . . . . . . . . . . 43

6.5 .3 Análise sintática . . . . . . . . . . . . . . . . . . . . 44 
6.6 Estratégias de Emissão de Mensagem e Continuação da Análise ou Recuperação de erros . . . . . . . . . . . . . . . . . . . . . . 47

6.6.1 Emissão automática de mensagem de erro . . . . . . . . . . . . . . . 47

6.6 .2 Inserção de token . . . . . . . . . . . . . . . . . . . . . 47

6.6 .3 Troca de token . . . . . . . . . . . . . . . . . . . 48

6.6 .4 Eliminação de token . . . . . . . . . . . . . . . . . . . . . . . . . . . . . . . . . 49

6.6 .5 Busca de delimitadores . . . . . . . . . . . . . . . . . . . . 50

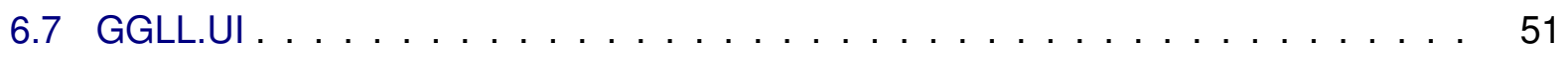

6.7 .1 Arquitetura . . . . . . . . . . . . . . . . . . . . 51

6.7 .2 Entrada de dados . . . . . . . . . . . . . . . . . 53

6.7 .3 Saída de dados . . . . . . . . . . . . . . . . . . . . 54

6.7 .4 APls utilizadas . . . . . . . . . . . . . . . . . . . . . . . . . . . . . . . . . . . . . . .

6.7 .5 Validação da Gramática Gráfica . . . . . . . . . . . . . . . . . . 54

6.7 .6 Desafios . . . . . . . . . . . . . . . . . . . . . . . . . . . . . . . . . . . . . . .

6.8 GGLL.Core . . . . . . . . . . . . . . . . . . . . . . . . . . . . 55

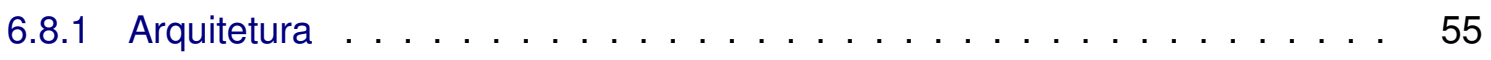

6.8 .2 Entrada de dados . . . . . . . . . . . . . . . . 60

6.8 .3 Saída de dados . . . . . . . . . . . . . . . . . . . . . . 60

6.8 .4 APls utilizadas . . . . . . . . . . . . . . . . . . . 60

6.8 .5 Desafios . . . . . . . . . . . . . . . . . . 60

7 Resultados $\quad 63$

7.1 Utilização didática . . . . . . . . . . . . . . . . . . . 63

7.2 Testes com usuários . . . . . . . . . . . . . . . . . . . . . 63

7.2 .1 Primeiro cenário . . . . . . . . . . . . . . . . . . . . 63

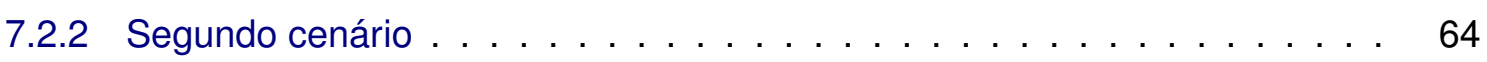

7.2 .3 Terceiro cenário . . . . . . . . . . . . . . . . . . . . . 64

8 Conclusões $\quad 65$

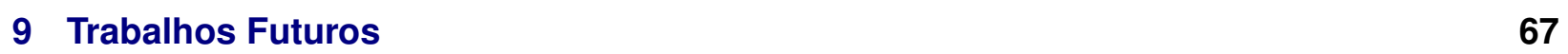

$\begin{array}{ll}\text { A Algoritmos } & \mathbf{6 9}\end{array}$

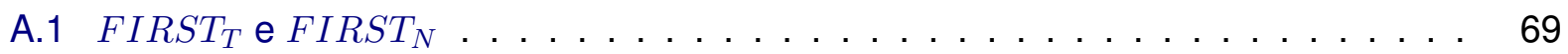

A.2 Eliminação de recursão à esquerda . . . . . . . . . . . . . . . . . 69

B Padrões de Projeto $\quad 71$

B.1 Visitor . . . . . . . . . . . . . . . . . . . . . . . . . . . 71

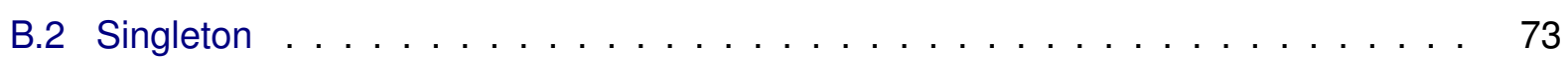

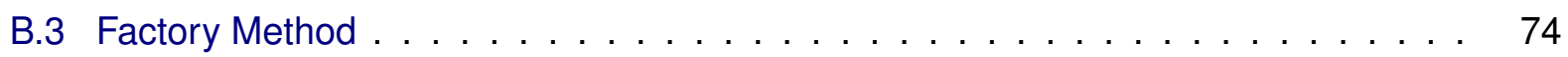

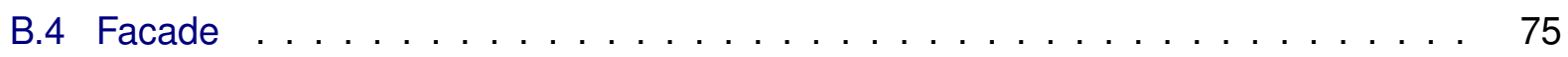

$\begin{array}{ll}\text { C Manual de utilização do GGLL } & 77\end{array}$

C.1 Prefácio . . . . . . . . . . . . . . . . . . . . . . . . 77

C.2 Acordo de Licença . . . . . . . . . . . . . . . . . . . . 77 
C.3 Introdução ao Sistema . . . . . . . . . . . . . . . . . . . . . . . . . . 78

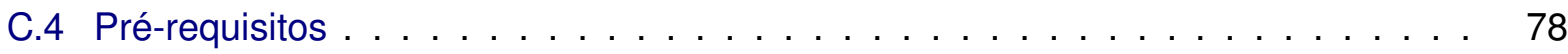

C.5 Configuração do GGLL.UI ． . . . . . . . . . . . . . . . . . . . . . . . . . . 78

C.6 Execução do GGLL.UI . . . . . . . . . . . . . . . . . . . . . . . . . . . . . . . . . 78

C.7 Interface do Sistema . . . . . . . . . . . . . . . . . . . . . . . . . . . 79

C.7.1 Menu superior . . . . . . . . . . . . . . . . . . . . . . . 80

C.7.2 Parser (menu lateral direito) . . . . . . . . . . . . . . . . . . . . . 81

C.7.3 Files . . . . . . . . . . . . . . . . . . . . . . . 82

C.7.4 Menu lateral esquerdo . . . . . . . . . . . . . . . . . . . 83

C.7.5 Área de trabalho para criação de gramática . . . . . . . . . . . . . . . . 83

C.7.6 Aba Output . . . . . . . . . . . . . . . . . . . . . . . . . . . 84

C.7.7 Aba Grammar . . . . . . . . . . . . . . . . . . . . . . 85

C.7.8 Aba Syntax Stack . . . . . . . . . . . . . . . . . . . . . . . . . . 85

C.7.9 Aba Semantic Stack . . . . . . . . . . . . . . . . . . . . . . 85

C.7.10 Editor de Texto . . . . . . . . . . . . . . . . . . . . . . . . 86

C.8 Execução passo a passo $($ debug $) \ldots \ldots \ldots \ldots$. . . . . . . . . . . . 86

C.9 Análise Léxica . . . . . . . . . . . . . . . . . . . . . . . . . . . . . 90

C.10 Análise Semântica ． . . . . . . . . . . . . . . . . . . . . . . . . 90

C.11 Exemplo de uma Calculadora com Atribuição . . . . . . . . . . . . . . . . . . . . 90

C.12 Adição de rotinas semânticas . . . . . . . . . . . . . . . . . . . . . . . . . 92

C.13 O GGLL.Core . . . . . . . . . . . . . . . . . . . . . . . . . . . . . . . . . . . 96

C.13.1 Arquivo Léxico . . . . . . . . . . . . . . . . . . . . . . . . . 96

C.13.2 Arquivo Semântico . . . . . . . . . . . . . . . . . . . . . . . . . . . 96

C.13.3 Arquivo Sintático . . . . . . . . . . . . . . . . . . . . . . . . . . 97

C.13.4 Execução do GGLL.Core . . . . . . . . . . . . . . . . . . . . . . . . . . . 98

$\begin{array}{ll}\text { Referências Bibliográficas } & 101\end{array}$ 


\section{Lista de Abreviaturas}

AntLR Another Tool for Language Recognition

BNF Backus Normal Form

ESLL Extended simple LL

LALR Look-Ahead LR parser

LL Left to right, and constructs a Leftmost derivation

LR Left to right, and constructs a Rightmost derivation

PCCTS Purdue Compiler Construction Tool Set

Yaac Yet Another Compiler Compiler 


\section{Lista de Figuras}

2.1 Exemplo de árvore de derivação $\ldots \ldots \ldots \ldots$

2.2 Hierarquia de Chomsky . . . . . . . . . . . . . . . . . . . . . . . . . . 10

2.3 Exemplo de gramática gráfica . . . . . . . . . . . . . . . . . . . . . . . . 12

2.4 Exemplo de cadeia de alternativas . . . . . . . . . . . . . . . . . . . . . . . 13

2.5 Gramática gráfica com expressão regular . . . . . . . . . . . . . . . . . . . . 14

4.1 Árvore de derivação ascendente . . . . . . . . . . . . . . . . . . . . . . . . 19

4.2 Árvore de derivação descendente . . . . . . . . . . . . . . . . . 21

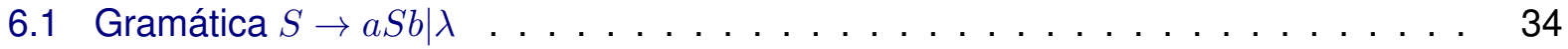

6.2 Interface do GGLL . . . . . . . . . . . . . . . . . . . . . 36

6.3 Entrada de uma cadeia no GGLL.UI . . . . . . . . . . . . . . . . . . . . 36

6.4 Aba Grammar . . . . . . . . . . . . . . . . . . . . . . . . . . . . . . . . 37

6.5 Aba Syntax Stack . . . . . . . . . . . . . . . . . . . . . . . . . . . . . 37

6.6 GGLL Aba Semantic Stack . . . . . . . . . . . . . . . . . . . . . . . 38

6.7 Exemplo de geração de tabela intermediária $\ldots \ldots \ldots$. . . . . . . . . . . . . 42

6.8 Exemplo de recuperação de erro (inserção) . . . . . . . . . . . . . . . . . . . . . 48

6.9 Exemplo de recuperação de erro (troca) . . . . . . . . . . . . . . . . . . . . . . . 49

6.10 Exemplo de recuperação de erro (eliminação) . . . . . . . . . . . . . . . . . . . 50

6.11 Exemplo de recuperação de erro (busca de delimitadores) . . . . . . . . . . . . . 51

6.12 Pacotes do GGLL.UI . . . . . . . . . . . . . . . . . . . . . . . . . . . 52

6.13 Pacotes do GGLL.Core . . . . . . . . . . . . . . . . . . . . . . . . . . 55

6.14 Gramática para o analisador do XML de entrada do GGLL.Core - 1 . . . . . . . . 58

6.15 Gramática para o analisador do XML de entrada do GGLL.Core - 2 . . . . . . . . . 59

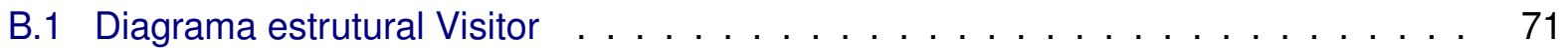

B.2 Diagrama estrutural Singleton . . . . . . . . . . . . . . . . . . . 73

B.3 Diagrama estrutural Factory Method . . . . . . . . . . . . . . . 74

B.4 Diagrama estrutural Facade . . . . . . . . . . . . . . . . . . . 75

C.1 GGLL.UI - Seleção de Workspace . . . . . . . . . . . . . . . . . . . . . . . . 79

C.2 GGLL.UI -tela principal . . . . . . . . . . . . . . . . . . . . . . . . . . . . 80

C.3 GGLL.UI-Menu superior . . . . . . . . . . . . . . . . . . . . . . . . . . . . . . 80

C.4 GGLL.UI-Parser . . . . . . . . . . . . . . . . . . . . . . . . . . . . . . . . . 81

C.5 GGLL.UI-aba Files . . . . . . . . . . . . . . . . . . . . . . . . . . . . 82

C.6 GGLL.UI - Menu lateral esquerdo . . . . . . . . . . . . . . . . . . . . . . . . . . 83 
C.7 GGLL.UI - Exemplo de criação de gramática . . . . . . . . . . . . . . . . . . . . . 84

C.8 GGLL.UI-Output . . . . . . . . . . . . . . . . . . . . . . . . . . . . . . 84

C.9 GGLL.UI-Grammar . . . . . . . . . . . . . . . . . . . . . . . . . . . . . . . . 85

C.10 GGLL.UI - Editor de Texto . . . . . . . . . . . . . . . . . . . . . . . . . . . . 86

C.11 GGLL.UI - Exemplo de debug - Gramática . . . . . . . . . . . . . . . . . . . . 87

C.12 GGLL.UI - Exemplo de debug - Passo $1 \ldots$. . . . . . . . . . . . . . . . . . . . . . . 87

C.13 GGLL.UI - Exemplo de debug - Passo $2 \ldots \ldots$. . . . . . . . . . . . . . . . . 88

C.14 GGLL.UI - Exemplo de debug - Passo $3 \ldots \ldots$. . . . . . . . . . . . . . . 88

C.15 GGLL.UI - Exemplo de debug - Passo $4 \ldots \ldots$. . . . . . . . . . . . . . . . . . . 89

C.16 GGLL.UI - Exemplo de debug - Passo $5 \ldots$. . . . . . . . . . . . . . . . . . . . . . 89

C.17 GGLL.UI - Gramática gráfica de uma calculadora ． . . . . . . . . . . . . . . . . 91

C.18 GGLL.UI - Adição de rotina semântica . . . . . . . . . . . . . . . . . . . . . . . . . 92

C.19 GGLL.UI - Código da Rotina Semântica . . . . . . . . . . . . . . . . . . . . . . . . 93

C.20 GGLL.UI - Gramática gráfica de uma calculadora com rotinas semânticas . . . . . 94 


\section{Lista de Tabelas}

3.1 Tokens, padrões e lexemas. Fonte: Adaptada de $[$ ALSU08, 71] . . . . . . . . . . 16

5.1 Comparação entre geradores de analisadores sintáticos . . . . . . . . . . . . . . 32

5.2 Comparação entre geradores de analisadores sintáticos . . . . . . . . . . . . . 32

6.1 Exemplo de execução do GGLL . . . . . . . . . . . . . . . . . . . . . . . . . . . . . . 35

6.2 Tabela GGLL . . . . . . . . . . . . . . . . . . . . . . . . . . . . . . . . 39

6.3 Exemplo de tabela intermediária . . . . . . . . . . . . . . . . . . . . . 42

6.4 Exemplo tabela nodes . . . . . . . . . . . . . . . . . . . 43

6.5 Exemplo tabela nTerminal . . . . . . . . . . . . . . . . . . . . . . . 43

6.6 Exemplo tabela Terminal . . . . . . . . . . . . . . . . . . . 43

C.1 GGLL.UI - Comandos Menu Superior . . . . . . . . . . . . . . . . . . . . . . . . . . . . 81

C.2 GGLL.UI - Comandos da aba Parser . . . . . . . . . . . . . . . . . . . . . . . . . . 82

C.3 GGLL.UI - Menu lateral esquerdo . . . . . . . . . . . . . . . . . . . . . . . . 83 


\section{Lista de Quadros}

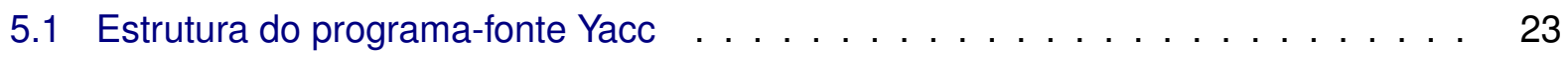

5.2 Regras de tradução do Yacc . . . . . . . . . . . . . . . . . . . 24

5.3 Exemplo de declaração em um arquivo do Lex . . . . . . . . . . . . . 25

5.4 Exemplo de regras de produção em um arquivo do Lex . . . . . . . . . 25

5.5 Exemplo de rotinas de suporte em um arquivo do Lex . . . . . . . . . . 25

5.6 Exemplo de declaração em um arquivo do Yacc . . . . . . . . . . . . 25

5.7 Exemplo de regras de produção em um arquivo do Yacc . . . . . . . . . . 25

5.8 Exemplo de rotinas de suporte em um arquivo do Yacc . . . . . . . . . . . 26

5.9 Exemplo de execução do Lex e Yacc . . . . . . . . . . . . . . . . . . 26

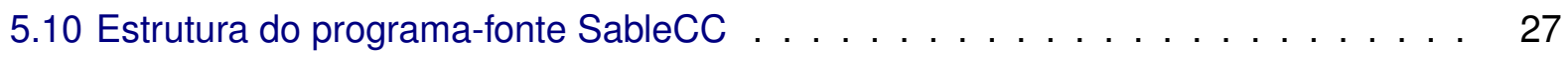

5.11 Exemplo de arquivo SableCC . . . . . . . . . . . . . . . . . 28

5.12 Estrutura do programa-fonte $\mathrm{COCO} / \mathrm{R} \ldots \ldots \ldots . \ldots . . \ldots 29$

5.13 Exemplo de arquivo COCO/R . . . . . . . . . . . . . . . . . . 29

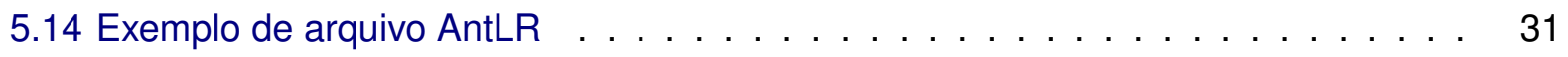

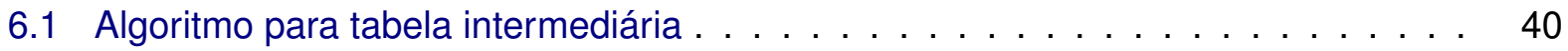

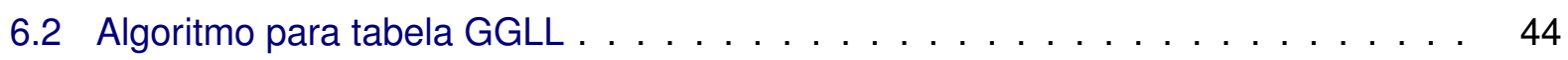

A.1 Algoritmo para detecção de recursão à esquerda . . . . . . . . . . . . . . 69

B.1 Exemplo de implementação do padrão de projeto Visitor . . . . . . . . . . 72

B.2 Exemplo de implementação do padrão de projeto Singleton . . . . . . . . . 73

B.3 Exemplo de implementação do padrão de projeto Factory Method . . . . . . 74

B.4 Exemplo de implementação do padrão de projeto Facade . . . . . . . . . . 75

C.1 Exemplo de rotinas semânticas . . . . . . . . . . . . . . . . . . . . . 94

C.2 Schema XML Gramática . . . . . . . . . . . . . . . . . . . . . . . . . 97

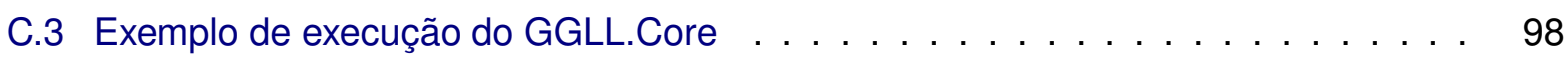




\section{Capítulo 1}

\section{Introdução}

Atualmente, o número de linguagens de programação de computadores em uso é vasto. Variando de propósitos gerais a altamente especializadas, elas estão presentes em quase todas as áreas da computação. Há linguagens gerais de programação como Fortran, Pascal, C e Java, mas também há muitas linguagens usadas em aplicações de domínios específicos. Linguagens de programação podem ser usadas para descrever muitas coisas além de algoritmos [GH98a], como é o caso do HTML, utilizado para formatar documentos para a internet, ou a SQL, utilizada para fazer acessos a bases de dados relacionais.

Para que uma linguagem de programação seja executada ou interpretada por um computador, é preciso ter um programa tradutor de um programa escrito nessa linguagem para outra linguagem, que pode ser interpretada ou, no caso da segunda ser uma linguagem de máquina, executada pelo computador. Esse programa tradutor é chamado de compilador. Uma parte essencial dos compiladores é o analisador sintático, que pode orientar toda a compilação quando a linguagem é descrita por uma gramática formal.

O objetivo deste trabalho foi apresentar um gerador de analisadores sintáticos que aceita uma descrição gráfica da gramática da linguagem a ser compilada, denominado "GGLL" (de 'Gerador de analisadores sintáticos para Gramáticas Gráficas $L L(1)$ '), realizar uma implementação desse gerador na linguagem de programação Java com uma arquitetura orientada a objetos, independente de ambientes de programação, compará-lo com outros geradores de analisadores sintáticos e colocá-lo à disposição pública como software livre, incluindo um manual de utilização. A comparação mostrou que o GGLL é em geral superior aos geradores em uso.

As gramáticas são fornecidas ao GGLL em uma especificação gráfica. O GGLL é uma extensão do gerador para gramáticas ESLL(1) (de Extended Simple LL(1)), definidas por V.W. Setzer [SDM83] [Set79], implementado provisoriamente por Gustavo Henrique Braga [Bra09] sob orientação do primeiro. Nesta extensão aqui descrita, são permitidos símbolos não terminais com alternativas, obtendo-se um analisador que aceita gramáticas LL(1), com isso as gramáticas podem ser bem mais compactas do que no caso das gramáticas ESLL(1). Uma das características favoráveis do GGLL é que o usuário não precisa aumentar a gramática ou programar absolutamente nada para obter mensagens de erros sintáticos e para a continuidade da análise (no jargão da compilação, "recuperação da análise"). Tudo isso é feito automaticamente a partida da gramática. São executados algoritmos que implementam várias estratégias de continuidade da análise, comunicando ao usuário qual foi a correção simulada na cadeia de entrada ou da análise efetuada. O GGLL ainda apresenta uma interface para o analisador léxico JFlex e suporte 
a rotinas semânticas escritas em Java. Rotinas semânticas são rotinas executadas pelo analisador sintático responsáveis pela execução da análise semântica da gramática, isto é, a análise de contexto e a geração de código. $O$ analisador léxico e o analisador sintático, expandido com as rotinas semânticas programadas pelo implementador formam um compilador completo. $\mathrm{O}$ analisador sintático serve para controlar todo o processo de compilação, sendo portanto o cerne de um compilador.

Além disso, essa implementação foi comparada com outros sistemas de geradores de analisadores sintáticos a fim de comprovar suas vantagens. Ela também contribui para facilitar a criação, implementação e compreensão de novas linguagens para problemas específicos.

Finalmente, este trabalho descreve detalhes da implementação do GGLL e apresenta um manual de sua utilização.

É interessante notar que a área de geradores de analisadores sintáticos ainda é pesquisada, e novos geradores estão sendo desenvolvidos e usados, como o AntLR 4 [Par13].

A redação desta dissertação segue as normas estabelecidas pelo Departamento de Ciência da Computação do IME-USP, conforme o padrão em LaTex fornecido [MC13].

\subsection{Motivação}

Este trabalho de pesquisa possui diversas motivações. A primeira delas deve-se à grande importância que as linguagens de programação apresentam na área da Ciência da Computação, para a implementação de algoritmos e na utilização de computadores. Dijkstra [Dij97] escreveu: "Eu vejo uma linguagem de programação principalmente como um veículo para a descrição (potencialmente muito complexa) de mecanismos abstratos".

Além disso, novas linguagens surgem constantemente para propósitos gerais, como $\mathrm{C} / \mathrm{C}++$, Java e C\#, ou para propósitos mais específicos, como HTML [W3C14] e Lex [LS90].

Um programa escrito em linguagem de programação deve necessariamente ser interpretado comando a comando por um programa (interpretador) sendo executado por um computador, ou compilado (isto é, traduzido) em sua totalidade por um programa (compilador), que gera um código que é executado pelo computador ou interpretado por um programa. Uma ferramenta essencial para se construir interpretadores ou compiladores é o analisador sintático. De fato, hoje em dia praticamente todos interpretadores e compiladores são orientados pela sintaxe, pela gramática da linguagem, pois essa gramática estabelece a estrutura sintática da linguagem. Reconhecido um elemento sintático, ele pode eventualmente ser interpretado ou compilado. Por exemplo, em uma expressão aritmética, o uso de uma gramática pode indicar cada operação (como uma soma ou uma multiplicação) que deve ser realizada na sequência correta das precedências em relação às outras operações.

Gramáticas têm sido usadas para definir as sentenças válidas de uma linguagem de programação. A linguagem ALGOL-60 foi definida em seu relatório original por meio de uma gramática usando uma notação que ficou conhecida como Backus Normal Form ou BNF [BBG+63]. Posteriormente, certas linguagens foram definidas graficamente, mediante grafos sintáticos. Esses grafos, por serem muito simples, ajudam os programadores, não exigindo deles maiores conhecimentos, como por exemplo da notação de expressões regulares (expressões que usam operadores para, por exemplo, indicar um fechamento transitivo de uma cadeia de símbolos). 
Como os analisadores sintáticos tornaram-se parte essencial dos interpretadores e dos compiladores, foram realizadas pesquisas para desenvolver geradores desses analisadores. Sendo assim, houve uma motivação em estudar alguns geradores de analisadores existentes e desenvolver um gerador de analisadores sintáticos com base nos algoritmos criados por V.W. Setzer que partem de uma descrição gráfica da gramática [SDM83]. Como a descrição gráfica da gramática é muito simples, esse gerador torna-se muito útil tanto educacional como profissionalmente. Além disso, ele abre um campo de pesquisa com o intuito de elaborar uma linguagem de descrição das rotinas semânticas, isto é, de análise de contexto e de geração de código, associadas à representação gráfica da gramática.

O método de análise sintática desenvolvido por Setzer possui, além da vantagem da definição gráfica de uma linguagem de programação e de sua gramática, uma recuperação automática de erros usando várias estratégias, sem necessidade de programação de regras gramaticais adicionais - como é o caso, por exemplo, do Yacc [Joh79] — , o que acelera o desenvolvimento e permite menos margem para erros no projeto da gramática. Em relação a esse projeto, é interessante notar que o gerador desenvolvido permite verificação automática da pertinência da gramática à classe de gramáticas aceitas pelo algoritmo de análise sintática. A representação gráfica da gramática permite que os erros de projeto da gramática sejam reconhecidos com muita facilidade, auxiliando sua correção.

\subsection{Caracterização da Pesquisa}

Este trabalho visa programar e descrever um gerador de analisadores sintáticos que seja de fácil uso e rápida compreensão. Para isso, usou-se a linguagem de programação Java, por ser uma linguagem popular [Lan13] e universal. Também foram realizadas pesquisas com três tipos de usuários: um leigo em programação, um com conhecimentos em programação, porém sem conhecimentos em linguagens formais e compiladores e um com bons conhecimentos em programação e com conhecimentos em linguagens formais e compiladores, que utilizaram o sistema e deram seus pareceres relatados neste estudo.

O objetivo principal foi de desenvolver um gerador de análise sintática que facilite o entendimento do processo de criação de novas linguagens, seja fácil de ser utilizado por programadores novatos, e direcionado para ser utilizado rapidamente por programadores mais experientes. Para isso, tentou-se responder as questões listadas abaixo:

- Quais as vantagens e desvantagens do GGLL em relação aos outros geradores de analisadores sintáticos comparados?

- Qual o conhecimento necessário para um programador desenvolver uma nova linguagem para um problema específico?

- Qual a importância da interface gráfica na criação de uma gramática?

\subsection{Contribuições}

Contribuições deste trabalho na área de compiladores: 
- Desenvolvimento de uma nova ferramenta potente, com uma interface gráfica intuitiva que auxilie na criação de analisadores sintáticos e, portanto, de compiladores e interpretadores.

- Essa ferramenta poderá ser utilizada como instrumento no ensino de gramáticas formais e compiladores.

- Um estudo sobre diversos geradores de analisadores sintáticos, além de uma comparação entre eles e o novo sistema desenvolvido.

\subsection{Divisão do Trabalho}

Além deste capítulo introdutório, o trabalho apresenta em seu capítulo 2 a definição formal de linguagens e gramáticas. No capítulo 3 é apresentado a estrutura de um compilador. No capítulo 4 são apresentadas definições relacionadas com a analise sintática. No capítulo 5 são enumerados alguns dos principais geradores de analisadores sintáticos em uso no mercado e são feitas comparações entre eles. No capítulo 6 é detalhado o desenvolvimento do GGLL, um novo gerador de analisadores sintáticos com algumas funcionalidades que não se encontram em nenhum dos outros geradores apresentados no capítulo 5 . No capítulo 7, são apresentados os resultados obtidos com o novo gerador de analisadores sintáticos e no capítulo 8 são enumerados alguns trabalhos futuros que podem ser desenvolvidos como extensão do GGLL. Também há três capítulos de apêndice onde são apresentados alguns algoritmos do sistema, os padrões de projetos utilizados neste trabalho e o manual de utilização do GGLL. 


\section{Capítulo 2}

\section{Linguagens e Gramáticas}

Um programa de computador é a descrição textual de um algoritmo, escrita em uma linguagem de programação, que é aceita por um computador e produz nele o processamento daquele algoritmo. As linguagens de programação podem ser divididas em duas categorias: alto nível e baixo nível.

As linguagens de baixo nível apresentam uma estrutura mais parecida com as linguagens de máquina, por exemplo, a Linguagem de Montagem (assembly language). Essa linguagem, cujos comandos geram em geral uma instrução em linguagem de máquina para cada comando, pode ser convertida para uma linguagem de máquina usando um programa montador. Um montador consegue extrair cada instrução da linguagem de baixo nível e convertê-la em uma instrução de máquina. A linguagem de máquina é interpretada diretamente pelos circuitos de um computador sem necessidade de ser convertida para outra linguagem.

Ao contrário das linguagens de baixo nível, as de alto nível apresentam alguns comandos ou formulações mais parecidas com as linguagens naturais e com notações matemáticas. Programas escritos nas linguagens de alto nível necessitam ser compilados, isto é, traduzidos para linguagens de baixo nível para serem montados em seguida, ou diretamente para linguagem de máquina e posteriormente interpretadas pelos computadores. Um exemplo desse tipo de linguagem é a C.

Um programa escrito em uma linguagem de alto nível pode não ser compilado, e sim interpretado. Um interpretador examina cada comando do programa e o executa imediatamente, sem traduzir o programa inteiro como faz um compilador; cada comando é examinado pelo interpretador como no original. Eventualmente, ao interpretar um programa, em uma primeira fase um interpretador pode produzir, funcionando como compilador, uma linguagem intermediária para acelerar a interpretação.

Tanto as linguagens de baixo nível como as de alto nível dispõem de vocabulário, sentenças e gramática para definir cadeias válidas da linguagem e sua estrutura. Um programa escrito em uma linguagem qualquer é denominado programa-fonte. O compilador faz uma tradução desse programa para outra linguagem, produzindo um programa-objeto.

Note-se que as chamadas linguagens de alto nível não têm um nível muito alto, pois todas contêm estruturas muito próximas das linguagens de máquina, como os comandos go to e if ... then ... else .... Linguagens voltadas para o processamento de banco de dados, por um tempo denominadas linguagens de $4^{a}$ geração, eram de nível muito mais alto, contendo, por exemplo, comandos de acesso a uma base de dados e descrevendo a geração de relatórios. 
Dão-se, a seguir, algumas definições formais [HU69].

\subsection{Alfabeto}

Definição: alfabeto $V$ é um conjunto finito de símbolos. Esses símbolos serão utilizados no programa-fonte.

Exemplo: $V=\{a, b, c\}$ ou $V=\{0,1,2,3,4, \ldots, 9\}$

Neste texto, um alfabeto genérico será representado por $V$.

\subsection{Sentenças}

Definição: sentença sobre um alfabeto é qualquer cadeia de caracteres de um tamanho finito composta pelos símbolos desse alfabeto. A sentença vazia (indicada por $\lambda$, do alemão Leer, vazio) é uma sentença composta de nenhum símbolo. Se $V$ é um alfabeto, então $V^{*}$ é o conjunto infinito de sentenças compostas pelos símbolos em $V$, incluindo a sentença vazia. $V^{+}$é utilizado para $V^{*}-\{\lambda\}$.

Exemplo: para o alfabeto $V=\{a, b, c\}$ as sentenças que compõem $V^{*}$ e $V^{+}$são, respectivamente: $V^{*}=\{\lambda, a, b, c, a b, a c, b c, a b c, b c a, \ldots\}$ e $V^{+}=\{a, b, c, a b, a c, b c, a b c, b c a, \ldots\}$.

\subsection{Linguagem}

Definição: linguagem é um conjunto de sentenças sobre um alfabeto. Muitas linguagens, como as de programação, possuem um número infinito de sentenças. Uma linguagem pode ser definida das seguintes formas:

- Enumeração de suas sentenças. Essa definição apenas pode ser utilizada para linguagens com um número finito de sentenças. Por exemplo: $\{a, a b, b, b c\}$

- Por meio de expressões matemáticas geradoras, como por exemplo as expressões regulares, que são definidas da seguinte maneira: se $A$ é um alfabeto, então $x \in A$ é uma expressão regular. Se $x$ e $y$ são expressões regulares então a cadeia $x y$ (a concatenação de $x \operatorname{com} y$ ) é uma expressão regular (indicando que a linguagem pode conter a cadeia $x$ ou a cadeia $y$ ). Se $x$ é uma expressão regular, então $x^{*}=\{\lambda, x, x x, x x x, \ldots\}$ é uma expressão regular. Se $x$ e $y$ são expressões regulares, então $x \mid y$ é uma expressão regular.

- Por uma regra de formação. Por exemplo: todos os números binários (cadeias com 0 e 1), ou $\left\{a^{n} b^{n} \mid n \geq 1\right\}$, onde $x^{1}=x, x^{2}=x x, \ldots$, note-se que $x^{0}=\lambda$.

- Por uma gramática, cujo cerne é um conjunto de regras de substituição usadas para gerar as cadeias que pertencem à linguagem. 


\subsection{Gramática}

Definição: uma gramática $G$ é definida por uma quádrupla ordenada $\left(V_{N}, V_{T}, P, S\right)$, onde $V_{N}$ é um alfabeto, denominado alfabeto de símbolos não terminais ou apenas alfabeto de não terminais; $V_{T}$ é um alfabeto, denominado alfabeto de símbolos terminais ou apenas alfabeto de terminais, onde $V_{N} \cap V_{T}=\emptyset$; $P$ é o conjunto de produções, definido abaixo; e $S \in V_{N}$ é o símbolo inicial. Todo símbolo terminal também pode ser denominado item léxico. Será representado por $V$ o conjunto de todos os símbolos da gramática, isto é, $V=V_{N} \cup V_{T}$. A linguagem $L$ gerada por uma gramática $G$ consiste de conjuntos de cadeias de $V_{T}^{*}$ é representada por $L(G)$; o processo de geração será dado posteriormente.

O conjunto de produções $P$ mostra as substituições válidas que podem ser feitas em cada passo no processo de geração de uma cadeia da linguagem definida por $G$. Portanto, cada produção de $P$ é uma regra de substituição. $P$ consiste de expressões da forma $\alpha \rightarrow \beta$, onde $\alpha \in V^{+}$ e $\beta \in V^{*}$, indicando que em uma cadeia $\gamma \alpha \delta$ gerada pela gramática, $\alpha$ pode ser substituída por $\beta$ gerando a cadeia $\gamma \beta \delta$, onde $\alpha \in V^{+} \mathrm{e} \gamma, \beta, \delta \in V^{*}$. Denomina-se $\alpha$ de lado esquerdo da produção e $\beta$ de lado direito da produção. Portanto uma produção de $P$ indica uma possível substituição de símbolos durante a geração de uma cadeia da linguagem. Se houver duas ou mais produções que compartilhem o lado esquerdo em comum, podem-se representar essas produções com o símbolo |, por exemplo, se $P \rightarrow A a, P \rightarrow b$ e $P \rightarrow C$, então, pode-se escrever $P \rightarrow A a|b| C$. O símbolo | pode ser lido como "ou", e se diz que $b$ é alternativa de $A a$ e $C$ é alternativa de $b$.

Exemplo: considere-se a gramática $G=\left(V_{N}, V_{T}, S, P\right)$, onde $V_{N}=\{S\}, V_{T}=\{a, b\}, P=$ $\{S \rightarrow a S b, S \rightarrow a b\}$. Como será visto posteriormente, $L(G)=\{a b, a a b b, a a a b b b, \ldots\}=\left\{a^{n} b^{n} \mid n \geq\right.$ $1\}$, o que pode ser provado facilmente por indução.

\subsection{Derivação}

No caso de existir uma produção $\alpha \rightarrow \beta \operatorname{com} \alpha \in V^{+}$e $\beta \in V^{*}$, uma geração de $\gamma \alpha \delta$ para $\gamma \beta \delta$, é indicada por $\gamma \alpha \delta \Rightarrow \gamma \beta \delta$. O símbolo $\Rightarrow$ pode ser lido como deriva em um passo. Quando há uma sequência de passos de derivação $\alpha_{1} \Rightarrow \alpha_{2} \Rightarrow \ldots \Rightarrow \alpha_{n}$ diz-se que $\alpha_{1}$ deriva $\alpha_{n}$. O símbolo $\stackrel{*}{\Rightarrow}$ significa deriva em zero ou mais passos assim como o símbolo $\stackrel{+}{\Rightarrow}$ significa deriva em um ou mais passos [ALSU08].

Diz-se que uma cadeia $\alpha \in V_{T}^{*}$ é gerada por uma gramática $G=\left(V_{N}, V_{T}, P, S\right)$ se existe uma derivação $S \stackrel{*}{\Rightarrow} \alpha$ usando-se uma produção de $P$ em cada passo. Nesse caso $L(G)$ é o conjunto $\left\{\alpha_{1}, \alpha_{2}, \ldots, \alpha_{n}\right\}$ tal que $\left\{S \stackrel{*}{\Rightarrow} \alpha_{1}, S \stackrel{*}{\Rightarrow} \alpha_{2}, \ldots, S \stackrel{*}{\Rightarrow} \alpha_{n}\right\}$.

Exemplo: considere-se a gramática $G=\left(V_{N}, V_{T}, S, P\right)$, onde $V_{N}=\{S\}, V_{T}=\{a, b\}, P=$ $\{S \rightarrow a S b \mid a b\}$. A cadeia de caracteres "aaabbb" é gerada pela seguinte derivação: $S \Rightarrow a S b \Rightarrow$ $a a S b b \Rightarrow a a a b b b$, isto é, $S \stackrel{*}{\Rightarrow} a a a b b b$. Uma derivação à esquerda é aquela que, em cada passo, um símbolo $N \in V_{N}$ mais à esquerda é substituído no próximo passo de substituição. Uma derivação à direita é aquela que, em cada passo, o símbolo $N \in V_{N}$ mais à direita é substituído no próximo passo. 
Exemplo: se $G=(\{S, T, A, B\},\{a, b\}, S, P)$, onde $P=\{S \rightarrow A T|T B, T \rightarrow a T b| \lambda, A \rightarrow$ $a A|a, B \rightarrow b B| \rightarrow b\}$. Tem-se:

- Derivação à esquerda: $S \Rightarrow \mathbf{A} T \Rightarrow a \mathbf{A} T \Rightarrow a a \mathbf{T} \Rightarrow a a a \mathbf{T} b \Rightarrow a a a b$.

- Derivação à direita: $S \Rightarrow A \mathbf{T} \Rightarrow A a \mathbf{T} b \Rightarrow \mathbf{A} a b \Rightarrow a \mathbf{A} a b \Rightarrow a a a b$.

(note-se que o não terminal substituído foi indicado em negrito.)

\subsection{Reconhecimento}

Reconhecimento é o processo inverso ao da derivação. Dada uma cadeia $\alpha \in V_{T}^{*}$, são aplicados os passos inversos $\alpha \Leftarrow \alpha_{n} \Leftarrow \alpha_{n-1} \Leftarrow \ldots \Leftarrow \alpha_{2} \Leftarrow \alpha_{1} \Leftarrow S$.

\subsection{Tamanho de uma cadeia}

Tamanho ou comprimento da cadeia $\alpha \in\left(V_{N} \cup V_{T}\right)^{*}$ é o número de símbolos de $\alpha$, representado como $|\alpha|$. Por exemplo, sendo $\alpha=a$, então $|\alpha|=1$, para $\alpha=x y z$ tem-se $|\alpha|=3$, $|\lambda|=0$.

\subsection{Gramáticas equivalentes}

Duas gramáticas $G_{1}$ e $G_{2}$ são equivalentes se e somente se $L\left(G_{1}\right)=L\left(G_{2}\right)$ são iguais, ou seja, se $G_{1}$ e $G_{2}$ geram a mesma linguagem.

\section{9 Árvore de derivação ou árvore sintática}

Uma árvore de derivação é uma representação gráfica em forma de árvore de dados de uma derivação que ignora, isto é, não representa a ordem na qual as produções são aplicadas (isto é, à direita ou à esquerda) para substituir não terminais [ALSU08, 128]. 


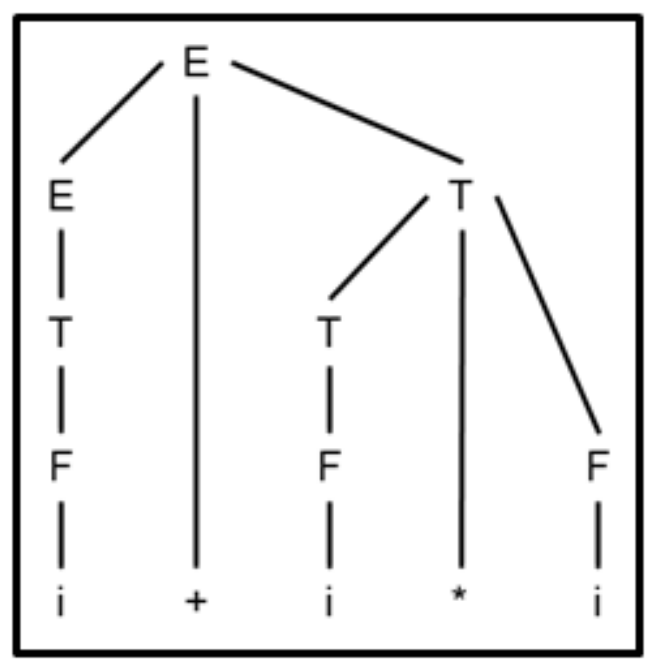

Figura 2.1: Exemplo de árvore de derivação

O símbolo inicial da gramática ( $E$, no exemplo da figura 2.1) é denominado de raiz da árvore; cada símbolo da árvore é denominado de nó, e cada nó que não contém uma derivação é denominado de folha da árvore $(i,+, i, *, i$, na figura 2.1).

\subsection{Gramáticas ambíguas}

Uma gramática $G$ é ambígua se e somente se existem duas arvores de derivação diferentes para uma mesma cadeia gerada por $G$.

\subsection{Tipos de gramáticas}

Chomsky [Cho59] introduziu uma classificação das gramáticas de acordo com a forma das produções, dividindo-as nos seguintes tipos, indicando que uma gramática de um tipo é também uma gramática do tipo em que a primeira está contida, como por exemplo, toda gramática de tipo 3 é também uma de tipo 2. 


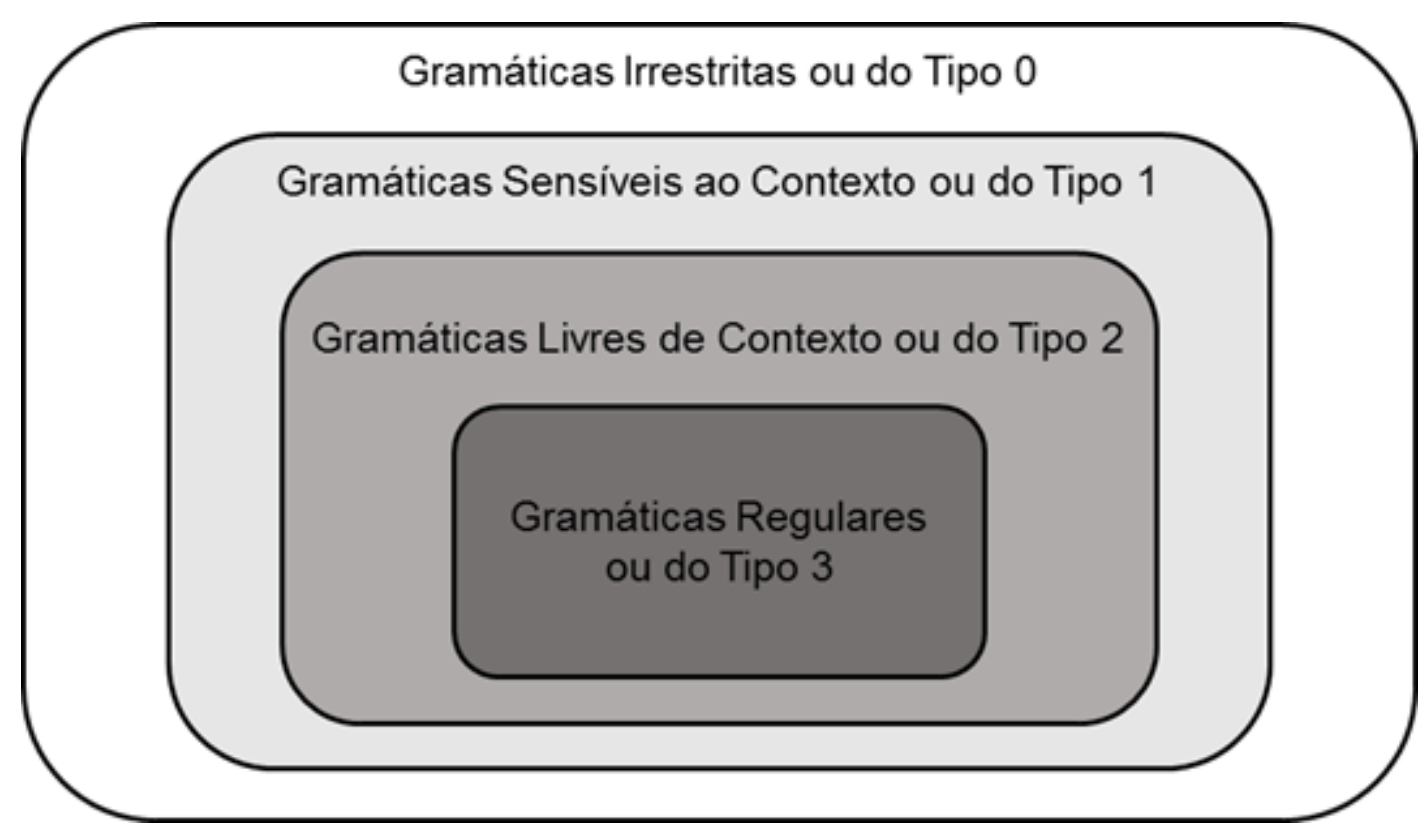

Figura 2.2: Hierarquia de Chomsky

\subsubsection{Gramáticas regulares ou do tipo 3}

Definição: se $G=\left(V_{N}, V_{T}, P, S\right)$ e $M, N \in V_{N}$ e $\alpha \in V_{T}^{*}$, então $G$ é uma:

- Gramática Linear à Direita (GLD): se todas as produções são da forma: $M \rightarrow \alpha N$ ou $M \rightarrow$ $\alpha$.

- Gramática Linear à Esquerda (GLE): se todas as produções são da forma: $M \rightarrow N \alpha$ ou $M \rightarrow \alpha$.

- Gramática Linear Unitária à Direita (GLUD): se todas as produções são como na linear à direita e, adicionalmente, $|\alpha| \leq 1$.

- Gramática Linear Unitária à Esquerda (GLUE): se todas as produções são como na linear à esquerda $\mathrm{e}$, adicionalmente, $|\alpha| \geq 1$.

Definição: se uma gramática é do tipo GLD ou (exclusivo) GLE, é uma gramática regular.

Exemplo: dada a gramática $G$ definida por $V_{N}=\{S, M\}, V_{T}=\{a, b, c\}$ e $P=\{S \rightarrow$ $b S|a M| c, M \rightarrow b S\}$, as produções de $G$ seguem a forma citada acima, então pode-se dizer que $G$ é uma gramática regular [SDM83, 33]. Essa gramática gera a linguagem $b^{*}\left(a b^{+}\right)^{*} c$.

\subsubsection{Gramáticas livres de contexto ou do tipo 2}

Definição: uma gramática é dita livre de contexto se suas produções são da forma: $N \rightarrow \alpha$, onde $N \in V_{N}$ e $\alpha \in V^{*}$.

Exemplo: dada a gramática $G$ definida por $V_{N}=\{S, M\}, V_{T}=\{a, b\}$ e $P=\{S \rightarrow a S b \mid \lambda\}$, as produções de $G$ seguem a forma citada acima, sendo, portanto, livre de contexto. Essa gramática 
gera a linguagem $L(G)=\left\{a^{n} b^{n} \mid n \geq 0\right\}$.

O nome livre de contexto vem do fato de, em uma cadeia intermediária de derivação, qualquer não terminal $N$ poder ser substituído por um dos lados direitos de suas produções, independentemente dos símbolos vizinhos a $N$. Para a definição de linguagens de programação e de sua estrutura gramatical, são normalmente usadas gramáticas livres de contexto, que são as empregadas neste trabalho.

\subsubsection{Gramáticas sensíveis ao contexto ou do tipo 1}

Definição: uma gramática é dita sensível ao contexto se suas produções são da forma: $\alpha \rightarrow \beta$, onde $\alpha \in V^{+}, \beta \in V^{*}$ e $|\alpha| \leq|\beta|$ ou $\alpha=S$ e $\beta=\lambda$, dado que $\lambda$ não pode constituir o lado direito de nenhuma produção.

Exemplo: dada a gramática $G$ definida por $V_{N}=\{S, M\}, V_{T}=\{a, b, c, d\}$ e $P=\{S \rightarrow$ $b S|a M| c, a M \rightarrow d S\}$, as produções de $G$ seguem a forma citada acima, sendo portanto uma gramática sensível ao contexto. Essa gramática gera a linguagem $L(G)=\{d c, b c, b b c, d d c, \ldots\}$.

\subsubsection{Gramáticas irrestritas ou do tipo 0}

Definição: uma gramática é dita irrestrita se suas produções são da forma: $\alpha \rightarrow \beta$, onde $\alpha \in V^{+}$e $\beta \in V^{*}$.

Exemplo: dada a gramática $G$ definida por $V_{N}=\{S, M\}, V_{T}=\{a, b, c\}$ e $P=\{S \rightarrow$ $a b c \mid \lambda, a b \rightarrow a a b b C, C b \rightarrow b C, C C \rightarrow c c\}$, as produções de $G$ seguem a forma citada acima, portanto $G$ é uma gramática irrestrita. Essa gramática gera a linguagem $L(G)=\{\lambda, a b c, a a b b c c, a a a b b b c c c, \ldots\}$.

\subsubsection{Gramáticas gráficas}

As gramáticas gráficas são utilizadas para representar graficamente gramáticas livres de contexto em muitos manuais de linguagens para mostrar quais cadeias pertencem à linguagem.

Exemplo: dada a gramática livre de contexto $G=\left(V_{N}, V_{T}, S, P\right)$, com $V_{N}=\{S, E, T, F\}$, $V_{T}=\{+, *, n\}$ e $P=\{S \rightarrow E, E \rightarrow T|E+T, T \rightarrow F| T * F, F \rightarrow i\}$, que gera expressões aritméticas com $+\mathrm{e} *$, tem-se a gramática gráfica da figura 2.3 usando a notação do GGLL (todas as gramáticas gráficas deste trabalho foram desenhadas e impressas com o GGLL). 




Figura 2.3: Exemplo de gramática gráfica

A seguir, tem-se a definição de cada símbolo para a gramática gráfica em comparação a uma gramática normal definida anteriormente; compare-se com a figura 2.3:

- Cada nó contém um símbolo, terminal ou não terminal, das produções da gramática.

- O símbolo inicial é representado por um nó com hexágono em laranja.

- Os não terminais do lado esquerdo das produções são representados por nós com pentágonos azuis.

- Os não terminais do lado direito das produções são representados por nós com retângulos verdes. A bolinha à esquerda de um desses nós representa a entrada desse nó.

- Os terminais são representados por retângulos vermelhos com bordas arredondadas. A bolinha à esquerda de um desses nós representa a entrada desse nó.

- Uma seta em azul indica a ligação que representa a sequência $x y$ pertencente a um lado direito de uma produção, onde $x, y \in V$; essa seta sai do nó representando $x$ e chega ao nó representando $y$. Esse tipo de seta sempre sai horizontalmente à direita do nó $x$.

- Uma seta em vermelho indica a ligação que representa a alternativa $x u \mid y v$ de um lado direito de uma produção, onde $x \in V, y \in V \cup\{\lambda\}$ e $u, v \in V^{*}$; essa seta sai do nó representando $x$ e chega ao nó representando $y$. Esse tipo de seta sempre sai verticalmente, para baixo, a partir da bolinha de entrada do nó $x$ e termina na bolinha de entrada do nó que é alternativa de $x$.

- Uma sequência de setas em vermelho representa a sequência de alternativas de um nó.

- Um nó correspondente ao símbolo $\lambda$ é representado por um círculo com circunferência amarela contendo um $\lambda$ no seu interior. 
Seja a sequência de nós terminais $C A=t_{1}, t_{2}, \ldots, t_{n}$. $C A$ é uma cadeia de alternativas se 0 nó $t_{i}$ é o nó alternativo a $t_{i-1}, 2 \leq i \leq n$.

Se, em lugar de um nó terminal $t_{i}$ houver um nó não terminal $N_{i}$ em uma cadeia de alternativas $C A$, está passa a conter os nós $t_{1}, t_{2}, \ldots, t_{i-1}, A_{i}, t_{i+1}, \ldots, t_{n}$, onde $A_{i}$ é a cadeia de alternativas começando no primeiro nó da primeira produção de $N_{i}$, isto é, contém os nós contendo $t \in V_{T}$ e $N \stackrel{*}{\rightarrow} t \alpha, \alpha \in V^{*}$. Assim, inclui-se em $C A$ a cadeia de alternativas começando no nó $t_{A}$ que é o sucessor do nó de um lado esquerdo contendo $N_{i}$.

Uma sequência de alternativas é o conjunto dos símbolos terminais de uma cadeia de alternativas. Assim, uma sequência de alternativas de um nó $n$ (terminal ou não terminal) é a sequência de símbolos terminais que são atingidos percorrendo-se as setas alternativas a partir de $n$, incluindo este último.

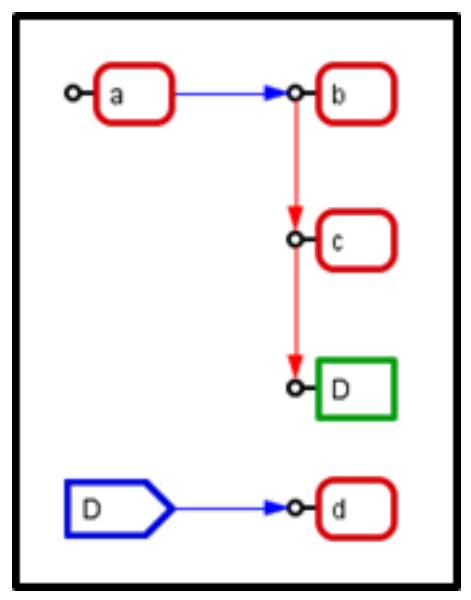

Figura 2.4: Exemplo de cadeia de alternativas

Na figura 2.4 a cadeia de alternativas começando no nó $b$ contém os nós $b, c$ e $d$.

As gramáticas gráficas são muito utilizadas por programadores para consultarem quais sentenças pertencem a uma linguagem de programação. Uma gramática gráfica também é utilizada para estabelecer a estrutura das sentenças da linguagem gerada por ela. A estrutura de uma sentença é dada pela sua árvore sintática.

As gramáticas gráficas permitem representar lados direitos de produções, contendo expressões regulares, por exemplo, $E \rightarrow T\{+T\}^{*}, T \rightarrow F\{* F\}^{*}, F \rightarrow n$, onde $\{$ e $\}$ são metassimbolos, que gera a mesma linguagem da gramática 2.3. Uma gramática gráfica equivalente é representada na figura 2.5 . 




Figura 2.5: Gramática gráfica com expressão regular 


\section{Capítulo 3}

\section{Estrutura de um Compilador}

Um compilador é um programa que recebe como entrada um programa escrito em uma linguagem específica, denominado programa-fonte, reconhece-o e o traduz para uma outra linguagem, o que gera um programa-objeto. Por exemplo: um compilador para Pascal é um programa de computador que traduz um programa-fonte escrito na linguagem Pascal para um programa-objeto, em uma outra linguagem, como uma linguagem de montagem ou de máquina.

Segundo Setzer e de Melo [SDM83, 14], um compilador divide-se nas seguintes fases:

- Análise léxica: o analisador léxico lê o fluxo de caracteres que compõem o programa-fonte e os agrupa em sequências dos símbolos usados pelo analisador sintático denominados de tokens.

- Análise sintática: o analisador sintático utiliza os tokens produzidos pelo analisador léxico para verificar se a sequência de tokens é válida. Para isso, utiliza as regras gramaticais e, além disso, com elas pode-se construir a árvore sintática ou determinar ações de compilação.

- Análise semântica: toda análise efetuada pelo compilador, além das análises léxica e sintática, é denominada comumente análise semântica. Ela engloba duas partes principais: a análise de contexto e a geração de código.

\subsection{Análise léxica}

De acordo com Delamaro [Del04, 10], "O analisador léxico encarrega-se de separar no programafonte cada símbolo que tenha algum significado para a linguagem ou avisar quando um símbolo que não faz parte da linguagem é encontrado". A tarefa principal do analisador léxico é ler os caracteres da entrada do programa-fonte, agrupá-los em lexemas (ver item 3.1.1) e produzir como saída uma sequência de tokens para cada lexema do programa-fonte.

Além disso, o analisador léxico pode realizar outras tarefas. Uma delas é ignorar os comentários e os espaços em branco. Em alguns compiladores o analisador léxico emite as mensagens de erro geradas pelo compilador ao analisar o programa-fonte. 


\subsubsection{Tokens}

Um token é um par que consiste de um nome e um valor de atributo opcional. O nome do token é um símbolo abstrato que representa um tipo de unidade léxica, por exemplo, uma palavra reservada da linguagem, como if, for, read, etc., ou uma sequência de caracteres da entrada que denota um identificador ou um número. Os nomes dos tokens são os símbolos que o analisador sintático processa [ALSU08, 71] e também podem ser denominados símbolos sintáticos elementares.

\subsubsection{Lexemas}

Um lexema é uma sequência de caracteres do programa-fonte que combina com o padrão de um token (ver o próximo item) e é identificado pelo analisador léxico como a instância de um token [ALSU08, 71], também pode ser denominado símbolo semântico.

\subsubsection{Padrões}

Um padrão é uma definição, eventualmente formal, da forma que os lexemas de um token podem assumir. No caso de uma palavra reservada da linguagem, como um token, o padrão é apenas a sequência de caracteres que formam a palavra reservada. Para identificadores e alguns outros tokens, o padrão é uma estrutura mais complexa, que é descrita por uma frase [ALSU08, 71]. Expressões regulares podem ser utilizadas para definir os padrões.

\begin{tabular}{c|c|c}
\hline Token & Padrão & Exemplo de Lexema \\
\hline If & Sequência de caracteres i, f & if \\
Numero & $\{0,1,2, \ldots, 9\}^{+}$ & 10 \\
Literal & Qualquer caractere diferente de “, cercado por “ & "sequência de caracteres" \\
Id & Letra seguida por letras ou dígitos & X10 \\
\hline
\end{tabular}

Tabela 3.1: Tokens, padrões e lexemas. Fonte: Adaptada de [ALSU08, 71]

\subsection{Análise sintática}

O analisador sintático é a parte central de um compilador orientado pela sintaxe (gramática) da linguagem que ele compila; além disso, verifica se um programa-fonte é válido ou não do ponto de vista sintático. $\mathrm{O}$ analisador sintático recebe do analisador léxico uma cadeia de tokens representando o programa-fonte, verifica se essa cadeia de tokens pertence à linguagem gerada pela gramática e estabelece a estrutura gramatical dessa cadeia, controlando assim toda a compilação.

$O$ analisador deve ser projetado para emitir mensagens para quaisquer erros de sintaxe encontrados no programa-fonte de forma inteligível e também para contornar esses erros a fim de continuar processando o restante do programa [ALSU08]. Existem três estratégias gerais de análise sintática para gramáticas livres de contexto: 
- Universal: essa estratégia pode analisar qualquer gramática, como é o caso do algoritmo CYK [You66] [Kas65] e o algoritmo de Earley [Ear70], porém, esses métodos não são muito eficientes para serem utilizados em compiladores de produção, que são aqueles utilizados em alta escala. Em particular, analisam sentenças geradas por gramáticas ambíguas (ver item 2.10), dando todas as possíveis análises para cada sentença da linguagem.

- Ascendente: traduzido do inglês bottom-up, essa estratégia constrói as árvores de derivação de baixo para cima, isto é, parte da cadeia de entrada e vai fazendo o reconhecimento sintático usando exclusivamente as cadeias intermediárias e os lados direitos completos das produções da gramática, substituindo os símbolos correspondentes nas cadeias intermediarias pelos não terminais dos lados esquerdos das produções, até chegar ao símbolo inicial da gramática.

- Descendente: traduzido do inglês top-down, essa estratégia constrói as árvores de derivação de cima para baixo, isto é, parte do símbolo inicial e vai aplicando as produções até chegar à cadeia a ser reconhecida.

Mais adiante são descritos mais detalhadamente os métodos de análise sintática e as gramáticas que cada método aceita.

\subsection{Análise semântica}

Delamaro [Del04, 19] afirma, no que denomina de análise de contexto, que "O analisador semântico irá verificar se os aspectos semânticos do programa estão corretos, ou seja, se não existe incoerência quanto ao significado das construções utilizadas pelo programador". Por exemplo, se existe em uma expressão aritmética uma mistura de tipos de números inteiros e de ponto flutuante, quando isso não é permitido, ou o uso de um identificador não declarado. Deve-se acrescentar que, além disso, o analisador semântico ainda é responsável por fazer a análise de contexto dos identificadores, como por exemplo associar ao token ou item sintático o tipo que foi declarado para um identificador, e validar a estrutura semântica e também pela geração do programa-objeto. Essa última etapa é denominada geração de código.

\subsubsection{Análise de contexto}

A análise de contexto é uma parte importante do analisador semântico, pois nela são tratados dos seguintes casos:

- Reconhecimento e verificação de declarações.

- Verificação de contexto.

- Verificação de tipo.

- Definição do endereço das variáveis e procedimentos no código-objeto.

Setzer e De Melo [SDM83, 15] utilizam um exemplo para especificar a análise de contexto: no comando $A:=5$ nas linguagens ALGOL e Pascal, é necessário fazer a seguinte análise: 
- A foi declarado? Se não, há um erro de contexto.

- Onde A foi declarado (procedure ou bloco mais internos englobando A ou outros mais externos)?

- Qual o tipo de A? A é um parâmetro?

- O tipo de A é um inteiro (compatível com o lado direito da atribuição)? Se não, há um erro de contexto ou deve ser feita uma conversão de tipo.

- Qual o endereço de A no código-objeto?

\subsubsection{Geração de código}

Para Setzer e De Melo [SDM83, 16], "A geração de código é a parte do compilador que gera o programa-objeto". Uma vez verificado, eventualmente trecho por trecho, que não existem erros sintáticos ou semânticos, o compilador pode realizar seu último objetivo, que é a criação do programa-objeto para cada trecho. O programa-objeto pode ser um código em linguagem de máquina a ser interpretado diretamente pelos circuitos do computador, ou um código intermediário que posteriormente será traduzido para a linguagem de máquina ou interpretado. 


\section{Capítulo 4}

\section{Análise Sintática}

Como já foi descrito na sessão anterior, a análise sintática é a parte do compilador responsável por verificar se o código-fonte segue a estrutura da gramática aceita por aquele compilador. Além disso, ela é responsável por apontar os erros sintáticos presentes no programa-fonte e determinar as estruturas sintáticas, estabelecendo quais trechos devem ser compilados e em que sequência.

Os métodos de análise sintática utilizados pelos principais compiladores são os métodos ascendentes e descendentes. Os métodos universais não são muito eficientes para serem utilizados por compiladores de uso extenso e, por esse motivo não serão estudados neste trabalho.

\subsection{Métodos ascendentes ou bottom-up}

A análise sintática ascendente corresponde à construção de uma árvore de derivação para uma cadeia de entrada a partir das folhas (ver 2.9) em direção à raiz da árvore (símbolo inicial da gramática) [ALSU08].

Exemplo: dada a gramática $G=(\{T, F\},\{*, i d\}, T,\{T \rightarrow T * F \mid F, F \rightarrow i d\})$, tem-se na figura 4.1 a possível árvore de derivação gerada pela análise ascendente com a ordem de reconhecimento indicada pelos números entre parenteses.

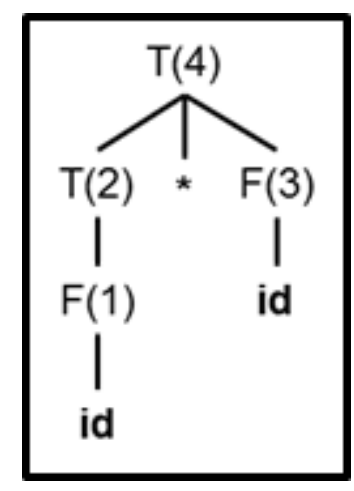

Figura 4.1: Árvore de derivação ascendente

Pode-se pensar na análise ascendente como o processo de reduzir uma cadeia $w \in L(G)$ para o símbolo inicial da gramática. Em cada passo da redução, uma subcadeia, compatível com 
o lado direito de uma produção, é substituída pelo não terminal na esquerda dessa produção [ALSU08].

T. Kowaltowski [Kow10a] define os problemas básicos do algoritmo de análise ascendente como a identificação da:

- Próxima subcadeia, chamada redutendo (handle), a ser reduzida;

- Produção a ser aplicada - pode haver duas ou mais produções com lados direitos iguais.

Os métodos bottom-up possuem a característica de apenas permitir a execução de uma rotina semântica quando ocorre o reconhecimento de um lado direito completo de uma produção, o que dificulta a elaboração da gramática da análise semântica. Por exemplo, a sequência if .... then ... else ...tem que ser subdividida em lados direitos envolvendo, cada um, os trechos if .... then ... e else ... ; pois cada um deles exige a geração imediata de código antes da análise do próximo, devido aos desvios que devem ser gerados.

A principal classe gramatical aceita pelos métodos ascendentes são as gramáticas LR, do inglês left-to-rigth rightmost derivation, introduzida por Knuth [Knu68] que corresponde a um reconhecimento da esquerda para direita com derivação mais à direita. Historicamente, os principais métodos de análise sintática descendente são: SLR [DeR71], LR(k) [Kor69] e LALR [Der69]. No capítulo 5 serão analisados o Yacc e o SableCC, que geram analisadores sintáticos utilizando o método LALR.

\subsection{Métodos descendentes ou top-down}

Nesses métodos a análise sintática gera uma árvore sintática de cima para baixo, ou seja, da raiz para as folhas. A principal classe gramatical usada pelos métodos descendentes são as gramáticas LL, do inglês left-to-rigth leftmost derivation, ou seja, reconhecimento da esquerda para direita com derivação mais à esquerda. Um método de análise sintática descendente é o recursive descent ou recursivo descendente, em que se programa um procedimento da linguagem de implementação (que deve ter procedimentos recursivos) para cada não terminal, e o código especifica quais terminais devem ser examinados para escolher cada produção ou para seguir adiante durante a análise do lado direito de uma produção. No capítulo 5 serão analisados dois sistemas, o AntLR e o COCO/R, que geram analisadores sintáticos utilizando o método recursivo descendente. O GGLL emprega um método top-down diferente do recursivo descendente.

Exemplo: dada a gramática $G=(\{T, F\},\{*, i d\}, T,\{T \rightarrow T * F \mid F, F \rightarrow i d\})$, tem-se na figura 4.2 a árvore de derivação gerada pela análise descendente com a ordem da derivação indicada pelos números entre parenteses. Note-se que depois de substituir $T$ no primeiro passo (1), substitui-se $T$ no segundo passo (2), pois isso corresponde a derivação mais à esquerda (LL). 


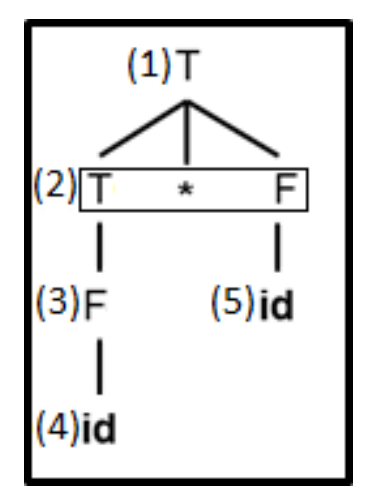

Figura 4.2: Árvore de derivação descendente

T. Kowaltowski [Kow10b] define o problema básico do algoritmo de análise descendente como: "determinar a produção a ser utilizada para expandir o não terminal corrente (o mais à esquerda da forma sentencial corrente - qualquer sentença gerada pela gramática, podendo conter não terminais - constituída pelas folhas da árvore)".

Nos métodos descendentes, os não terminais viram objetivos a serem reconhecidos na cadeia de entrada. Se um não terminal $N$ é um objetivo, procuram-se dentre suas produções qual deve ser seguida, eventualmente usando-se para isso os próximos símbolos da cadeia de entrada. Detectada qual produção deve ser seguida, o seu lado direito é varrido passo a passo, usando-se símbolos da entrada. Isso significa que os métodos top-down possuem a característica de permitir a execução de uma rotina semântica quando ocorre o reconhecimento de qualquer símbolo do lado direito de uma produção, o que facilita a elaboração da gramática e da análise semântica. No exemplo visto para métodos bottom-up pode-se ter um lado direito completo de uma produção com if ... then ... else ..., em lugar de ter que subdividi-lo nas partes if ..., then .... else ... como necessários nos métodos bottom-up com o intuito de poder compilar os desvios necessários dentro do código-objeto.

Note-se que nos métodos bottom-up só se localiza uma produção que será aplicada no reconhecimento ao se completar o seu lado direito. Já nos métodos top-down sabe-se a cada passo em que ponto se está um determinado lado direito, o que dá uma vantagem a esses métodos.

\subsection{Gramáticas LL(k)}

As gramáticas LL(k) são usadas por métodos descendentes que utilizam k símbolos de lookahead, ou seja, $k$ símbolos da cadeia de entrada para determinar a produção a ser escolhida durante uma análise, ou uma alternativa de uma sequência de alternativas.

Exemplo 1: se $G=(\{S\},\{a, b, c\}, S,\{S \rightarrow a S|b S| c\})$, então $G$ é uma gramática $\operatorname{LL}(1)$, pois é necessário verificar um único símbolo da cadeia para determinar a produção a ser escolhida ou se é necessário ler o próximo símbolo de entrada em cada passo da análise. Os passos do reconhecimento da cadeia " $a a b c$ " são $\Rightarrow a S \Rightarrow a a S \Rightarrow a a b S \Rightarrow a a b c$; em casa passo é necessário usar apenas um só símbolo da cadeia intermediária para decidir qual produção deve ser usada, isto é, $S \rightarrow a S, S \rightarrow a S, S \rightarrow b S$ e $S \rightarrow c$ respectivamente. 
Exemplo 2: se $G=(\{S\},\{a, b, c, d\}, S,\{S \rightarrow a b S|a c S| d\})$, então $G$ é uma gramática $\operatorname{LL}(2)$, pois pode ser necessário verificar os dois primeiros símbolos de cada produção para determinar a produção a ser escolhida. De fato, na cadeia " $a b d$ ", no primeiro passo depois de $a b S \Rightarrow a b d$ é necessário examinar os dois símbolos antes de $S$ para decidir entre $S \rightarrow a b S$ ou $S \rightarrow a c S$.

\subsubsection{Recursão à esquerda}

Pelo fato de, ao se ter um não terminal $N$ como objetivo, sempre se fazer uma busca pelos primeiros símbolos à direita de uma produção, uma gramática $L L(k)$ não pode ter uma recursão à esquerda, isto é, não pode haver uma geração da forma $N \stackrel{+}{\Rightarrow} N \alpha$ onde $N \in V_{N}$ e $\alpha \in V^{*}$, como na figura 2.3. A razão disso é que, por exemplo, se em um reconhecimento tem-se como objetivo o não terminal $N$ e as produções de $N$ são $N \rightarrow N a \mid b$, e não ocorrendo $b$ na entrada, deve-se usar a produção $N \rightarrow N a$, passando a ter novamente $N$ como objetivo, e assim sucessivamente. $N$ transforma-se recursiva e indefinidamente em objetivos, sem que nenhum símbolo de entrada seja lido. No método recursivo descendente, isso corresponde a uma chamada recursiva do procedimento $N$ sem nenhuma outra ação, gerando um loop infinito de chamadas.

O algoritmo para transformar uma gramática com recursão à esquerda em uma gramática equivalente (isto é, que gera a mesma linguagem) sem recursão a esquerda pode ser encontrado no apêndice $A$.

\subsubsection{Fatoração à esquerda}

Se, para as produções de um certo não terminal, há várias delas começando à esquerda com o mesmo símbolo terminal, para obterem-se gramáticas do tipo LL(1) pode-se utilizar a técnica de fatoração à esquerda.

Se $G$ é uma gramática com uma produção do tipo $N \rightarrow \alpha \beta_{1}\left|\alpha \beta_{2}\right| \ldots \mid \alpha \beta_{n}$ onde $\beta_{1} \neq \beta_{2} \neq$ $\ldots \neq \beta_{n}$, então $G$ não é $\operatorname{LL}(1)$, mas pode ser transformada em uma gramática equivalente $G^{\prime}$ $\mathrm{LL}(1)$ substituindo aquelas produções pela produção $N \rightarrow \alpha\left(\beta_{1}\left|\beta_{2}\right| \ldots \mid \beta_{n}\right)$. 


\section{Capítulo 5}

\section{Geradores de Analisadores Sintáticos em Uso}

Existem diversos programas de computador desenvolvidos com o propósito de facilitar a criação de analisadores sintáticos. Esses programas em geral consistem em receber como entrada uma gramática e retornam como saída um programa que é um analisador sintático para essa gramática. Alguns desses programas possibilitam que se descrevam a análise de contexto e a geração de código para casos simples, obtendo-se com isso um compilador completo sem que seja necessário programá-lo em uma linguagem corrente de programação.

A seguir será feita uma breve análise sobre alguns geradores de analisadores sintáticos e, posteriormente, será dada uma tabela comparativa entre eles.

\subsection{Yacc/Lex e Bison/Flex}

O Yacc (Yet another compiler compiler) foi desenvolvido nos laboratórios da AT\&T por S.C. Johnson [Joh78] e foi por muito tempo utilizado no sistema operacional Unix como seu gerador de analisadores sintáticos padrão.

\subsubsection{Entrada}

O Yaac recebe um programa-fonte em linguagem Yacc contendo uma gramática $\operatorname{LALR}(1)$ e gera as tabelas necessárias para que o método LALR(1) (Look-Ahead LR parser) seja executado. Esse arquivo é dividido em três partes:

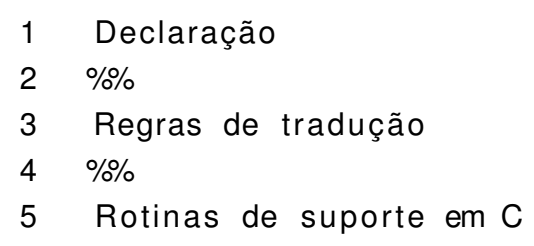

Quadro 5.1: Estrutura do programa-fonte Yacc 


\section{Declaração}

Essa é uma parte opcional, dividida em duas subpartes. Na primeira, são colocadas declarações em linguagem C, por exemplo, includes de bibliotecas externas delimitadas por \%\{...\}\%. $\mathrm{Na}$ segunda, podem ser declarados os tokens da gramática, por exemplo, \%token DIGIT que declara a palavra DIGIT como sendo um token.

\section{Regras de produção}

Nessa parte são colocadas as produções da gramática e a ação semântica associada a cada regra. As regras de produção seguem a forma do quadro 5.2.

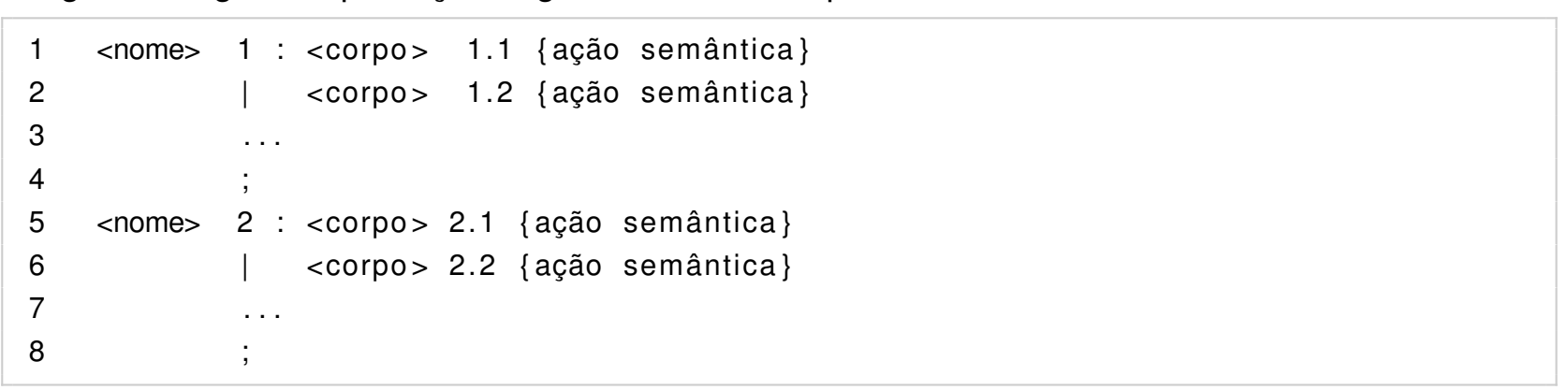

Quadro 5.2: Regras de tradução do Yacc

Cada $<$ nome $>$ representa um não terminal à esquerda da produção, cada <corpo > representa o lado direito de uma produção desse não terminal. Além disso, pode ser definida uma ação semântica em linguagem $\mathrm{C}$ para cada derivação, fazendo referência ao conteúdo semântico dos itens do lado esquerdo e direito de uma produção.

A geração do analisador com base nas regras de tradução é feita por um processo top-down de varredura da gramática, relativamente complexo de ser entendido. $\mathrm{O}$ analisador é um autômato, em que cada transição corresponde a um símbolo terminal de um lado direito das produções da gramática ou um não terminal que acabou de ser reconhecido.

\section{Rotinas de suporte}

Nessa parte são definidas as rotinas que serão utilizadas pelas ações semânticas da seção anterior. Também é necessário informar uma rotina nomeada yylex(), que será responsável por realizar a análise léxica.

O Yaac não tem um método padrão para análise léxica. Inicialmente era necessário que esse método fosse desenvolvido pelos programadores e incluído na parte de rotinas de suporte. Lesk e Schmidt [LS75] criaram o Lex, um gerador de analisadores léxicos simples e que foi muito bem aceito, chegando a ser considerado o gerador de analisador léxico padrão do Yacc.

Assim como o Yaac, o Lex recebe um programa-fonte em uma linguagem Lex e gera um programa-fonte em linguagem $\mathrm{C}$ contendo o analisador léxico. O programa-fonte em Lex contém as seguintes partes: declaração, regras de tradução e rotinas de suporte. Essas partes são similares às partes do Yacc, diferenciando-se apenas na parte das declarações, onde são aceitas apenas expressões regulares no lugar de uma gramática LR, além de não existir a opção de se declarar tokens. 
Exemplo: a seguir será apresentada uma calculadora simples com as operações de soma e multiplicação. As produções da gramática LR utilizadas são:

$$
\begin{aligned}
& \text { line } \rightarrow \text { expr 'In' } \mid \lambda \\
& \text { expr } \rightarrow \text { term } \mid \text { expr '+' term } \\
& \text { term } \rightarrow \text { factor } \mid \text { term '*' factor } \\
& \text { fator } \rightarrow \text { '(' expr ')' | DIGIT }
\end{aligned}
$$

Note-se que nos métodos LR pode haver recursão de não terminais à esquerda. No YACC os símbolos terminais são representados com apóstrofes.

Antes de se gerar o programa-fonte Yacc, deve-se gerar o programa-fonte do Lex, denominado aqui "calculadora.l" (quadro 5.3 a quadro 5.5).

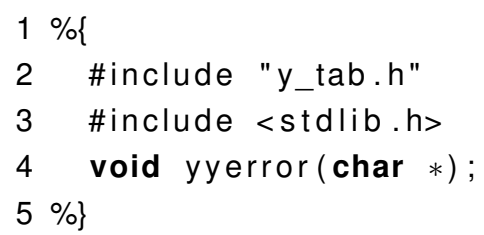

Quadro 5.3: Exemplo de declaração em um arquivo do Lex

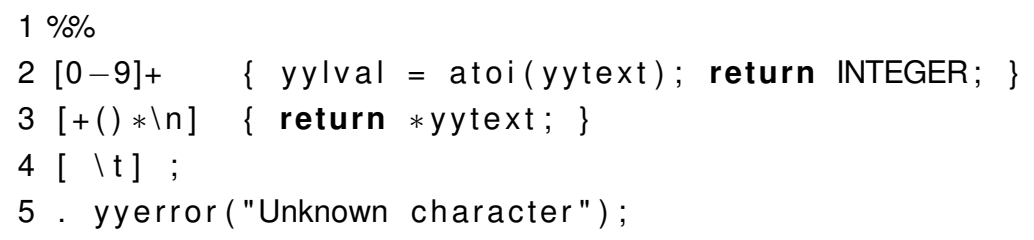

Quadro 5.4: Exemplo de regras de produção em um arquivo do Lex

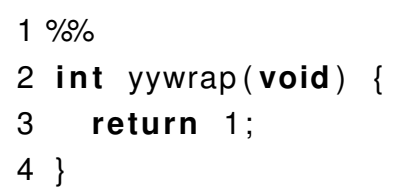

Quadro 5.5: Exemplo de rotinas de suporte em um arquivo do Lex

Depois de gerado o programa-fonte do Lex deve ser gerado o programa-fonte do Yacc, denominado aqui "calculadora.y" (quadro 5.6 a quadro 5.8).

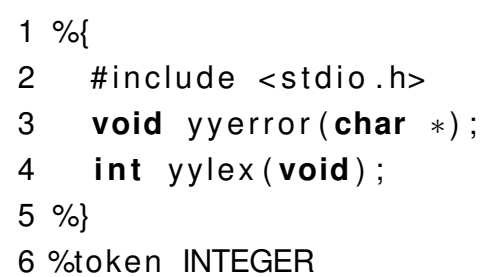

Quadro 5.6: Exemplo de declaração em um arquivo do Yacc

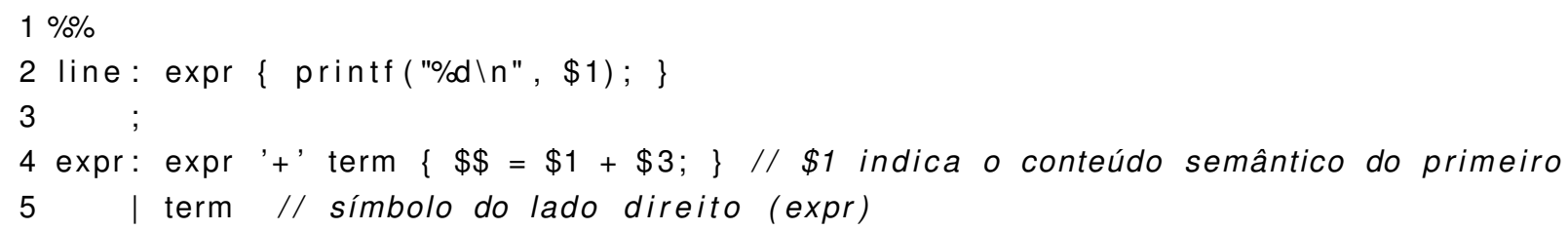




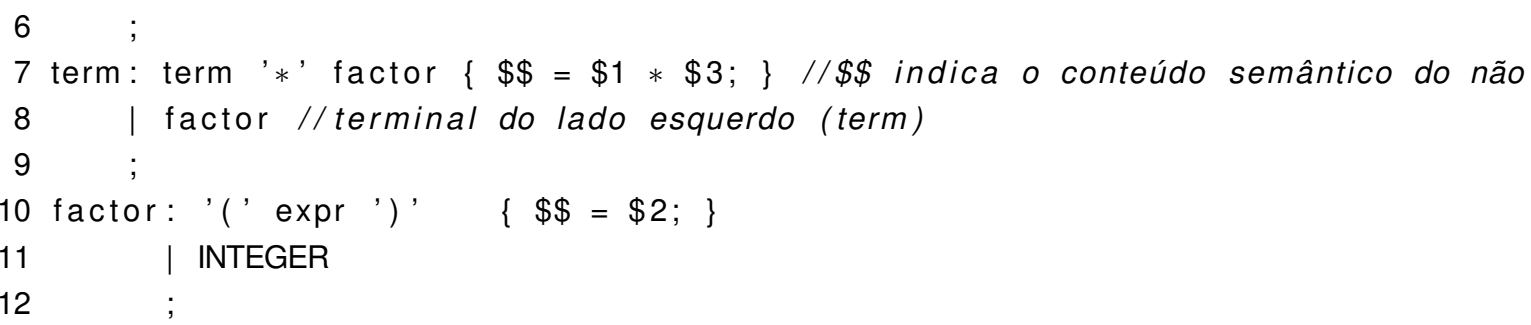

Quadro 5.7: Exemplo de regras de produção em um arquivo do Yacc



Quadro 5.8: Exemplo de rotinas de suporte em um arquivo do Yacc

Com os dois programas fontes gerados pode-se criar um programa executável no Unix com os seguintes comandos do quadro 5.9

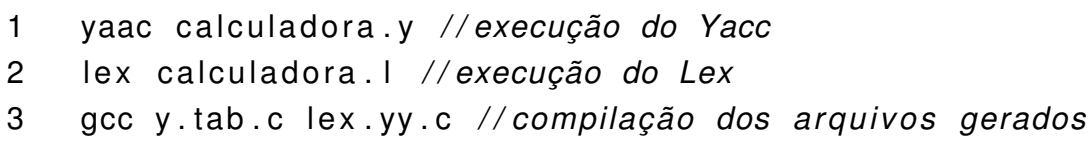

Quadro 5.9: Exemplo de execução do Lex e Yacc

\subsubsection{Saída}

Após executado, o Yaac retorna como saída um programa-fonte em linguagem $\mathrm{C}$, o qual contém o analisador LALR(1) e as tabelas necessárias para sua execução.

\subsubsection{Recuperação de erros}

No Yaac, em caso de erro durante uma análise sintática, a emissão de mensagens de erro e a continuação da análise não são automáticas. Para que sejam realizadas, devem-se inserir produções de erros na gramática gerada, aumentando assim o número de produções e complicando o trabalho de projetar uma gramática. Essas produções de erros são reconhecidas apenas quando ocorre um erro na análise, e em sua rotina semântica deve-se programar o tratamento de erro para aquela produção.

\subsubsection{Bison/Flex}

O Bison foi o sucessor do Yacc. Similar a este, o Bison também utiliza o método LALR(1), porém, pode utilizar o método GLR [Lan74] quando se emprega uma gramática ambígua, além de poder gerar como saída códigos em linguagem C, C++ ou Java. O Bison utiliza como seu gerador de analisador léxico padrão o Flex, que é uma versão aprimorada do Lex citado anteriormente. 


\subsection{SableCC}

O SableCC [GH98b] é um sistema desenvolvido como tese de doutorado de Étienne Gagnon. O sistema é totalmente escrito na linguagem Java, utiliza o método LALR(1), e apresenta dois fundamentos básicos:

- O sistema utiliza técnicas de orientação a objeto para construir uma árvore sintática estritamente tipada.

- O sistema gera classes para percorrer a árvore de derivação utilizando o design-pattern visitor ${ }^{1}$.

\subsubsection{Entrada}

O SableCC possui como entrada um arquivo com programa-fonte com uma especificação léxica e sintática. Esse arquivo possui a estrutura apresentada no quadro 5.10.

$\begin{array}{ll}1 & \text { Package } \\ 2 & \text { Helpers } \\ 3 & \text { Tokens } \\ 4 & \text { Ignored Tokens } \\ 5 & \text { Productions }\end{array}$

Quadro 5.10: Estrutura do programa-fonte SableCC

- Package: é o nome do pacote em Java de cada classe gerada pelo SableCC.

- Helpers: nessa parte são declaradas constantes que auxiliam nas declarações seguintes.

- Tokens: nessa parte são declarados os tokens utilizados pelo compilador.

- Ignored tokens: nessa parte são declarados os tokens ignorados pelo compilador.

- Productions: nessa parte são declaradas as produções da gramática utilizada pelo compilador.

Exemplo: a seguir será apresentada uma calculadora simples com as operações de soma e multiplicação. As produções da gramática LR utilizadas são:

$$
\begin{aligned}
& \text { line } \rightarrow \text { expr } \\
& \text { expr } \rightarrow \text { term | expr '+' term } \\
& \text { term } \rightarrow \text { factor | term '*' factor } \\
& \text { factor } \rightarrow \text { '(' expr ')' | DIGIT }
\end{aligned}
$$

No quadro 5.11 é apresentado o arquivo com a especificação SableCC.

\footnotetext{
${ }^{1}$ Para mais informações, vide Visitor no apêndice B
} 


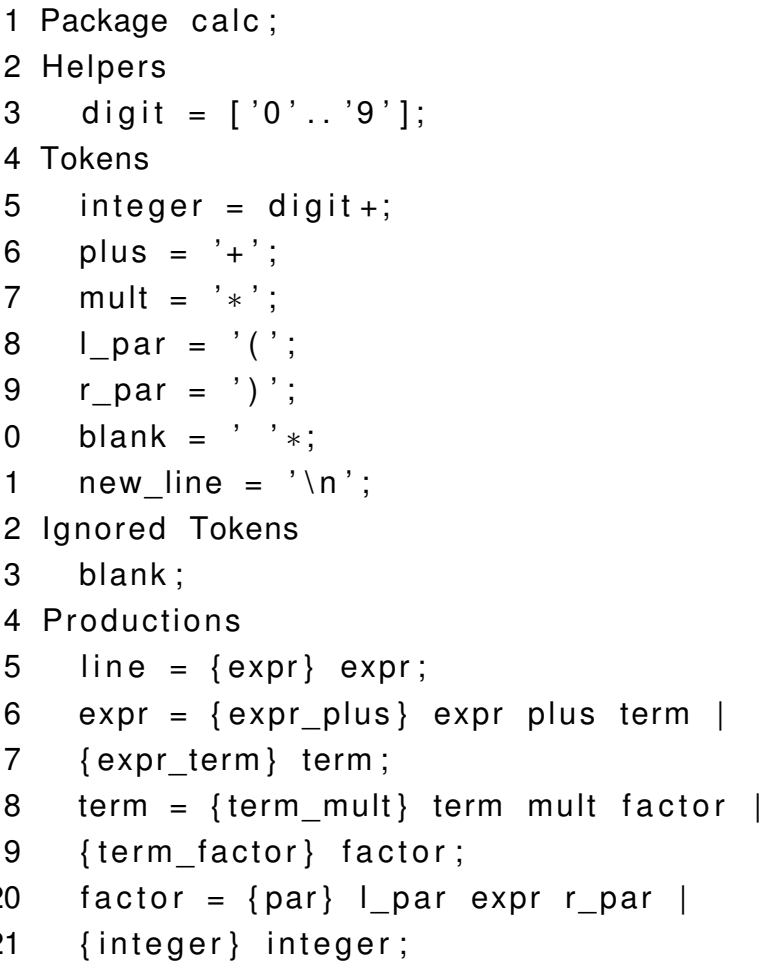

Quadro 5.11: Exemplo de arquivo SableCC

\subsubsection{Saída}

Após dar a especificação na linguagem do SableCC, deve-se executá-lo e processá-lo, gerando um programa-fonte em linguagem Java. Esse programa-fonte contém arquivos necessários para a geração do compilador.

O programa-fonte gerado pelo SableCC contém diversas classes em linguagem Java, entre elas destacam-se:

- As classes geradas para cada token.

- As classes geradas para cada lado esquerdo de uma produção.

- As classes geradas para cada alternativa do lado direito de uma produção. Essas classes herdam a classe gerada para o lado esquerdo de sua produção.

A análise semântica deve ser especificada após a geração do programa-fonte e deve ser escrita em linguagem Java.

\subsubsection{Recuperação de erros}

Assim como o Yacc e o Bison, o SableCC utiliza o método LALR(1) para gerar o analisador sintático e, por esse motivo, não tem um tratamento automático de erros, devendo ser utilizados métodos manuais para se gerar a recuperação de erros. Eles consistem em especificar produções adicionais, reconhecendo cada erro possível. 


\section{$5.3 \mathrm{COCO} / \mathrm{R}$}

O COCO/R é um gerador de analisadores sintáticos que gera um analisador top-down recursivo descendente e possui um sistema simples de tratamento de erros. Ele foi baseado no COCO [RM89] que gerava um analisador sintático dirigido por tabelas.

\subsubsection{Entrada}

O COCO/R aceita como entrada um arquivo com um programa-fonte contendo uma gramática com notação BNF estendida. Além disso, é utilizada gramática de atributos [Knu68] para a especificação semântica.

A estrutura de um arquivo de entrada do COCO/R é apresentada no quadro 5.12.

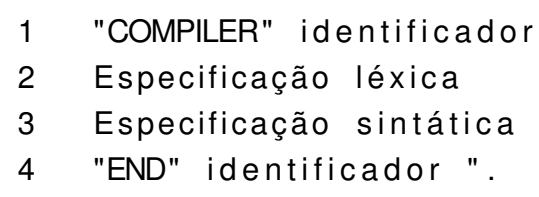

Quadro 5.12: Estrutura do programa-fonte COCO/R

Exemplo: a seguir será apresentada uma calculadora simples com as operações de soma e multiplicação. As produções da gramática LL utilizadas são:

$$
\begin{aligned}
& \text { calc } \rightarrow \text { expr } \\
& \text { expr } \rightarrow \text { term }\{\text { '+' term }\}^{*} \\
& \text { term } \rightarrow \text { factor }\left\{{ }^{* *} \text { factor }\right\}^{*} \\
& \text { factor } \rightarrow \text { '(' expr ')' | DIGIT }
\end{aligned}
$$

No quadro 5.13 é apresentado o arquivo com a especificação COCO/R.

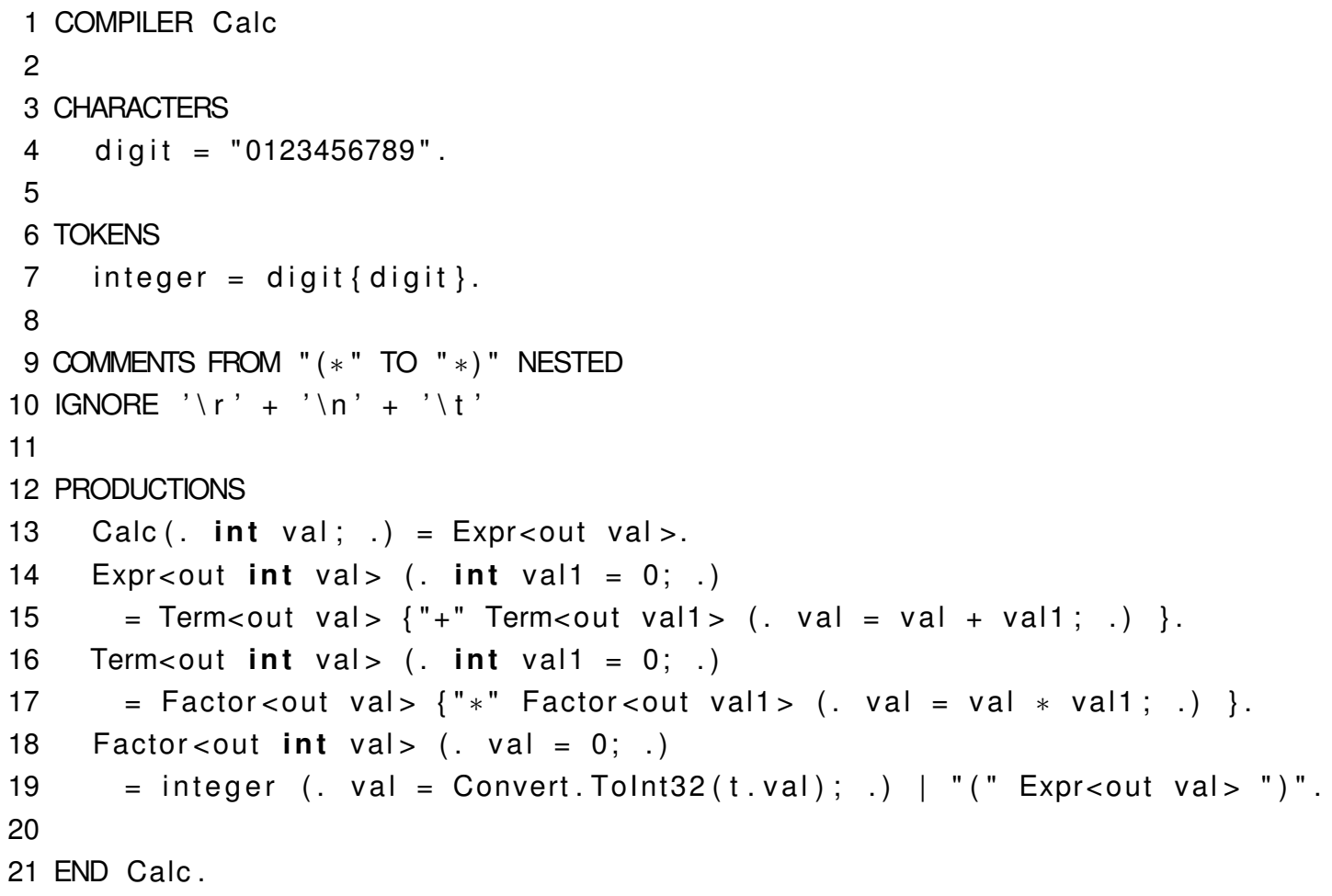




\section{Quadro 5.13: Exemplo de arquivo COCO/R}

Note-se que, como no caso do Yacc há uma linguagem para especificação semântica. Por exemplo, nas linhas 14 e 15 são decladas as variáveis val e val1, que conterão os valores semânticos associados a algum não terminal utilizando a palavra reservada out, como por exemplo na linha 16 o primeiro não terminal Term irá retornar val e o segundo não terminal Term irá retornar val1.

\subsubsection{Saída}

O COCO/R gera como saída um programa-fonte contendo um analisador recursivo descendente em linguagens Java, $\mathrm{C}, \mathrm{C}++, \mathrm{C \#}$, entre outras.

\subsubsection{Recuperação de erros}

Para realizar o tratamento de erros no $\mathrm{COCO} / \mathrm{R}$, devem-se utilizar as palavras reservadas SYNC e WEAK. A primeira representa um ponto de sincronização que deve ser especificado em um ponto seguro da gramática, ou seja, que quase nunca é ausente ou digitado erroneamente. Quando o compilador encontra esse ponto da gramática, ajusta a entrada com o próximo símbolo esperado. Em muitas linguagens é aconselhado utilizar esses pontos antes de blocos (por exemplo, if, while) ou de declaração de variáveis e tipos. A segunda palavra reservada é utilizada para identificar pontos em que possam ocorrer erros de digitação ou falta de um símbolo de entrada, como é o caso de ; após um bloco.

\subsection{AntLR}

O AntLR (Another Tool for Language Recognition) é um gerador de compiladores desenvolvido por Terrence Parr [PQ95]. O AntLR é o sucessor do PCCTS (Purdue Compiler Construction Tool Set) desenvolvido em 1989.

Atualmente o AntLR encontra-se em sua versão 4. Uma das novidades dessa versão é que ela aceita qualquer gramática LL como entrada com exceção de gramáticas que possuem recursão indireta à esquerda. Para isso, ele utiliza uma técnica de análise sintática chamada Adaptive $\mathrm{LL}\left({ }^{*}\right)$ desenvolvida por Sam Harwell [Har13]. Essa técnica consiste em reescrever as regras gramaticais recursivas diretamente à esquerda em regras sem a recursão à esquerda. Além disso, se houver uma ambiguidade na gramática, ainda sim esta poderá ser executada, pois o analisador sempre escolherá a primeira opção da ambiguidade.

\subsubsection{Entrada}

O AntLR recebe como entrada um programa-fonte com uma gramática LL em notação BFN estendida. 
Exemplo: a seguir será apresentada uma calculadora simples com as operações de soma e multiplicação. As produções da gramática LL utilizadas são:

$$
\begin{aligned}
& \text { prog } \rightarrow \text { expr } \\
& \text { expr } \rightarrow \text { term }\{\text { '+' term }\}^{*}
\end{aligned}
$$

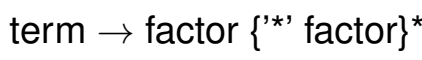

$$
\begin{aligned}
& \text { factor } \rightarrow \text { '(' expr ')' | INT }
\end{aligned}
$$

O arquivo com a especificação AntLR é apresentado no 5.14

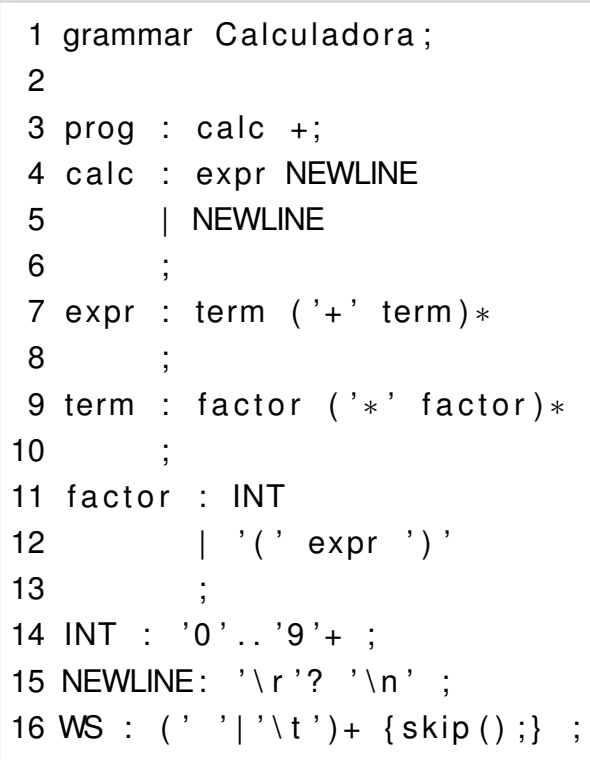

Quadro 5.14: Exemplo de arquivo AntLR

\subsubsection{Saída}

O AntLR em sua versão 4 gera programas-fontes de analisadores sintáticos nas linguagens C\# e Java. Além disso, o AntLR gera dois tipos de analisadores sintáticos, o primeiro utilizando o design patter listener e o segundo utilizando o design patter visitor [GJHV06]. Em ambos casos o compilador gerado é do tipo recursivo descendente, sob a forma de um conjunto de métodos recursivos, um para cada produção da gramática. Recorde-se que um analisador recursivo descendente é um analisador top-down.

As operações sobre a árvore sintática, também conhecidas como operações semânticas, são feitas em códigos Java ou C\#.

\subsubsection{Recuperação de erro}

O AntLR apresenta uma boa recuperação de erros. Além disso, podem-se alterar as mensagens padrões de erro, capturar exceções e até alterar as estratégias de recuperação de erros padrões. Essas estratégias são baseadas nas ideias de Niklaus Wirth [Wir78], inserção e exclusão de um token. Também há um mecanismo de sincronismo quando nenhuma das estratégias anteriores funcionou. Esse mecanismo busca uma sincronização entre a entrada e a gramática para que a análise possa continuar; essa estratégia também é conhecida como recuperação de erro em nível de frase. 


\subsubsection{AntLRWorks 2}

O AntLRWorks 2 é um software desenvolvido por Sam Harwell [Har13] para auxiliar o desenvolvimento de novas gramáticas para o AntLR. Nesse software é possível escrever a gramática em modo texto e gerar o gráfico sintático de cada produção da gramática para verificação visual, além de testar a gramática por meio de um arquivo fonte. O AntLRWorks 2 foi desenvolvido usando o ambiente NetBeans e, por esse, motivo possui todas as facilidades desse ambiente.

\subsection{Discussão}

Vimos que, dos geradores de analisadores sintáticos analisados, apenas o COCO/R e o AntLR possuem recuperação automáticas de erros. Isso se deve ao fato de esses geradores utilizarem métodos top-down. Outra característica encontrada foi que nenhum deles possui uma interface gráfica para geração e testes dos analisadores criados. Apenas o AntLR tem uma interface desenvolvida por outros programadores para auxiliar a criação das gramáticas, porém, essa interface não aceita entrada gráfica. Somente é possível gerar a representação gráfica a partir da gramática fornecida em forma de texto, para verificação e compreensão visual da mesma. Devese ainda notar que a análise do tipo LR é bastante complexa, isto é, não é fácil compreender como o autômato do analisador é gerado e como o analisador funciona. Já o funcionamento dos métodos top-down é facilmente compreensível.

As tabela 5.1 e tabela 5.2 são comparações entre os geradores de analisadores sintáticos avaliados.

\begin{tabular}{l|l|l|l}
\hline Nome & Método utilizado & Interface & Recuperação automática de erros \\
\hline Yacc & LALR(1) & Texto & Não \\
Bison & LALR(1), LR(1) e GLR & Texto & Não \\
SableCC & $\operatorname{LALR}(1)$ & Texto & Não \\
COCO/R & LL(1) & Texto & Simples \\
AntLR 4 & LL $\left(^{*}\right)$ & Texto & Sim \\
\hline
\end{tabular}

Tabela 5.1: Comparação entre geradores de analisadores sintáticos

\begin{tabular}{|c|c|c|c|}
\hline Nome & $\begin{array}{l}\text { Analisador } \\
\text { léxico }\end{array}$ & Análise semântica & Linguagem de saída \\
\hline Yacc & Externo & $\begin{array}{l}\text { Rotinas em linguagem } \\
\text { própria }\end{array}$ & C \\
\hline Bison & Externo & $\begin{array}{l}\text { Rotinas em linguagem } \\
\text { própria }\end{array}$ & C, C++ ou Java \\
\hline SableCC & $\begin{array}{l}\text { Junto à especifi- } \\
\text { cação sintática }\end{array}$ & $\begin{array}{l}\text { Rotinas em linguagem } \\
\text { Java }\end{array}$ & Java \\
\hline $\mathrm{COCO} / \mathrm{R}$ & $\begin{array}{l}\text { Junto à especifi- } \\
\text { cação sintática }\end{array}$ & $\begin{array}{l}\text { Rotinas em linguagens } \\
\mathrm{C} / \mathrm{C}++ \text {, Java, Pascal, } \\
\text { C\#, entre outras }\end{array}$ & $\begin{array}{l}\mathrm{C} / \mathrm{C}++, \text { Java, Pascal, } \\
\mathrm{C \#} \text {, entre outras }\end{array}$ \\
\hline AntLR 4 & $\begin{array}{l}\text { Junto à especifi- } \\
\text { cação sintática }\end{array}$ & $\begin{array}{l}\text { Rotinas em linguagens } \\
\text { Java e C\# }\end{array}$ & Java e C\# \\
\hline
\end{tabular}

Tabela 5.2: Comparação entre geradores de analisadores sintáticos 


\section{Capítulo 6}

\section{O Sistema GGLL}

Neste capítulo é apresentado o cerne deste trabalho: o GGLL. O GGLL de "gerador de analisadores sintáticos para Gramáticas Gráficas LL(1)", foi concebido com o propósito de facilitar a criação de novas linguagens de programação e a construção de compiladores ou interpretadores.

\subsection{Funcionamento do GGLL}

O GGLL é baseado no algoritmo desenvolvido por Valdemar Setzer [Set79], denominado posteriormente ASIN [SDM83]. Outras implementações do ASIN foram realizadas, como as de Luiz Fernando Pereira [Per04], que utilizava a interface do IBM Eclipse, o qual tinha suporte apenas para gramáticas ESLL(1), ou seja, gramáticas LL(1) em que não podem haver não terminais com alternativa. Outra implementação foi a de Gustavo Henrique Braga [Bra09] em Java independente de ambiente, porém, essa implementação não foi totalmente finalizada e necessitava de muitos ajustes e extensões.

A implementação realizada nesse trabalho partiu daquela de Gustavo Henrique Braga para gramáticas LL(1), e não mais ESLL(1). Com isso, pode-se reduzir bastante o número de produções da gramática criada. Ademais, as partes de modelagem da gramática, da recuperação de erros, da análise léxica e da análise semântica foram totalmente refeitas, bem como foi introduzido um algoritmo para validação do tipo da gramática.

É um sistema de fácil utilização, pois é baseado numa interface gráfica que permite a criação de analisadores sintáticos com base em gramáticas gráficas. Além disso, possui um meio de se validar a gramática criada, quanto a ser uma gramática LL(1), e de se poder testá-la enquanto está sendo desenhada, sem a necessidade de valer-se de arquivos externos, pois o sistema gera um código-fonte em Java que é automaticamente compilado. Esse código-fonte pode ser exportado para uso em outros projetos. Além disso, o algoritmo de análise sintática é muito simples, intuitivo, portanto de fácil compreensão. Essa característica não existe, por exemplo, nos analisadores baseados nas gramáticas LALR, como o Yacc, já que a geração do analisador e o algoritmo de análise são relativamente complexos. O GGLL aceita como entrada uma gramática desenhada usando-se os recursos gráficos do próprio sistema, isto é, sem recursos de um ambiente específico de programação e, com base nela, é gerada uma tabela que é a descrição dessa gramática. Essa tabela é então interpretada durante a análise sintática.

Além disso, o GGLL possui uma emissão automática de erros sintáticos e uma continuação 
(recuperação) automática da análise fundamentada exclusivamente na gramática apresentada. Isso dispensa qualquer ação do projetista de um compilador ou interpretador com o objetivo de implementar esses dispositivos no tocante ao tratamento de erros.

Para a análise sintática de uma gramática, isto é, para percorrer corretamente o seu grafo sintático é empregada uma pilha, denominada pilha do analisador, na qual cada célula contém uma referência (isto é localização no grafo) de um nó não terminal $N$. Ao ser atingido um nó contendo $N$, essa referência é empilhada e desvia-se para o nó à esquerda da produção de $N$. Ao chegar-se ao final de um lado direito de uma produção de $N$ desempilha-se aquela referência (que por construção estará no topo da pilha) e se continua a análise a partir do nó sucessor do que continha $N$.

Uma segunda pilha, a pilha sintática é usada como comentário da análise, contendo nas células os símbolos dos lados direitos à medida que são reconhecidos. Quando um lado direito de uma produção é reconhecido são desempilhados todos os símbolos correspondentes. Com essa pilha pode-se acompanhar com precisão e facilmente todos os passos de uma análise sintática.

Na figura 6.1 é apresentado um exemplo de reconhecimento de uma gramática pelo GGLL.

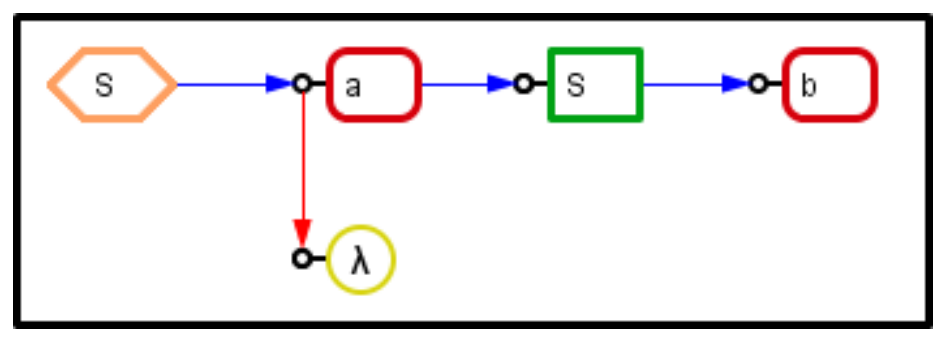

Figura 6.1: Gramática $S \rightarrow a S b \mid \lambda$

Dada a gramática da figura 6.1 e a cadeia de entrada aabb tem-se a execução apresentada na tabela 6.1

Seja $\mathrm{N}$ um nó não terminal, e n um nó terminal ou não terminal então:

- $E_{a}(N)$ : empilha o nó $N$ na pilha do analisador;

- $E_{s}(n)$ : empilha o nó $n$ na pilha sintática;

- $D_{a}(N)$ : desempilha o nó $N$ na pilha do analisador;

- $D_{s}(x)$ : desempilha a cadeia de símbolos $x$ na pilha sintática;

- $L_{t}$ : lê o próximo token;

- $L_{p}(N)$ : lê o primeiro nó do lado direito da produção de $N$;

- $L_{s}(n)$ : lê o nó sucessor de $n$;

- $L_{a}(n)$ : lê a alternativa de $n$;

- $C\left(n_{1}, n_{2}\right)$ : compara o símbolo do nó $n_{1}$ com o símbolo do nó $n_{2}$;

- $R(N)$ : reconhece o não terminal $N$. 


\begin{tabular}{|c|c|c|c|c|c|}
\hline Reconhecido & Token (k) & $\begin{array}{c}\text { Pilha } \\
\text { do Analisador }\end{array}$ & $\begin{array}{c}\text { Pilha } \\
\text { sintática }\end{array}$ & $\begin{array}{l}\text { Posição no grafo } \\
\text { sintático (nó n) }\end{array}$ & Comando \\
\hline- & $a$ & vazia & vazia & $S$ & $E_{a}(S) ; L_{p}(S)$ \\
\hline$a$ & $a$ & $S$ & vazia & $a$ & $\begin{array}{c}C(k, n) ; E_{s}(a) \\
L_{s}(a) ; L_{t}\end{array}$ \\
\hline$a$ & $a$ & $S$ & $a$ & $S$ & $E_{a}(S) ; L_{p}(S)$ \\
\hline$a a$ & $a$ & $S S$ & $a$ & $a$ & $C(k, n) ; E_{s}(a) ; L_{t}$ \\
\hline$a a$ & $b$ & $S S$ & $a a$ & $S$ & $E_{a}(S) ; L_{p}(S)$ \\
\hline$\overline{a a}$ & $b$ & $S S S$ & $a a$ & $a$ & $C(k, n) ; L_{a}(a)$ \\
\hline$a a$ & $b$ & $S S S$ & $a a$ & $\lambda$ & $\begin{array}{l}R(S) ; D_{a}(S) \\
E_{s}(S) ; L_{s}(S)\end{array}$ \\
\hline$a a$ & $b$ & $S S$ & $a a S$ & $b$ & $\begin{array}{c}C(k, n) ; E_{s}(b) \\
L_{t}\end{array}$ \\
\hline$a a b$ & $b$ & $S S$ & $a a S b$ & $b$ & $\begin{array}{c}R(S) ; D_{a}(S) \\
D_{s}(a S b) ; E_{s}(S) \\
L_{s}(S)\end{array}$ \\
\hline$a a b$ & $b$ & $S$ & $a S$ & $b$ & $\begin{array}{c}C(k, n) ; E_{s}(b) \\
L t\end{array}$ \\
\hline$a a b b$ & vazio & $S$ & $a S b$ & $b$ & $\begin{array}{c}R(S) ; D_{a}(S) ; \\
D_{s}(a S b) ; E_{s}(S) ; \\
L_{s}(s)\end{array}$ \\
\hline$a a b b$ & vazia & vazia & $S$ & vazia & reconhecida \\
\hline
\end{tabular}

Tabela 6.1: Exemplo de execução do GGLL

Ao final da execução, como a pilha do analisador está vazia, não há mais tokens a serem lidos e na pilha sintática está o nó inicial, a cadeia de entrada é considerada reconhecida.

\subsection{Interface do GGLL}

Na figura 6.2 tem-se a interface do GGLL. Nessa interface é apresentada a criação da gramática gráfica equivalente a $S \rightarrow a S b \mid \lambda$. 


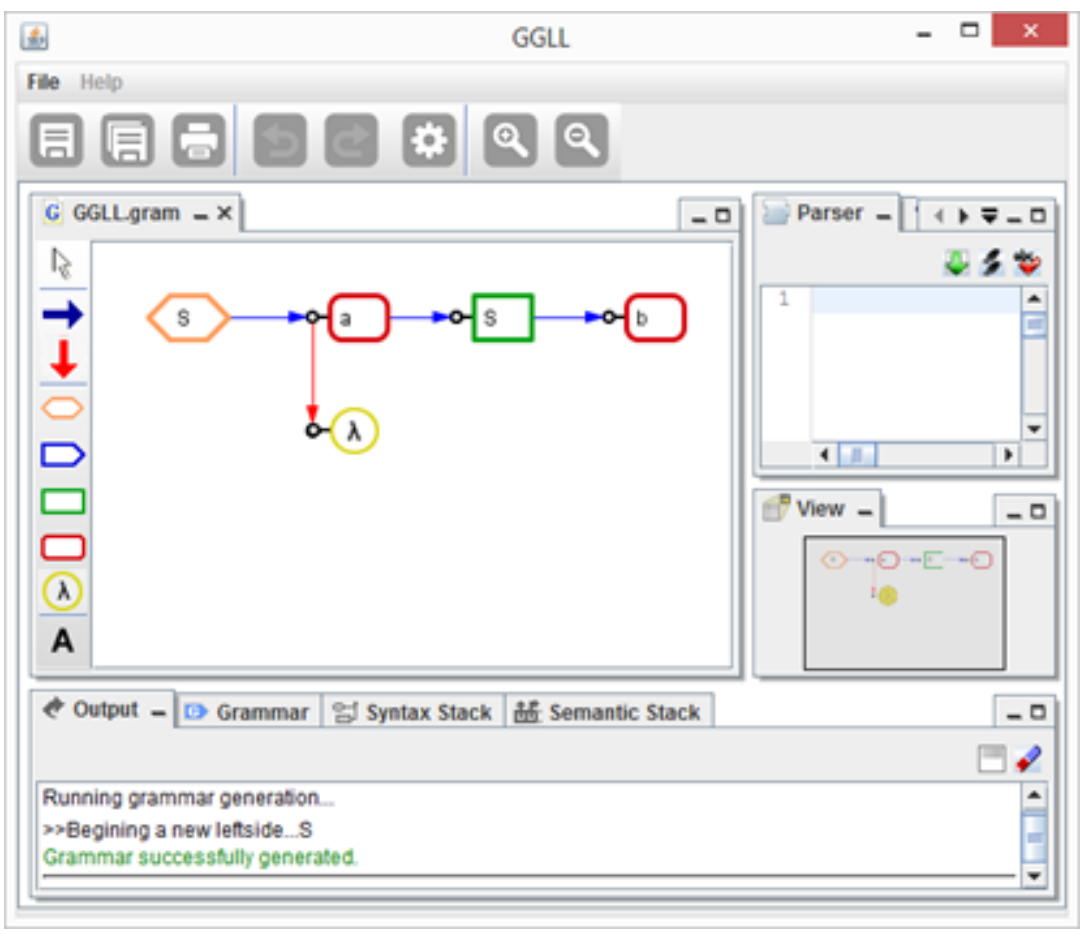

Figura 6.2: Interface do GGLL

Na figura 6.3 é apresentada a interface do sistema após a execução da análise sintática para a cadeia de entrada "aabb". Essa análise dá como resultado final "sucesso".

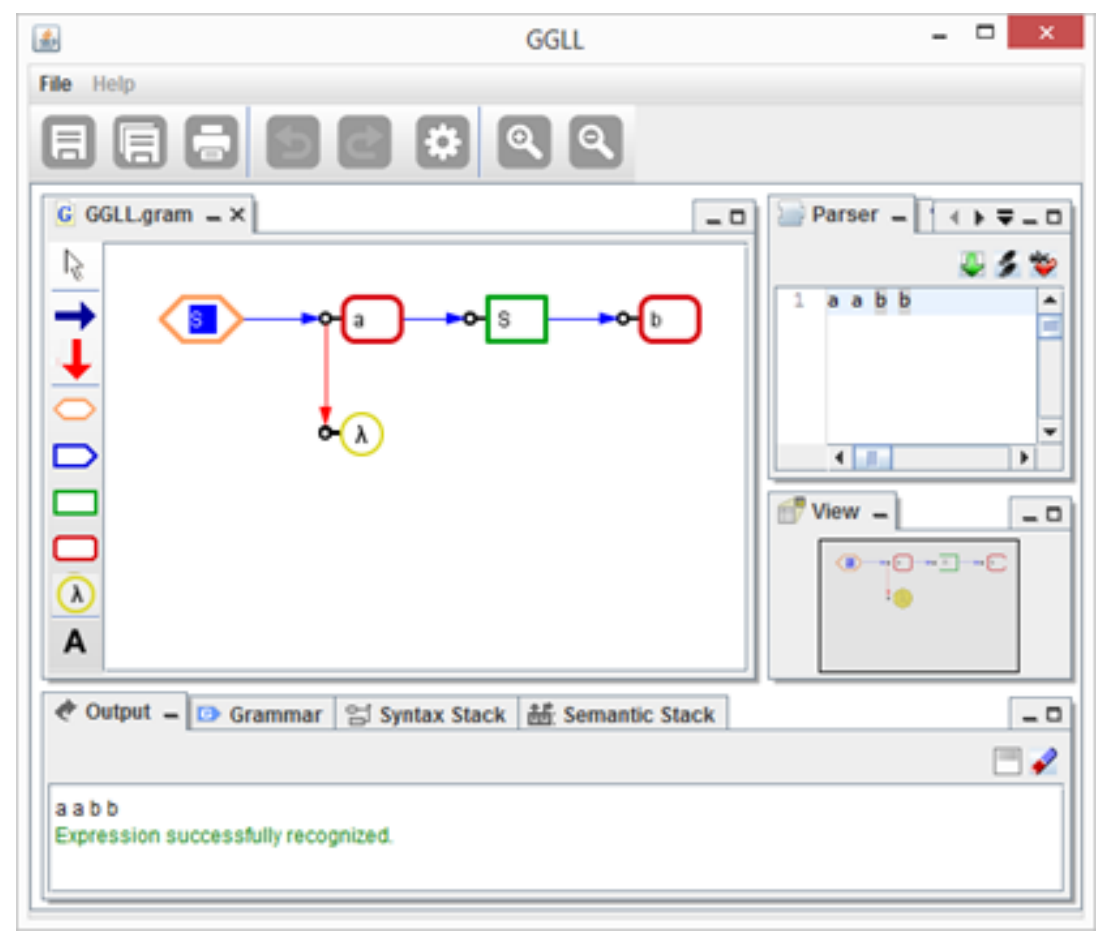

Figura 6.3: Entrada de uma cadeia no GGLL.UI

Para a gramática criada pode-se ainda verificar na aba Grammar a tabela gerada pelo GGLL. Essa tabela é utilizada pelo GGLL.Core (ver 6.8) para realizar a análise sintática da cadeia de entrada. 


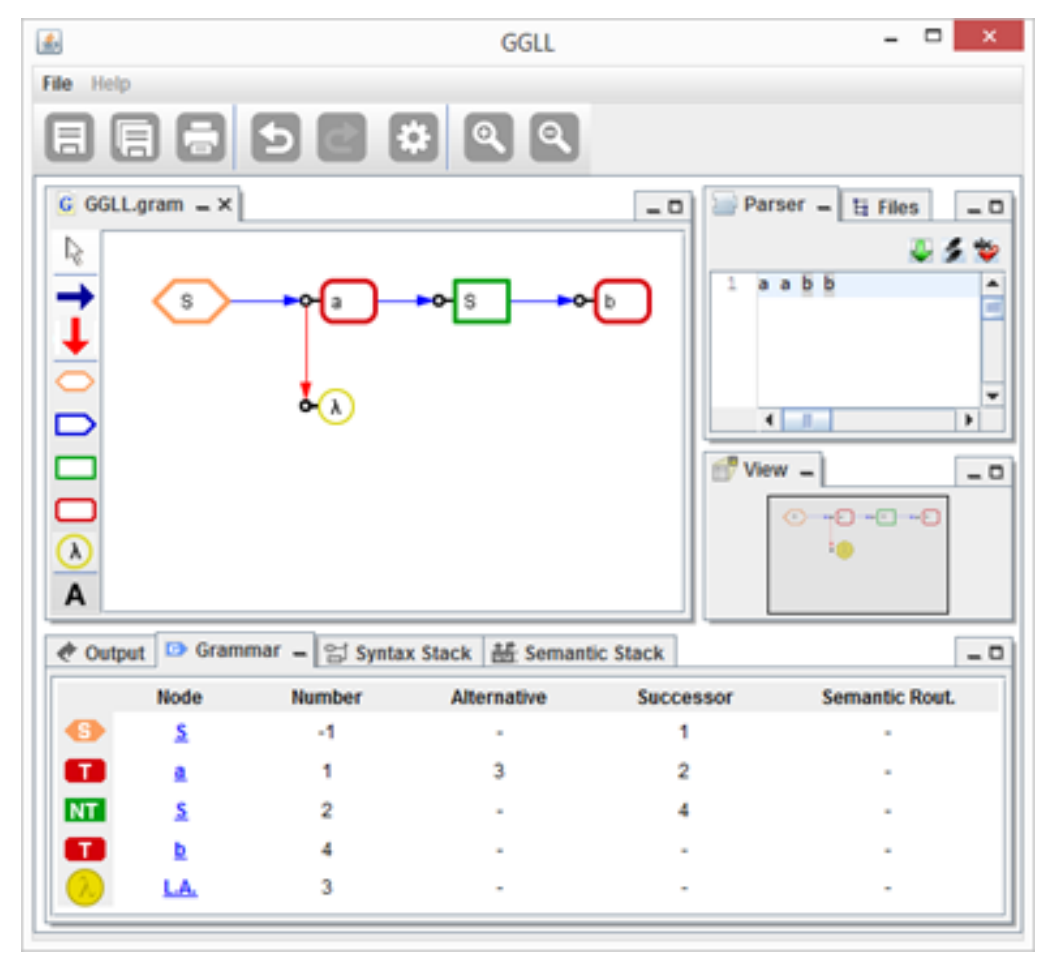

Figura 6.4: Aba Grammar

Outras abas importantes são as abas Syntax Stack e Semantic Stack, mostradas nas figuras 6.5 e figura 6.6, nas quais são apresentadas as pilhas sintática e semântica respectivamente. No exemplo os elementos da pilha semântica foram programados para serem o mesmo da pilha sintática. Essas pilhas são geradas pelo algoritmo de análise sintática e podem ser acessadas pelas rotinas semânticas no momento da análise semântica.

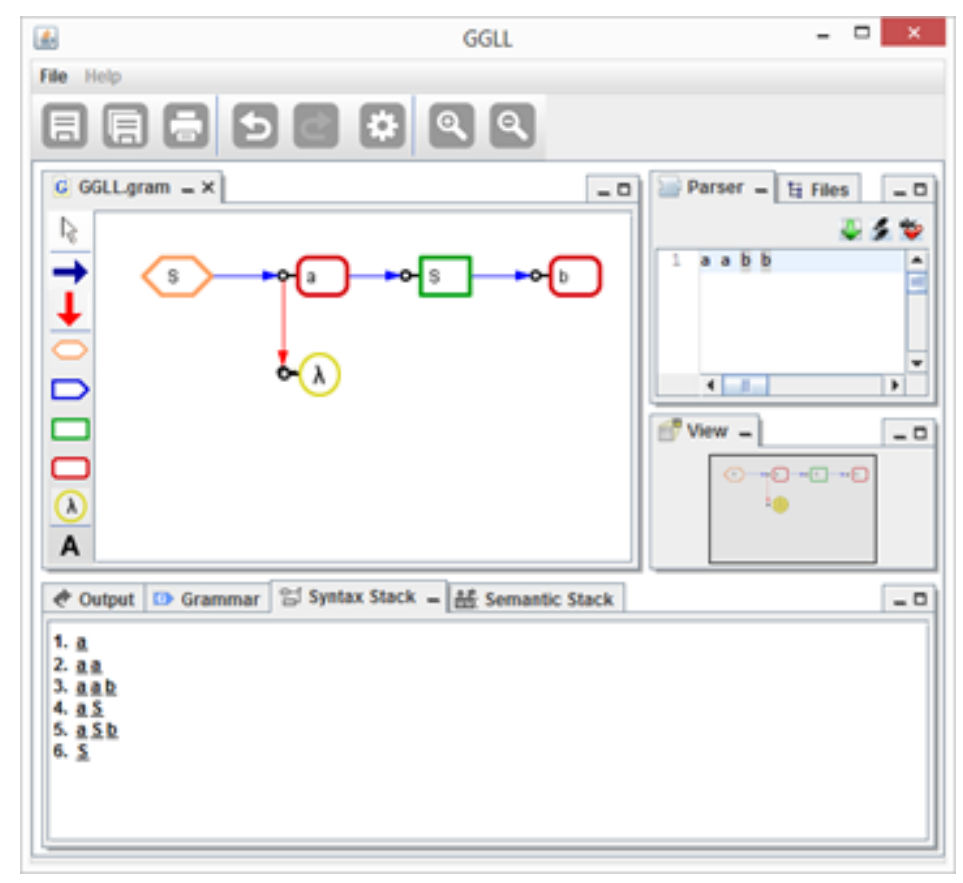

Figura 6.5: Aba Syntax Stack 


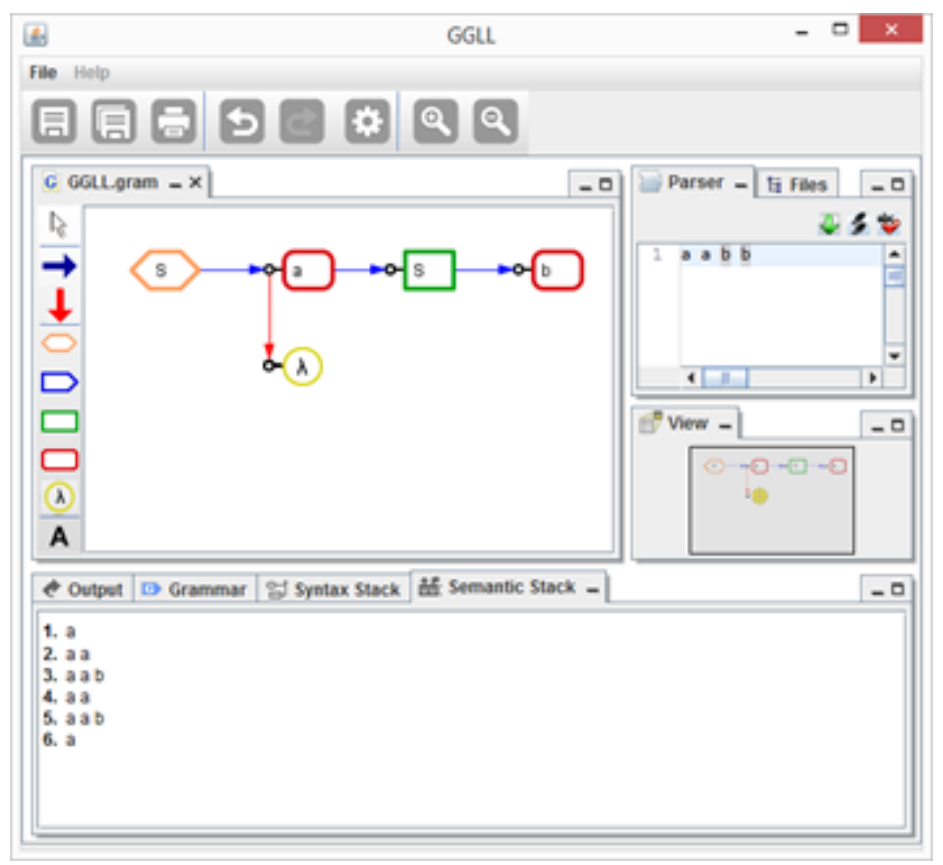

Figura 6.6: GGLL Aba Semantic Stack

Pelas rotinas semânticas pode-se fazer acesso tanto à pilha sintática quanto à pilha semântica para realizar a análise semântica. Em geral a exibição da pilha sintática serve para verificar se a gramática está correta, pois a análise sintática não depende dela, e para mostrar o significado sintático dos elementos da pilha semântica.

\subsection{Estrutura do GGLL}

O GGLL foi desenvolvido na linguagem Java em sua versão 7, utilizando conceitos de orientação a objeto e design patterns. O GGLL foi dividido em dois módulos para auxiliar o desenvolvimento e a sua utilização:

- GGLL.UI: usado no desenho gráfico da gramática e responsável pela geração e verificação da gramática, contendo as interfaces gráficas mostradas nas figuras 6.2 a figura 6.6;

- GGLL.Core: módulo responsável por executar o algoritmo de análise do GGLL sobre a gramática gerada pelo GGLL.UI.

Essa divisão em módulos possibilita que o programador referencie apenas o GGLL.Core em seu programa final para utilizar o analisador sintático gerado. Como o GGLL.Core é muito menor comparado ao GGLL.UI, o programa final que utilizará o analisador sintático gerado será relativamente pequeno. Outra característica importante é que novas funcionalidades podem ser adicionadas ao GGLL.UI sem que seja necessária uma alteração do GGLL.Core, desde que se mantenha o formato das tabelas de interface entre os dois módulos.

\subsection{Utilização do GGLL}

Para se usar o GGLL devem-se seguir os seguintes passos: 
1. Iniciar o GGLL.UI e criar um novo projeto de gramática;

2. Alterar o arquivo léxico em JLex responsável pela criação do analisador léxico; essa tarefa é opcional pois o GGLL.UI cria um arquivo léxico com as regras léxicas mais comuns;

3. Criar uma nova gramática graficamente;

4. Validar a gramática criada quanto a ser uma gramática LL(1), essa validação é automaticamente feita pelo GGLL.UI;

5. Adicionar rotinas semânticas à nova gramática criada;

6. Criar pelo GGLL.UI um arquivo XML correspondente à gramática. Com base no arquivo léxico do passo 2, neste passo também é gerado pelo GGLL.UI um arquivo contendo o programa-fonte do analisador léxico. Esse programa-fonte é gerado pelo JLex, que é ativado automaticamente pelo GGLL.UI. Além disso, este último gera um arquivo contendo uma classe em Java com as rotinas semânticas criadas no passo 3;

7. Utilizar o GGLL.Core em uma classe em Java, empregando como argumentos de entrada os três arquivos supramencionados (gramática em formato XML, analisador léxico e arquivo com rotinas semânticas);

8. Executar o método Parse para realizar a análise sintática de uma cadeia de entrada.

Com esses passos pode-se criar uma gramática e executá-la para várias cadeias de entrada que se deseja analisar. Note-se também que o arquivo contendo as rotinas semânticas pode ser alterado para realizar uma análise semântica completa e assim ter um compilador completo. Para mais detalhes desses procedimentos, vide o apêndice $C$.

\subsection{Algoritmos}

O GGLL consiste em um sistema onde se desenha, como entrada, uma representação gráfica de uma gramática; essa representação é também denominada grafo sintático. Essa entrada gráfica é convertida em três tabelas construídas pelo sistema. Essas tabelas são usadas na análise sintática de uma cadeia, isto é, na execução do algoritmo de análise sintática, que também usa três pilhas. Todos esses elementos estruturais são descritos a seguir.

\subsubsection{Tabelas}

O GGLL.UI gera a partir do grafo sintático uma tabela denominada tabela intermediária, que será utilizada posteriormente por outro algoritmo para gerar outras três tabelas. O seu formato foi definido em [SDM83]. O formato da tabela intermediária é representado na tabela 6.2.

\begin{tabular}{|c|c|c|c|c|c|}
\hline & & $\begin{array}{l}\text { Ind } \\
\text { rela }\end{array}$ & $\begin{array}{l}\text { Indi } \\
\text { alter }\end{array}$ & & ser \\
\hline
\end{tabular}

Tabela 6.2: Tabela GGLL 
Uma tabela intermediaria possui uma linha para cada nó $n$ do grafo sintático. A coluna Tipo de nó contém uma identificação do tipo de $n$, se $n$ é um nó correspondente ao lado esquerdo de uma produção essa coluna contém $H$ (de header); se é um terminal ou um não terminal em um lado direito de uma produção, contém $T$ ou $N$ respectivamente; um nó $\lambda$ é um nó terminal. A coluna Símbolo sintático contém o símbolo sintático de $n$, isto é, o token se for um símbolo terminal, ou o nome de um símbolo não terminal. A coluna Índice relativo contém -1 se $n$ corresponde ao lado esquerdo de uma produção; nos outros casos contém o índice de n relativo ao índice do não terminal do lado esquerdo de sua produção, adotando-se uma numeração da esquerda para a direita (sucessores) e de cima para baixo (alternativas) começando no valor 1 . A coluna Índice da alternativa contém o índice relativo do nó alternativo de $n$; se $n$ não tiver alternativa, a coluna contém -1. A coluna Índice do sucessor contém valores semelhantes à coluna anterior, mas para o nó sucessor de $n$. A coluna Rotina semântica indica o nome de uma rotina semântica no caso de $n$ fazer referência a uma tal rotina.

Uma tabela intermediaria é construída pelo algoritmo apresentado no quadro 6.1.

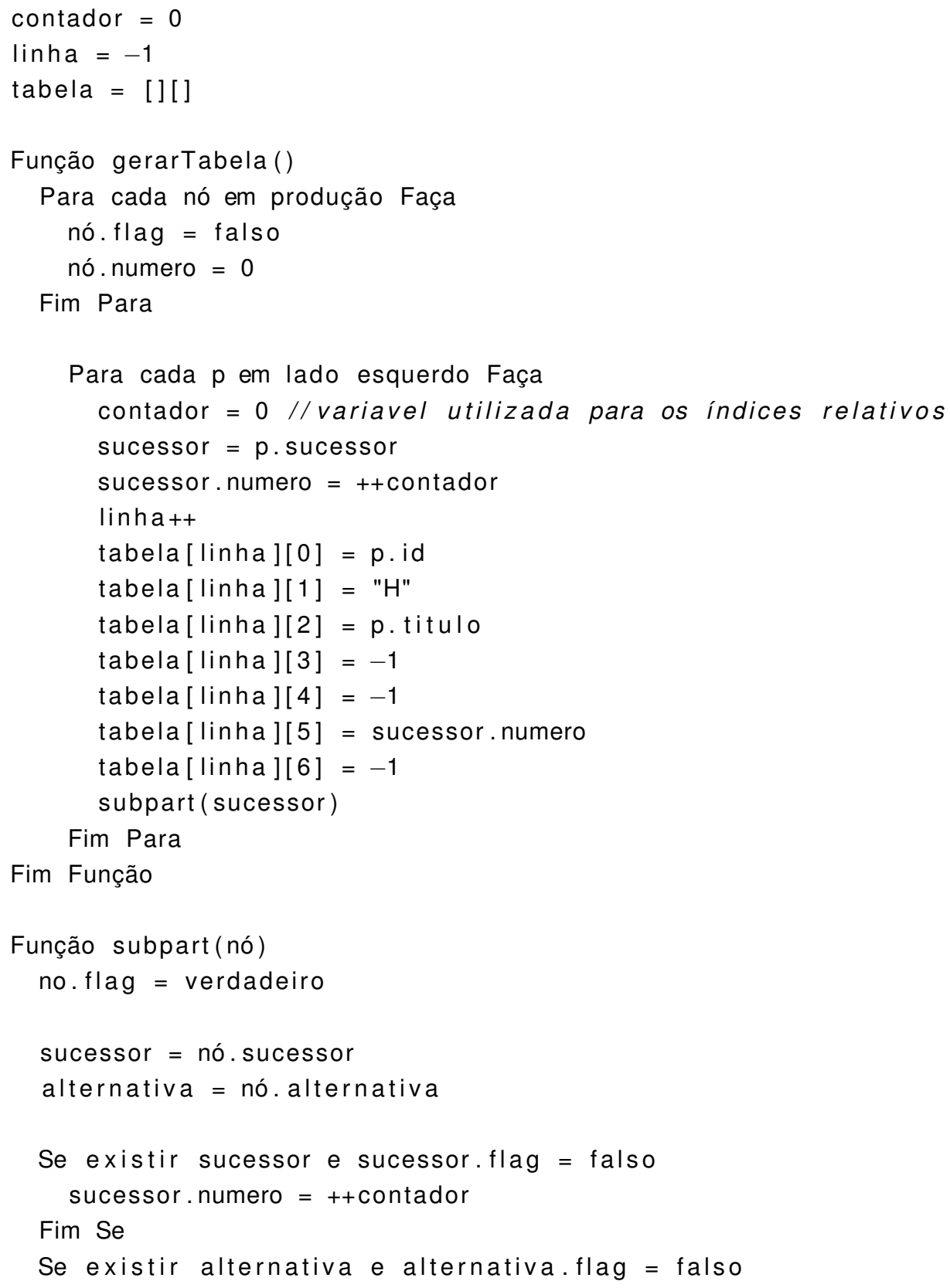




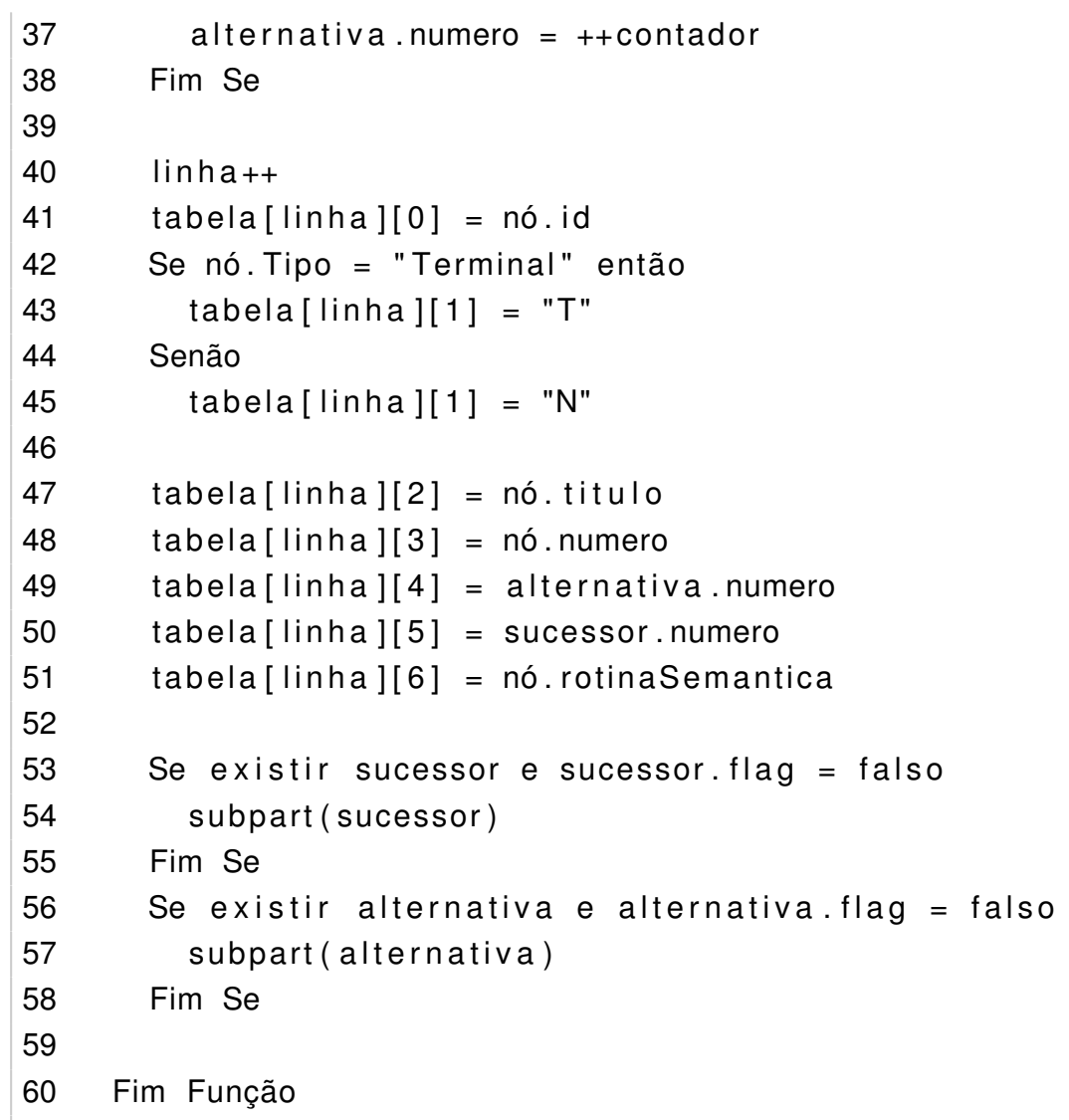

Quadro 6.1: Algoritmo para tabela intermediária

Exemplo: na figura 6.7 está apresentado um exemplo de uma gramática gráfica e sua tabela intermediaria gerada está apresentada na tabela 6.3. 


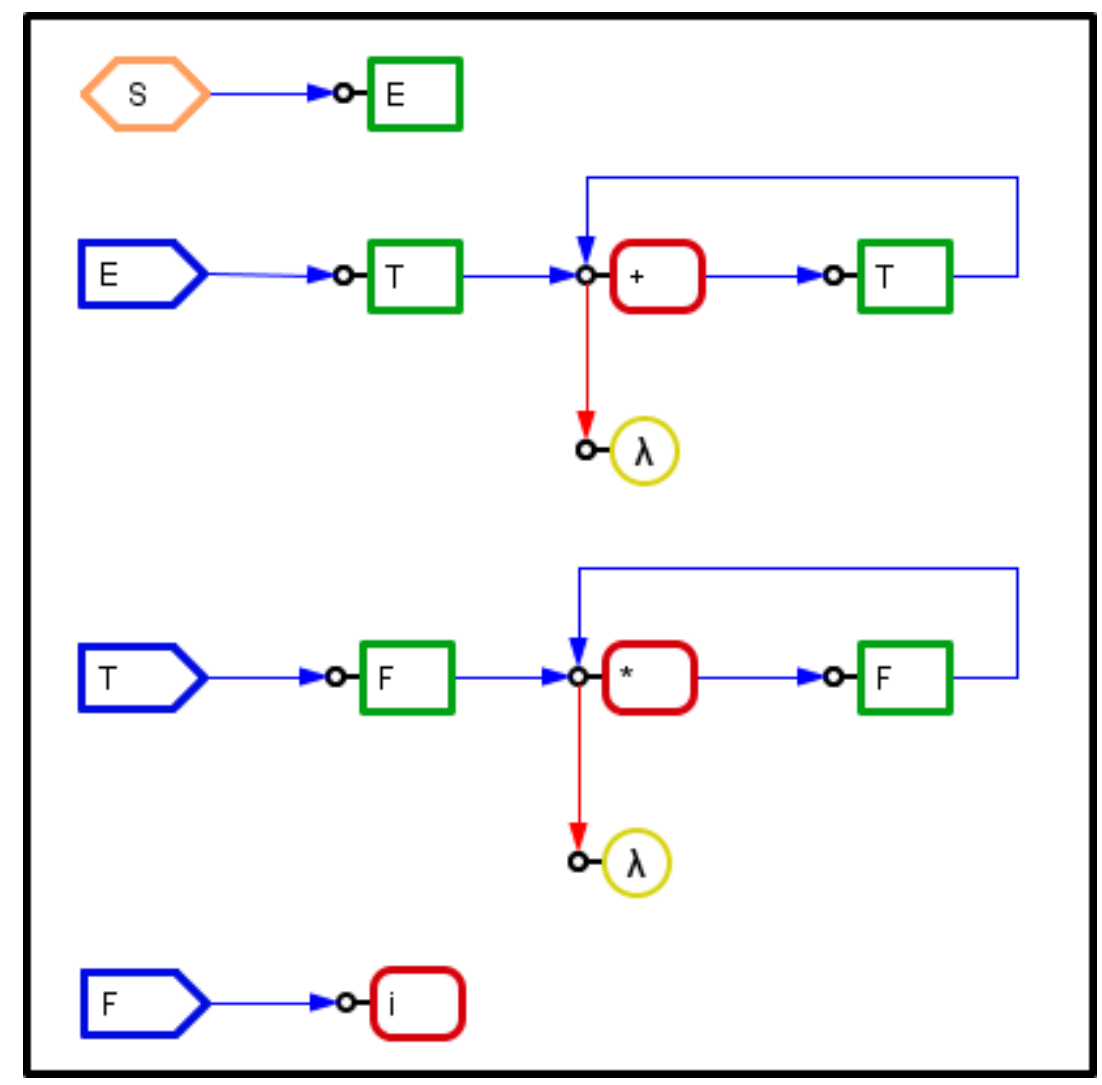

Figura 6.7: Exemplo de geração de tabela intermediária

\begin{tabular}{ccccccc}
\hline Nó & $\begin{array}{c}\text { Típo } \\
\text { de nó }\end{array}$ & $\begin{array}{c}\text { Símbolo } \\
\text { sintático }\end{array}$ & $\begin{array}{c}\text { Índice } \\
\text { relativo }\end{array}$ & $\begin{array}{c}\text { Índice da } \\
\text { alternativa }\end{array}$ & $\begin{array}{c}\text { Índice do } \\
\text { sucessor }\end{array}$ & $\begin{array}{c}\text { Rotina } \\
\text { semântica }\end{array}$ \\
\hline$S$ & $H$ & $S$ & -1 & -1 & 1 & - \\
$E$ & $N$ & $E$ & 1 & -1 & -1 & - \\
$E$ & $H$ & $E$ & -1 & -1 & 1 & - \\
$T$ & $N$ & $T$ & 1 & -1 & 2 & - \\
+ & $T$ & + & 2 & 4 & 3 & - \\
$T$ & $N$ & $T$ & 3 & -1 & 2 & - \\
$\lambda$ & $T$ & - & 4 & -1 & -1 & - \\
$T$ & $H$ & $T$ & -1 & -1 & 1 & - \\
$F$ & $N$ & $F$ & 1 & -1 & 2 & - \\
$*$ & $T$ & $*$ & 2 & 4 & 3 & - \\
$F$ & $N$ & $F$ & 3 & -1 & 2 & - \\
$\lambda$ & $T$ & - & 4 & -1 & -1 & - \\
$F$ & $H$ & $F$ & -1 & -1 & 1 & - \\
$i$ & $T$ & $i$ & 1 & -1 & -1 & - \\
\hline
\end{tabular}

Tabela 6.3: Exemplo de tabela intermediária

Esse algoritmo é de complexidade linear, isto é, $O(n)$, no tamanho da gramática, pois passa por cada nó apenas uma vez.

O segundo algoritmo percorre a tabela intermediaria e gera três tabelas: nodes, nTerminal e Terminal [SDM83].

A tabela nodes é gerada a partir da tabela intermediária, com a transformação dos índices relativos em índices absolutos, isto é, com uma numeração sucessiva para todos os nós do grafo, 
independente dos lados esquerdos. Cada linha da tabela intermediária gera uma linha na tabela nodes.

As tabelas nTerminal e Terminal, (tabela 6.5 e tabela 6.6), possuem uma entrada s para cada símbolo não terminal e terminal, respectivamente. A entrada s possui o símbolo sintático. Além disso na tabela nTerminal s possui o índice absoluto do primeiro nó do lado direito de sua produção; esse índice é referente à tabela nodes e indica o índice absoluto daquele primeiro nó.

Exemplo: para a gramática da figura 6.7, tem-se as tabelas 6.4, 6.5, 6.6 geradas pelo sistema.

\begin{tabular}{ccccc}
\hline Índice & Índice Referência & Índice Sucessor & Índice Alternativa & Tipo de Nó \\
\hline 1 & 2 & 0 & 0 & $N T$ \\
2 & 3 & 3 & 0 & $N T$ \\
3 & 1 & 4 & 5 & $T$ \\
4 & 3 & 3 & 0 & $N T$ \\
5 & 0 & 0 & 0 & $T$ \\
6 & 4 & 7 & 0 & $N T$ \\
7 & 2 & 8 & 9 & $T$ \\
8 & 4 & 7 & 0 & $N T$ \\
9 & 0 & 0 & 0 & $T$ \\
10 & 3 & 0 & 0 & $T$ \\
\hline
\end{tabular}

Tabela 6.4: Exemplo tabela nodes

A coluna Índice contém o índice absoluto do nó. A coluna Índice Referência contém os índices das tabelas nTerminal e Terminal, apontando assim para o conteúdo de cada nó. As colunas Índice Sucessor e Índice Alternativa contêm os índices absolutos do nó sucessor e do nó alternativa. Um índice com valor 0 indica que não há sucessor ou alternativa.

\begin{tabular}{ccc}
\hline Índice & Símbolo Sintático & Primeiro Índice \\
\hline 1 & $S$ & 1 \\
2 & $E$ & 2 \\
3 & $T$ & 6 \\
4 & $F$ & 10 \\
\hline
\end{tabular}

Tabela 6.5: Exemplo tabela $n$ Terminal

\begin{tabular}{cc}
\hline Índice & Símbolo Sintático \\
\hline 1 & + \\
2 & $*$ \\
3 & $i$ \\
\hline
\end{tabular}

Tabela 6.6: Exemplo tabela Terminal

\subsubsection{Pilhas}

O algoritmo de análise sintática utiliza três pilhas: NTerminalStack, ParseStack e GGLLStack. 
A pilha GGLLStack implementa a pilha do analisador (ver 6.1). Cada uma de suas células contém dois campos: o primeiro armazena o índice de um nó não terminal $N$ do grafo sintático. O segundo armazena um ponteiro para a pilha sintática, indicando a localização do primeiro símbolo que será reconhecido por $N$, isto é, um ponteiro para o topo atual da pilha sintática mais uma célula dela. Com este último campo é possível desempilhar a pilha sintática com todos os símbolos reconhecidos como $N$. Ao encontrar um nó não terminal durante o percurso do grafo o índice para esse nó e o índice para o topo mais um da pilha sintática são armazenados no topo de GGLLStack.

A pilha ParseStack implementa a pilha sintática (ver 6.1) e contém dois campos em cada célula. O primeiro contém o objeto correspondente a um símbolo terminal ou não terminal, e o segundo contém o valor semântico desse símbolo, essencial para a compilação ou interpretação. Essa pilha é utilizada para construir os lados direitos das produções com os respectivos elementos sintáticos reconhecidos pelo analisador sintático. Com isso pode-se acompanhar a análise passo a passo. Ela serve também para se testar a gramática vendo-se nos elementos do topo todos os tokens sendo lidos e todas as reduções resultantes de cada produção aplicada.

A pilha NTerminalStack é uma pilha auxiliar que permite a análise de uma gramática com não terminais com alternativas. Para isso são nela armazenados os índices dos nós não terminais encontrados em uma cadeia de alternativas. Sempre que um nó terminal é reconhecido, essa pilha é esvaziada pois não se trata mais do caso de se estar percorrendo uma cadeia de alternativas com não terminais com alternativas já encontrados.

\subsubsection{Análise sintática}

Esse algoritmo utiliza as três tabelas e as três pilhas supracitadas. Ele é responsável por realizar a análise sintática, além de executar as rotinas semânticas.

O quadro 6.2 apresenta o algorítmo em pseudocódigo.

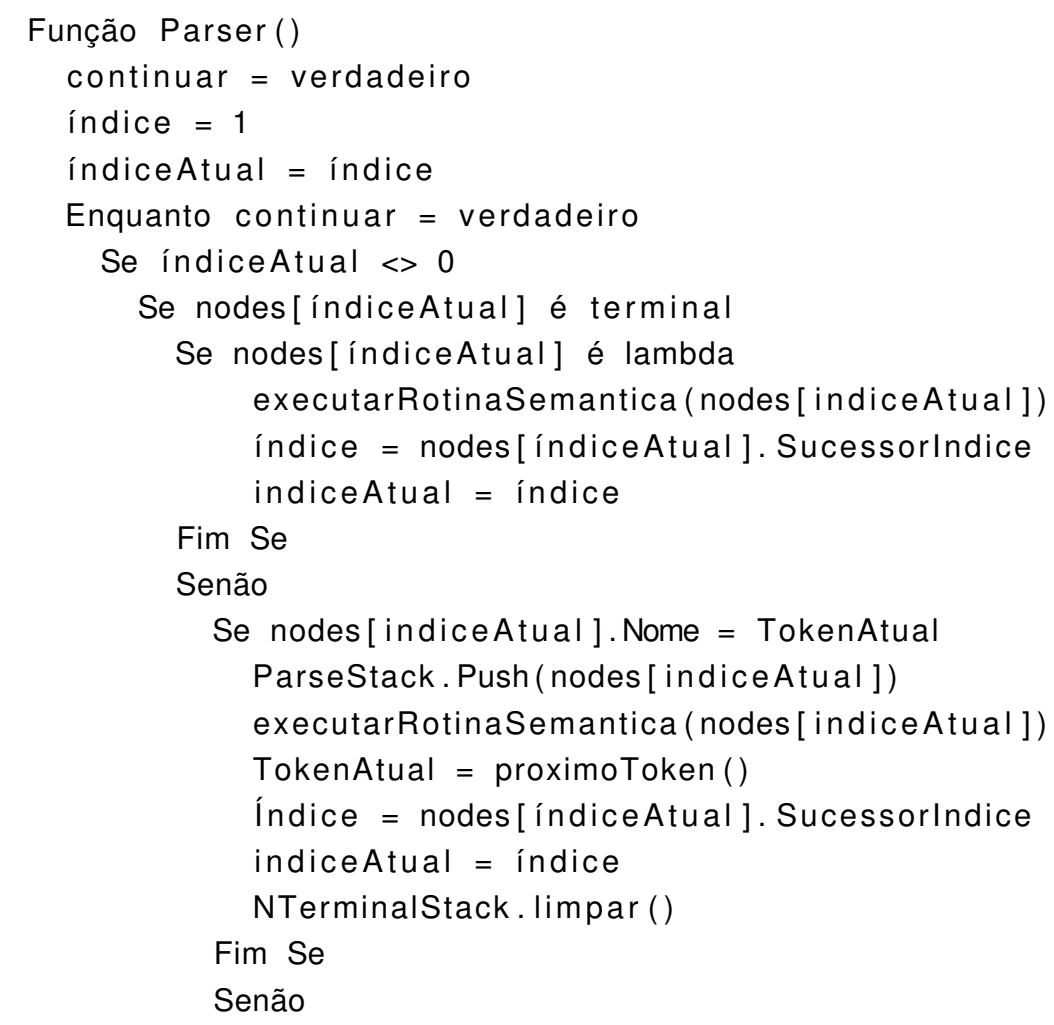


Se nodes[indiceAtual]. Alternativalndice $<0$

indiceAtual $=$ nodes $[$ indiceAtual $]$. Alternativalndice

Fim Se

Senão

Se NTerminalStack não está vazia

alternativalndice = encontrarAlternativa()

Se alternativalndice $<>0$

indiceAtual = alternativalndice

Fim Se

Senão

RecuperaçãoErro (índice )

Fim Senão

Senão

RecuperaçãoErro (índice )

Fim Senão

Fim Senão

Fim Senão

Fim Senão

Fim Se

Senão

NTerminalStack. Push (nodes [indiceAtual])

GGLLStack.Push (indiceAtual, ParseStack. Tamanho)

indiceAtual $=$ nodes $[$ indiceAtual $]$. Primeirolndice

Fim Senão

Fim Se

Senão

Se GGLLStack não está vazia

estadoAntigo = GGLLStack.Pop $($ )

elementoSintatico $=$ NULO

Enquanto estadoAntigo. Tamanho > ParseStack. Tamanho elementoSintatico $=$ ParseStack.Pop ()

Fim Enquanto

Se elementoSintatico <> NULO

ParseStack. Push (nodes [ estadoAntigo. Indice ])

Fim Se

executarRotinaSemantica (nodes [ estadoAntigo . Indice ])

Índice = nodes [estadoAntigo. Indice]. Sucessorlndice

indiceAtual = índice

Fim Se

Senão

Se TokenAtual é Fim de Arquivo

Continuar $=\mathrm{falso}$

Fim Se

Senão

RecuperaçãoErro (índice)

Fim Senão

Fim Senão

Fim Senão

Fim Enquanto

Fim Função

Quadro 6.2: Algoritmo para tabela GGLL

Na linha 2 do algoritmo acima, é declarada a variável continuar; por meio dela, verifica-se se 
o loop da linha 5 à 72 será executado.

O algoritmo também declara duas variáveis para os índices de nós do grafo sintático. A variável indiceAtual aponta para o índice do próximo nó a ser visitado do grafo sintático, e a variável índice aponta para o índice do último nó reconhecido pelo analisador.

Da linha 5 à 71 é executado o loop principal do analisador sintático. Na linha 6 é verificado se o indiceAtual é igual a 0 . Nesse caso, ele indica que o algoritmo chegou no fim de uma produção, caso contrário é verificado na linha 7 se o nó relativo ao indiceAtual, denominado nó atual, é um terminal. Na linha 8 é verificado se o nó atual contém $\lambda$ (cadeia vazia). Nesse, caso é executada a rotina semântica desse nó, e os índices com o valor do índice do sucessor do nó atual são atualizados. No fim é executado novamente o loop da linha 5 à 71 .

Na linha 14 é verificado se o nó atual é igual ao token que está sendo analisado da cadeia de entrada. Nesse caso, o nó atual é empilhado na pilha ParseStack, e a rotina semântica desse nó é executada. Além disso, o analisador léxico é chamado; ele retornará o próximo token a ser analisado. As variáveis índice e indiceAtual são atualizados, e o loop da linha 5 à 71 é novamente executado para que o próximo token da cadeia de entrada seja analisado.

Caso o nó atual não contenha $\lambda$ e seu conteúdo não for igual ao token que está sendo analisado, é verificado na linha 23 se o nó atual tem uma alternativa. Nesse caso, o indiceAtual recebe o valor do índice dessa alternativa e volta a executar o loop da linha 5 à 71 para que seja verificado se o token é igual a essa alternativa. Se o nó atual não possuir uma alternativa, é verificado se a pilha NTerminalStack é diferente de vazia. Isso significa que o nó atual está dentro de um não terminal. Nesse caso, é então executado um algoritmo que busca uma alternativa ao não terminal; caso exista uma alternativa, seu índice é atribuído ao indiceAtual e é executado novamente o loop da linha 5 à 71 ; do contrário, é executado o algoritmo de recuperação de erros.

A linha 42 é executada caso o nó atual seja um nó não terminal. Nesse caso o nó atual é empilhado na pilha NTerminalStack, também é empilhada em GGLLStack o índice atual e o tamanho da pilha ParseStack. Ainda é atribuído ao indiceAtual o índice do primeiro nó da produção desse não terminal. Por fim, é executado novamente o loop da linha 5 à 71.

A linha 48 é executada quando se chega no fim de um lado direito de um não terminal. $\mathrm{Na}$ linha 49 é verificada se a pilha GGLLStack não é vazia. Nesse caso, é desempilhado o topo da pilha GGLLStack. O primeiro campo do elemento desempilhado é usado para se saber em que nó do grafo estava o não terminal que acabou de ser reconhecido para poder continuar a análise com o seu nó sucessor. O segundo campo indica até que ponto a pilha ParseStack deve ser desempilhada. Note-se que com isso os lados direitos das produções podem conter expressões regulares com tamanho variável. Por fim, é empilhado o não terminal na pilha ParseStack e executada a rotina semântica referente a esse não terminal.

A linha 62 é executada caso a pilha GGLLStack seja vazia, o que indica que foi reconhecido o símbolo inicial da gramática procurado no começo da análise, isto é, o fim da análise sintática. Se o token atual é final de cadeia, então a análise sintática foi realizada com sucesso, caso contrário, é chamada a rotina de recuperação de erros. 


\subsection{Estratégias de Emissão de Mensagem e Continuação da Análise ou Recuperação de erros}

O sistema GGLL apresentado anteriormente foi elaborado com a intenção de tornar mais fácil e prática a construção de compiladores e interpretadores e portanto o desenvolvimento de novas linguagens de programação. Além da interface gráfica já citada, foram também desenvolvidas estratégias que permitem a emissão automática de mensagens de erros e a continuação automática da análise (recuperação de erros). Por "automática" entenda-se o fato de não ser necessário programar absolutamente nada para se obter esses resultados; para isso, o algoritmo usa a própria gramática.

Estratégias de continuação são algoritmos executados caso ocorra um erro na cadeia de entrada. Esses algoritmos simulam uma correção da cadeia de entrada para que seja possível executar a análise até o fim da cadeia. Caso ocorra um erro na análise sintática, as rotinas semânticas não serão mais executadas, pois poderiam acarretar erros inesperados que não ocorreriam se a cadeia de entrada estivesse correta.

As estratégias de continuação implementadas são as descritas em [SDM83] não realizam as correções da cadeia de entrada. Elas são apenas mecanismos para que se possa realizar a análise da cadeia até o fim e assim apresentar todos os erros encontrados. Por esse motivo, caso ocorra um erro e esse seja "recuperado", o resultado da análise do GGLL será erro e não sucesso.

Embora algumas estratégias sejam bastante simples, conforme os testes realizados elas se comportam muito bem em diversos cenários e na maioria dos casos conseguem realizar a continuação da análise de maneira satisfatória.

Para a descrição do funcionamento da rotina de emissão de mensagens de erro bem como das estratégias de continuação suponha-se que a análise chegou ao nó $n_{1}$, e que a cadeia de alternativas (ver item 2.11.5) começando em $n_{1}$ contenha os nós terminais $t_{1}, t_{2}, \ldots, t_{n}$; se $n_{1}$ é um nó terminal essa cadeia de alternativas é que começa no sucessor do nó inicial (lado esquerdo) de $n_{1}$. Suponha-se ainda que o próximo token da cadeia de entrada seja $e_{1}$ e o seguinte seja $e_{2}$.

As estratégias de recuperação de erro presentes no GGLL são as seguintes.

\subsubsection{Emissão automática de mensagem de erro}

Para emitir essa mensagem, é executado o mesmo algoritmo usado para percorrer uma cadeia de alternativas. Começando no nó $n_{1}$, essa cadeia é percorrida montando-se uma mensagem de erros dizendo que $e_{1}$ foi encontrado na cadeia de entrada mas $t_{1}, t_{2}, \ldots, t_{n}$ eram esperados.

Em seguida as estratégias de "recuperação" são executadas, na ordem em que são aqui apresentadas; essa ordem procura evitar ao máximo a perda dos símbolos da cadeia de entrada.

\subsubsection{Inserção de token}

$\mathrm{Na}$ execução dessa estratégia, procura-se $e_{1}$ na cadeia de alternativas do sucessor de $t_{1}$, depois na cadeia de alternativas do sucessor de $t_{2}$, etc., até a cadeia de alternativas do sucessor 
de $t_{n}$. Se $e_{1}$ for encontrado na cadeia de alternativas do sucessor $n$ de $t_{i}$, isto é, o conteúdo de $n$ é igual a $e_{1}$, o algoritmo simula a inserção de $t_{i}$, emitindo uma mensagem de que $t_{i}$ foi inserido, e continua a análise a partir de $n$ procurando $e_{2}$.

Se $e 1$ não é encontrado da maneira descrita o GGLL passa à estratégia seguinte.

Exemplo: na figura 6.8, a cadeia de entrada é "aebf"; o símbolo $c$ é supostamente inserido na cadeia antes do $f$ para que a análise possa continuar (no caso, terminar). Note-se que o GGLL especifica qual a correção que foi feita na cadeia de entrada.

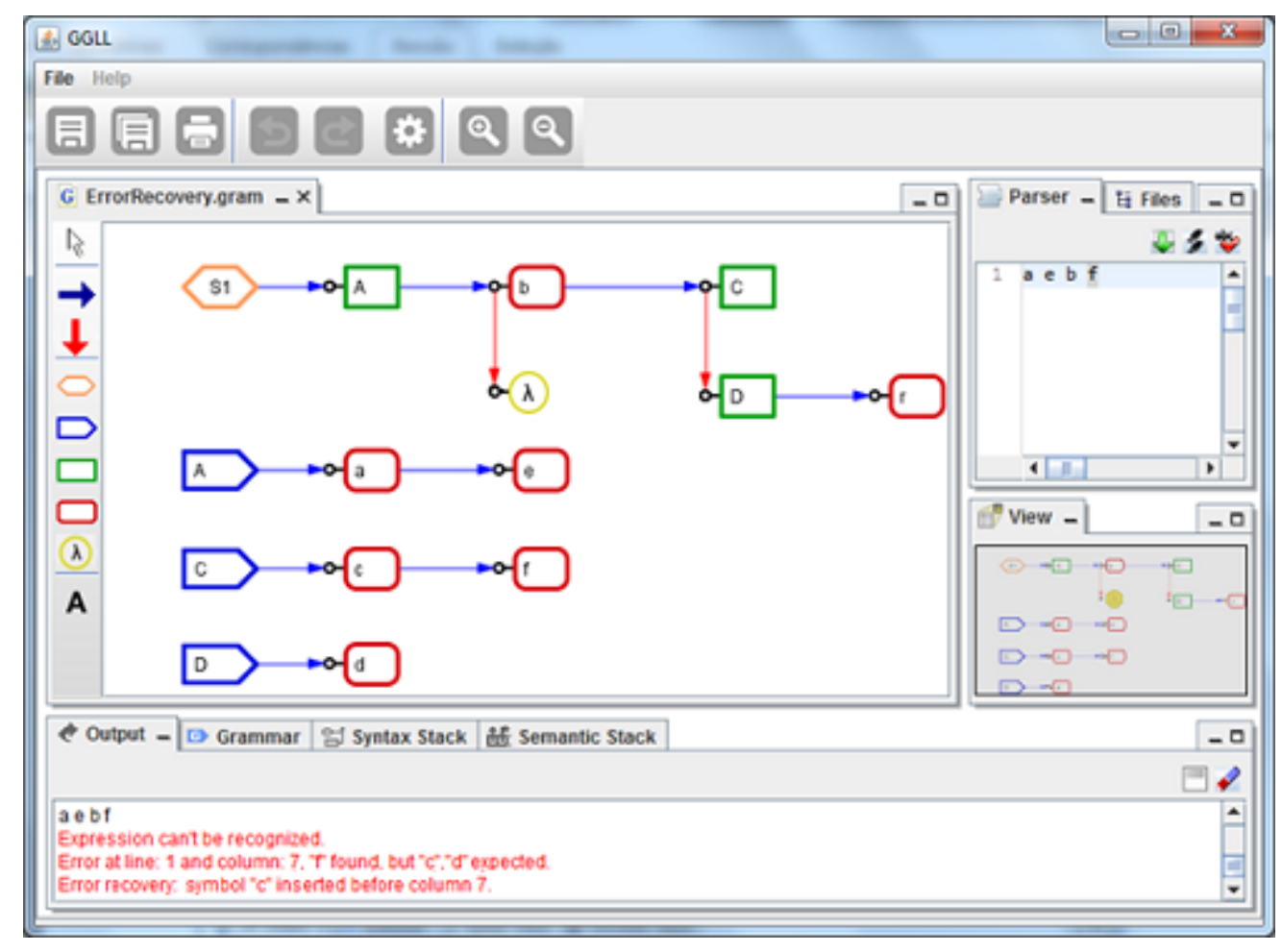

Figura 6.8: Exemplo de recuperação de erro (inserção)

\subsubsection{Troca de token}

Nesta estratégia são verificados, como na anterior, a cadeia de alternativas que começa no sucessor de $t_{1}$, depois na do sucessor de $t_{2}$, etc. Se $e_{2}$ for encontrado em um nó $n$ na cadeia de alternativas começando no sucessor de $t_{i}$, simula-se a troca de $e_{1}$ pelo conteúdo de $t_{i}$ emitindo uma mensagem correspondente, e continua-se a análise a partir de $n$. Se $e_{2}$ não for encontrado como descrito, o GGLL passa à estratégia seguinte.

Exemplo: na figura 6.9, a cadeia de entrada é "aebvf"; o símbolo $v$ é supostamente trocado pelo símbolo $c$ para que a análise possa continuar. Note-se que o GGLL especifica qual a correção que foi feita na cadeia de entrada. 


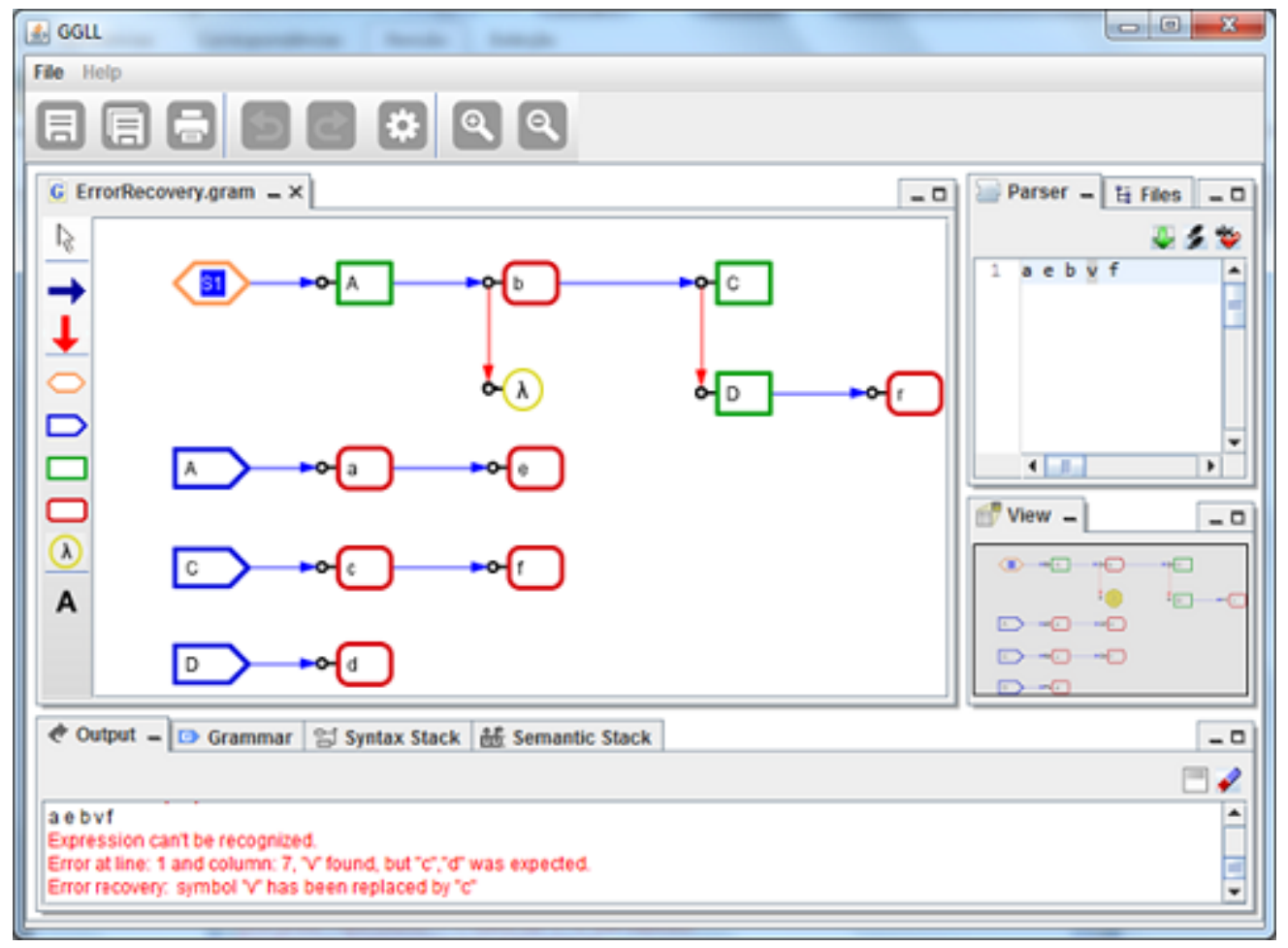

Figura 6.9: Exemplo de recuperação de erro (troca)

\subsubsection{Eliminação de token}

Nesta estratégia, verifica-se que $e_{2}$ é o conteúdo de um nó $t_{i}$ da cadeia de alternativas $t_{1}, t_{2}, \ldots, t_{n}$ sendo percorrida. Nesse caso simula-se a eliminação de $e_{1}$ e emite-se a mensagem correspondente. Se $e_{2}$ não for encontrado da maneira descrita, o GGLL passa à estratégia seguinte.

Exemplo: na figura 6.10, a cadeia de entrada é "aer"; o símbolo $r$ é supostamente eliminado da cadeia para que a análise possa continuar (no caso, terminar). Note-se que o GGLL especifica qual a correção que foi feita na cadeia de entrada. 


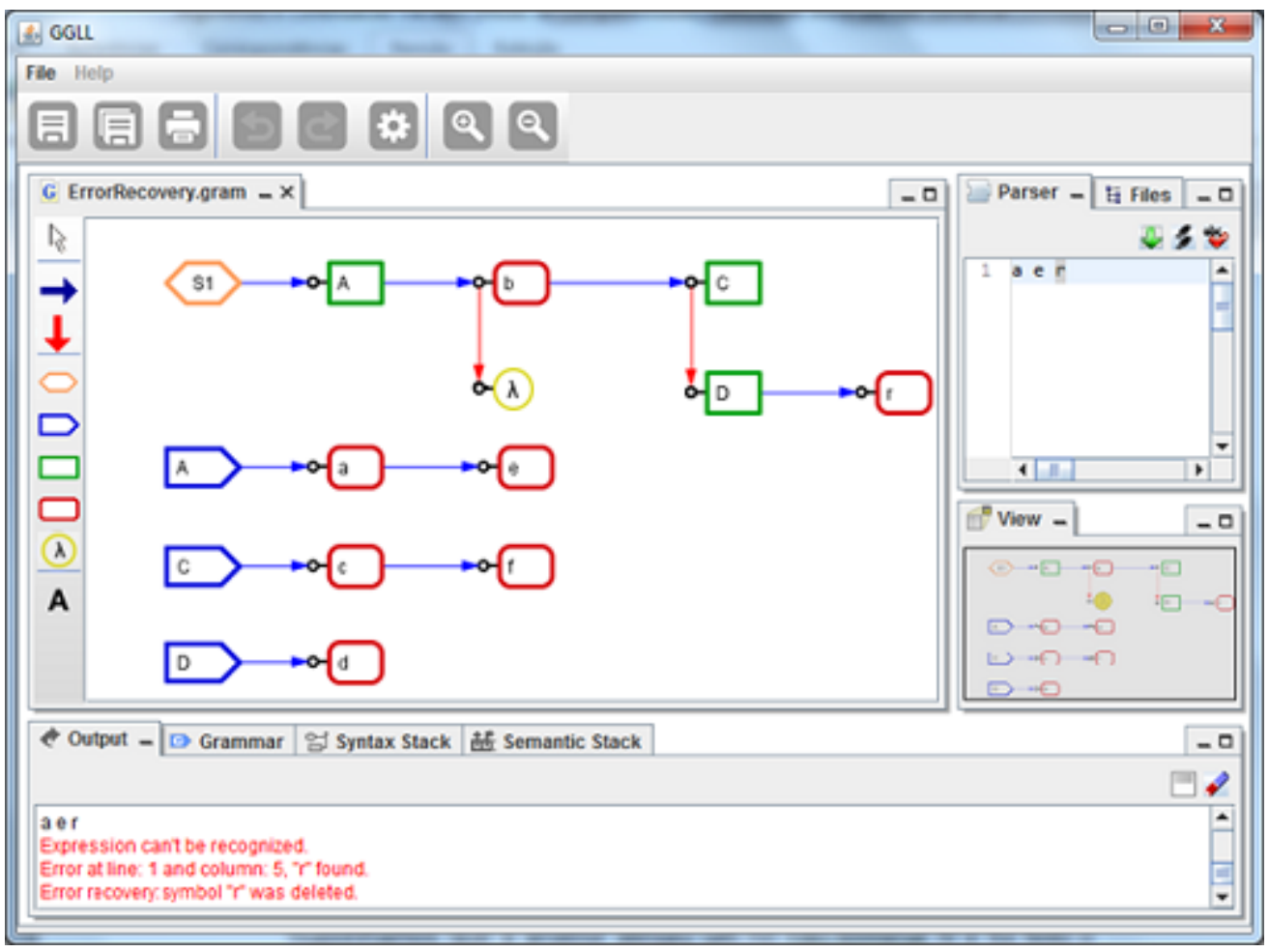

Figura 6.10: Exemplo de recuperação de erro (eliminação)

\subsubsection{Busca de delimitadores}

Supõe-se que a análise atingiu um nó não terminal $N$ e foi feito o desvio para as produções do não terminal. No entanto, houve um erro durante esse trecho do reconhecimento. Nesse caso, tenta-se a estratégia de busca de um delimitador para $N$, into é, $e_{1}$ pertence à cadeia de alternativas que começa no sucessor de $N$. Note-se que o índice de $N$ está empilhado na pilha GGLLStack.

Se $e_{1}$ for encontrado no nó $t$ da cadeia que começa no sucessor do nó $N$, então simula-se que o não terminal $N$ foi reconhecido, desempilha-se o índice do nó $N$ da pilha GGLLStack, emite-se a mensagem de recuperação correspondente, e continua-se a análise a partir do nó $n$.

Se $e_{1}$ não for encontrado na cadeia de alternativas do sucessor de $N$, desempilha-se o índice de $N$ da pilha GGLLStack. Se o topo dessa pilha contém agora o índice de um nó não terminal $N_{1}$, procura-se $e_{1}$ na cadeia de alternativas começando no sucessor de $N_{1}$, e assim por diante até que a pilha GGLLStack fique vazia. Nesse caso elimina-se $e_{1}$ e passa-se a aplicar todas as estratégias, na ordem vista, para $e_{2}$.

Exemplo: na figura 6.11, a cadeia de entrada é "aqqqbcf"; os símbolos $q q q$ são supostamente eliminados da cadeia e o símbolo $b$ é assumido como delimitador para que a análise possa continuar. Note-se que o GGLL especifica qual "correção" foi feita na cadeia de entrada. 


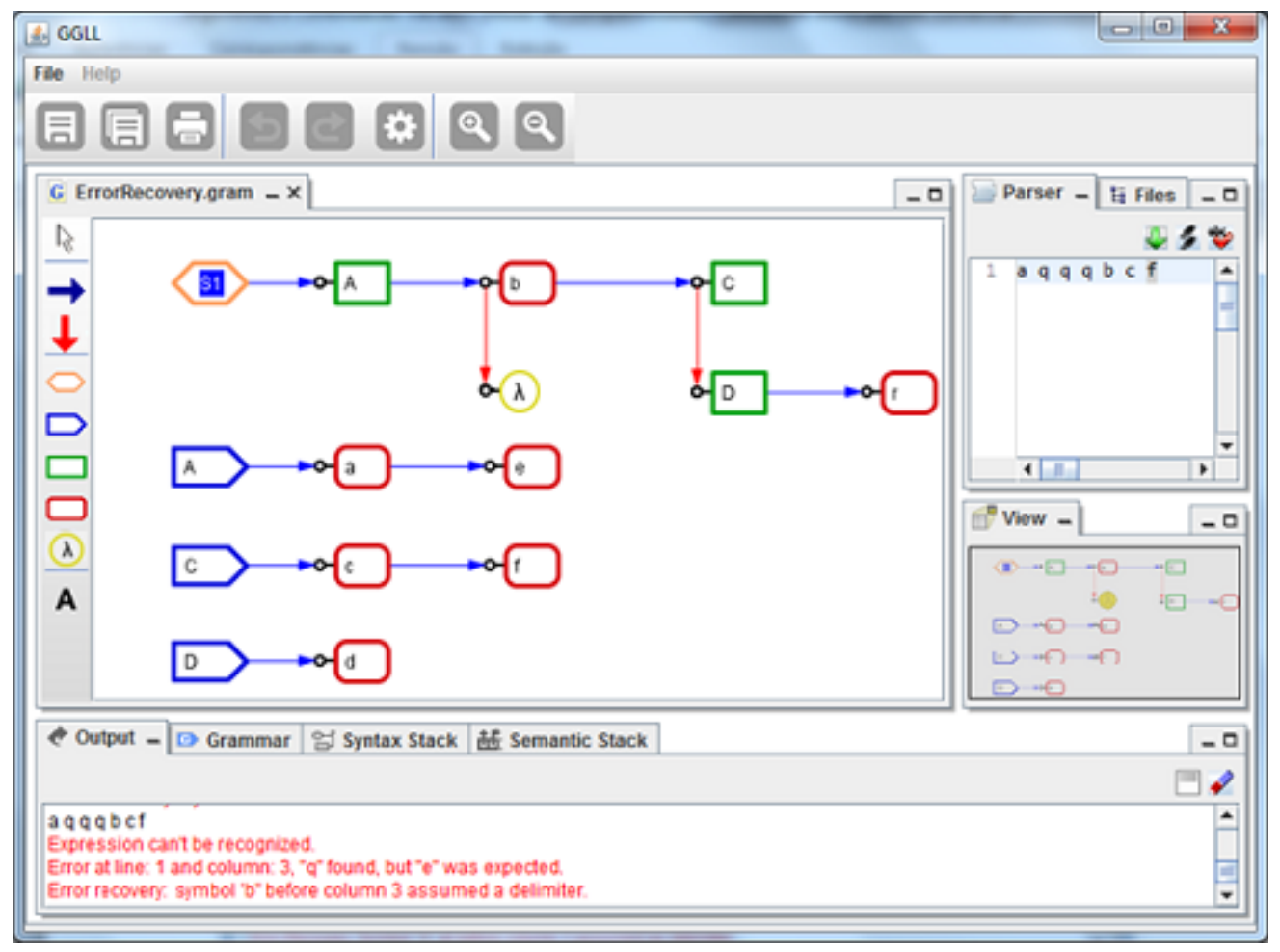

Figura 6.11: Exemplo de recuperação de erro (busca de delimitadores)

As estratégias de inserção e eliminação foram citadas pela primeira vez por Wirth [Wir66]. A busca de delimitadores foi desenvolvida por Valdemar Setzer [SDM83]. Ela pode ser executada, pois o algoritmo do GGLL tem acesso à pilha do analisador, o que não acontece nos métodos recursivos descendentes, em que a pilha do analisador é a de retorno dos procedimentos, inacessível ao programador.

Ao ocorrer um erro será apresentada uma exceção do tipo SyntacticException contendo uma mensagem informando o token, a linha e coluna onde foi encontrado o erro. Ao se executar uma estratégia de continuação com sucesso, é apresentada uma exceção do tipo ErrorRecoveryException informando a estratégia utilizada e o que foi realizado. Todas as exceções são armazenadas em uma lista presente na classe Parser, que é a classe onde se encontra o método de análise sintática.

\subsection{GGLL.UI}

Esse módulo é responsável pela criação e geração do arquivo GGLL, que conterá as informações da gramática. Ainda é nesse módulo que o programador define o arquivo com o analisador léxico e as rotinas semânticas.

\subsubsection{Arquitetura}

Na figura 6.12 estão apresentado os diagramas presentes no GGLL.UI. 

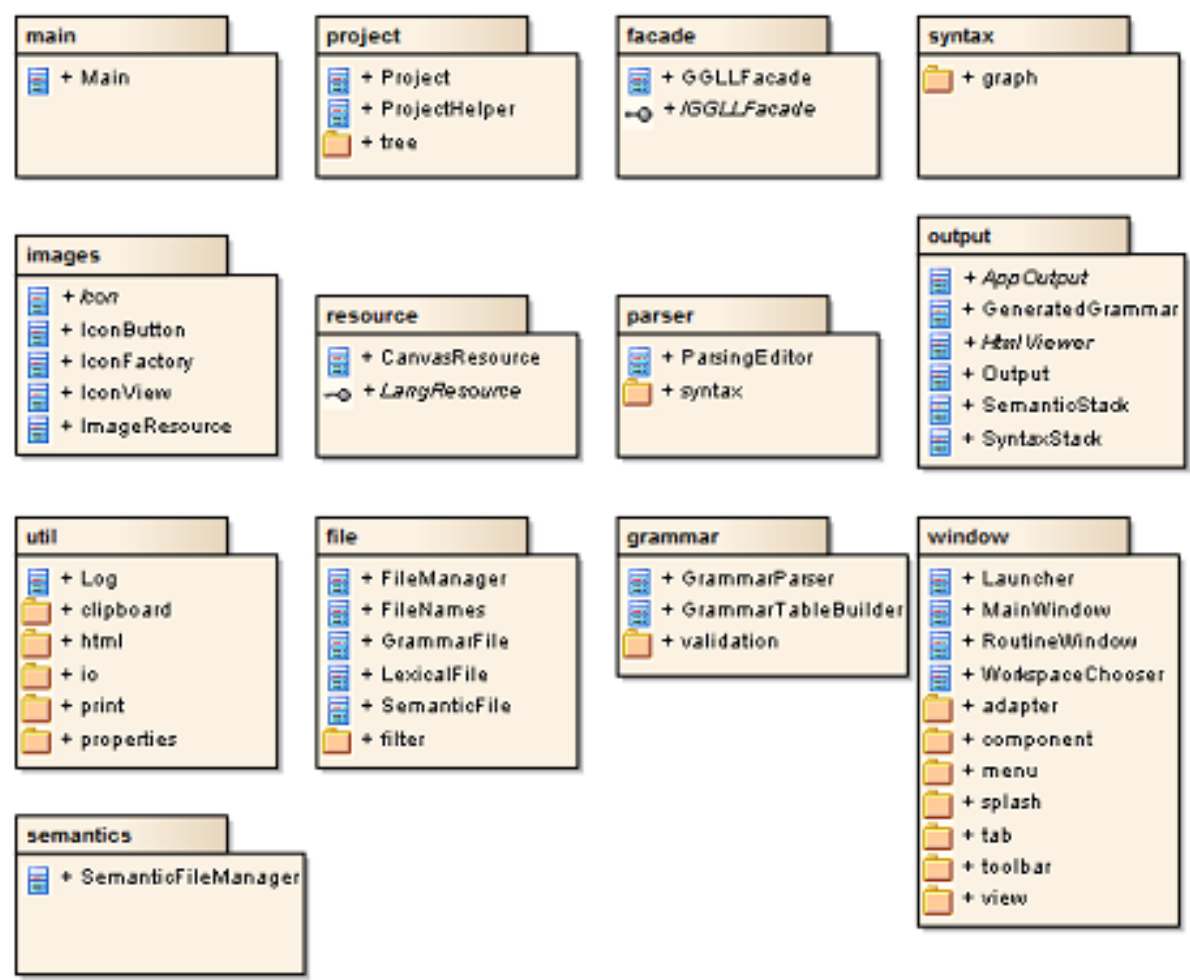

Figura 6.12: Pacotes do GGLL.UI

\section{Pacotes main, project e facade}

Esses são os pacotes responsáveis por gerenciar todo o sistema GGLL.UI. O pacote main contém o método principal que será executado ao se iniciar o programa. Esse método é responsável por chamar outros métodos, como o de criar a janela principal do sistema.

O pacote project é responsável por gerenciar todos os arquivos do projeto, como arquivos com a especificação da gramática, arquivos com as especificações léxicas e arquivos com as rotinas semânticas.

O pacote facade é responsável pela classe onde ocorre a maioria das interações do projeto. Para seu desenvolvimento foi utilizado o design pattern Facade ${ }^{1}$. De acordo com Gamma e Helm [GJHV06], esse design pattern visa definir um objeto que oculta a complexidade de uma ou mais classes, além de promover um acoplamento fraco. Foi utilizado o design patter Singleton $^{2}$ em conjunto com o Facade.

\section{Pacote syntax}

O pacote syntax é responsável por manipular os elementos gráficos da geração da gramática gráfica. Dentro desse pacote foi utilizado o design pattern Factory Method ${ }^{3}$, utilizado na criação de conectores na representação gráfica. A classe ConnectorFactory foi implementada para que sejam criados conectores do tipo alternativa ou sucessor.

\footnotetext{
${ }^{1}$ Para mais informações, vide Facade no apêndice $B$.

${ }^{2}$ Para mais informações, vide Singleton no apêndice B.

${ }^{3}$ Para mais informações, vide Factory no apêndice $B$.
} 


\section{Pacote images e resource}

Esses pacotes são responsáveis por gerenciar os ícones, as imagens e os recursos textuais do sistema, facilitando assim a alteração e a globalização do software, ou seja, é possível fazer tradução para diversas línguas.

\section{Pacotes output, util e file}

O pacote output é responsável por gerenciar toda a saída do sistema, por exemplo, a formatação de textos.

O pacote util contém vários métodos que facilitam o desenvolvimento do sistema, por exemplo, a classe Log que grava informações sobre a execução do sistema para futura análise.

O pacote file contém classes para cada tipo de arquivo que pode ser gerado pelo sistema, por exemplo, arquivos de gramática gráfica ou arquivos semânticos.

\section{Pacote grammar}

O pacote grammar é responsável por realizar a tradução da gramática gráfica no arquivo contendo as tabelas do GGLL (arquivo em código XML), que será utilizado pelo GGLL.Core; além disso, nesse pacote é realizada a validação da gramática que será detalhada no item 6.7.5.

\section{Pacotes view e window}

Os pacotes view e window são responsáveis pela criação e manipulação das janelas e abas utilizadas no sistema.

\section{Pacote semantics}

Esse pacote é responsável por manipular o arquivo com as rotinas semânticas. É nele que é criado, pelo usuário, o arquivo em código Java contendo as rotinas semânticas que serão executadas.

\subsubsection{Entrada de dados}

O GGLL.UI utiliza uma entrada de dados baseada em uma interface gráfica com o usuário. Isso facilita a utilização do sistema para usuários que não estão familiarizados com gramáticas em forma de texto, além de facilitar o projeto e compreensão da gramática, agilizando, assim, a fase de geração de um analisador sintático.

A interface com o usuário utiliza janelas e abas para facilitar a utilização do sistema, além de conceitos como drag-and-drop, em que o usuário seleciona e arrasta os elementos gráficos da gramática a fim de dispor os elementos gráficos. Para mais informações sobre a utilização da interface gráfica, vide o apêndice $C$, que contém o manual completo de utilização do sistema GGLL. 


\subsubsection{Saída de dados}

O GGLL.UI possui como saída de dados três arquivos. O primeiro deles é um arquivo no formato $\mathrm{XML}\left[\mathrm{BPSM}^{+}\right.$08], no qual são encontradas as três tabelas do algoritmo GGLL: tabela de nós do grafo sintático, tabela de símbolos terminais e tabela de símbolos não terminais (ver item 6.5). O segundo arquivo contém o analisador léxico que é gerado pelo JFLex [Kle09] e o terceiro arquivo é um arquivo onde são encontradas as rotinas semânticas que são criadas e executadas pelo sistema.

\subsubsection{APIs utilizadas}

Para auxiliar seu desenvolvimento do GGLL.UI foram utilizadas as seguintes APIs:

- NetBeans Visual Library [Ora13]: auxilia na implementação dos gráficos utilizados para geração da gramática.

- InfoNode [Inf09]: auxilia na implementação de janelas e abas.

- HtmIParser [Osw06]: utilizada para formatação da saída do sistema com o auxílio da linguagem HTML.

- JFlex [Kle09]: utilizada para gerar o analisador léxico com o auxílio da notação Lex (LESK e SCHMIDT, 1975).

\subsubsection{Validação da Gramática Gráfica}

O GGLL.UI possui uma validação da gramática gráfica desenhada que é executada antes da tradução dessa gramática para o arquivo GGLL, verificando se ela é LL(1) (ver item 4.3). Caso ocorra algum erro na validação, é apresentado um erro ao usuário apontando os nós onde estão os erros encontrados, e a operação de tradução da gramática é abortada. Seguem as regras de validação:

- Validação do nó inicial: a gramática gerada deve conter apenas um nó inicial.

- Validação do lado esquerdo de cada produção: deve conter sempre um nó sucessor.

- Validação dos não terminais: todo não terminal deve ter pelo menos uma produção vinculada a ele, onde ele aparece do lado esquerdo.

- Validação de cadeias de alternativas: em uma cadeia de alternativas, não pode haver dois terminais iguais. Para isso foi utilizado o algoritmo $\operatorname{FIRST}_{T}$ (ver o apêndice A), aplicado ao primeiro nó dessa cadeia.

- Recursão à esquerda: por se tratar de um algoritmo para gramáticas LL não pode existir recursão à esquerda (ver 4.3.1). Por esse motivo há uma validação para encontrar essa recursão mesmo que indiretamente (por exemplo: $M \rightarrow N \alpha_{1}, N \rightarrow P \alpha_{2}, P \rightarrow M \alpha_{3}$ ). Para essa validação foi utilizado o algoritmo $F I R S T_{N}$ aplicado no sucessor do símbolo inicial de cada produção.

Uma validação resulta em uma classe única que herda a classe abstrata GrammarValidation. Com isso é possível escrever novas classes de validação para serem inseridas no sistema. 


\subsubsection{Desafios}

O principal desafio do desenvolvimento do GGLL.UI foi a implementação da interface gráfica. A interface foi planejada para facilitar ao máximo a utilização pelo usuário. Foram implementadas funcionalidades para simplificar os processos mais complexos da criação da gramática. Outro desafio foi a estruturação do código-fonte para que este se tornasse de fácil manutenção e entendimento.

\subsection{GGLL.Core}

O GGLL.UI recebe como entrada uma gramática gráfica e gera como saída os três arquivos (ver item 6.8.2) necessários para o GGLL.Core executar o algoritmo GGLL responsável pelas análises léxica, sintática e semântica da gramática de entrada.

\subsubsection{Arquitetura}

A figura 6.13 apresenta o diagrama dos pacotes presentes no GGLL.Core.
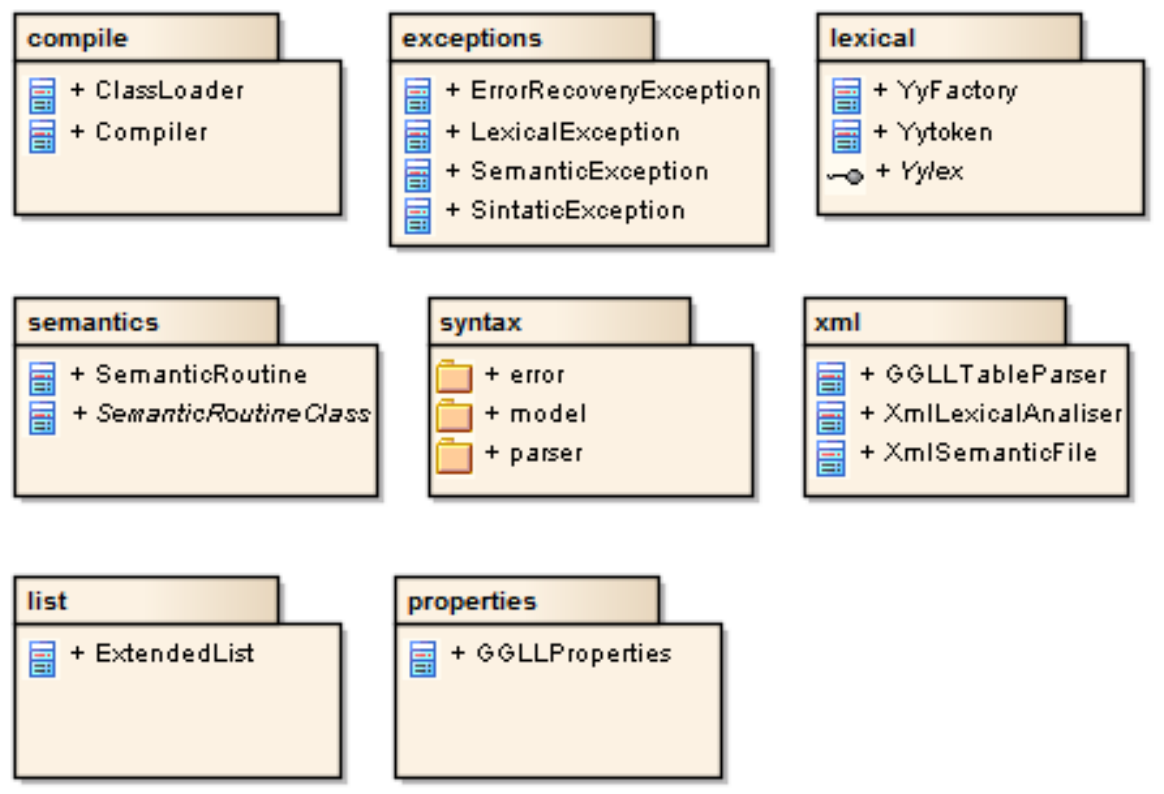

Figura 6.13: Pacotes do GGLL.Core

\section{Pacote compile}

Neste pacote estão presentes classes que executarão a compilação em tempo real do analisador léxico gerado e da classe com as rotinas semânticas. Para realizar essa compilação em tempo real é utilizado o Java JDK [Jav14].

\section{Pacote exceptions}

Neste pacote estão presentes diversas classes de exceções que podem ser geradas pelo GGLL.Core no momento da execução do algoritmo GGLL. São elas: 
- ErrorRecoveryException: exceção gerada ao realizar uma recuperação automática de erros durante uma análise sintática.

- LexicalException: exceção gerada quando ocorre um erro léxico.

- SemanticException: exceção gerada quando ocorre um erro em uma rotina semântica. Essa exceção não é gerada automaticamente, mas pode ser utilizada pelo programador para identificar um erro semântico.

- SyntacticException: exceção gerada quando ocorre um erro sintático, geralmente essa exceção vem seguida de exceções do tipo ErrorRecoveryException.

\section{Pacote lexical}

Neste pacote está presente a classe YyFactory, que é responsável por gerar o analisador léxico. Essa classe chama a API JFLex [Kle14] utilizando como entrada um programa-fonte em linguagem Lex, que contém a especificação léxica, e retorna um programa-fonte com uma classe que implementa a interface Yylex, contendo o analisador léxico. Quando executado o analisador léxico retorna instâncias da classe Yytoken; esses objetos são os tokens reconhecidos pelo analisador.

\section{Pacote semantics}

Nesse pacote estão as classes responsáveis pelas rotinas semânticas. A classe SemanticRoutine é responsável pela chamada das rotinas semânticas. Essas rotinas estão presentes na classe de rotinas semânticas geradas pelo GGLL.UI. A classe de rotinas semânticas herda a classe abstrata SementicRoutineClass e seus métodos são chamados utilizando técnicas de reflection, técnica para examinar e modificar a estrutura e o comportamento de um programa em tempo de execução.

\section{Pacote list}

Neste pacote está presente a classe ExtendedList, que implementa o design pattern List [GJHV06], essa implementação é utilizada para facilitar a manipulação de listas genéricas de objetos.

\section{Pacote properties}

Nesse pacote está presente a classe responsável pelas propriedades do sistema. Entre elas está a propriedade que defini o local onde Java SDK está instalado.

\section{Pacote $X M L$}

Este pacote é responsável por realizar a tradução do arquivo com o código em XML com a gramática gerada usando-se o próprio sistema GGLL (em um processo de boot strapping) em objetos das classes TableGraphNode e TableNode (ver item 6.5.1), que estão presentes no pacote Model descrito adiante. 
Para se realizar a tradução do arquivo XML gerado foi implementada uma gramática que reconhece o arquivo e, com algumas rotinas semânticas programadas em Java, o traduz para o conjunto de objetos supracitados.

Nas figuras 6.14 e 6.15 é apresentada a gramática construída para se realizar a tradução (esse grafo sintático foi impresso a partir do GGLL, onde foi implementado). 


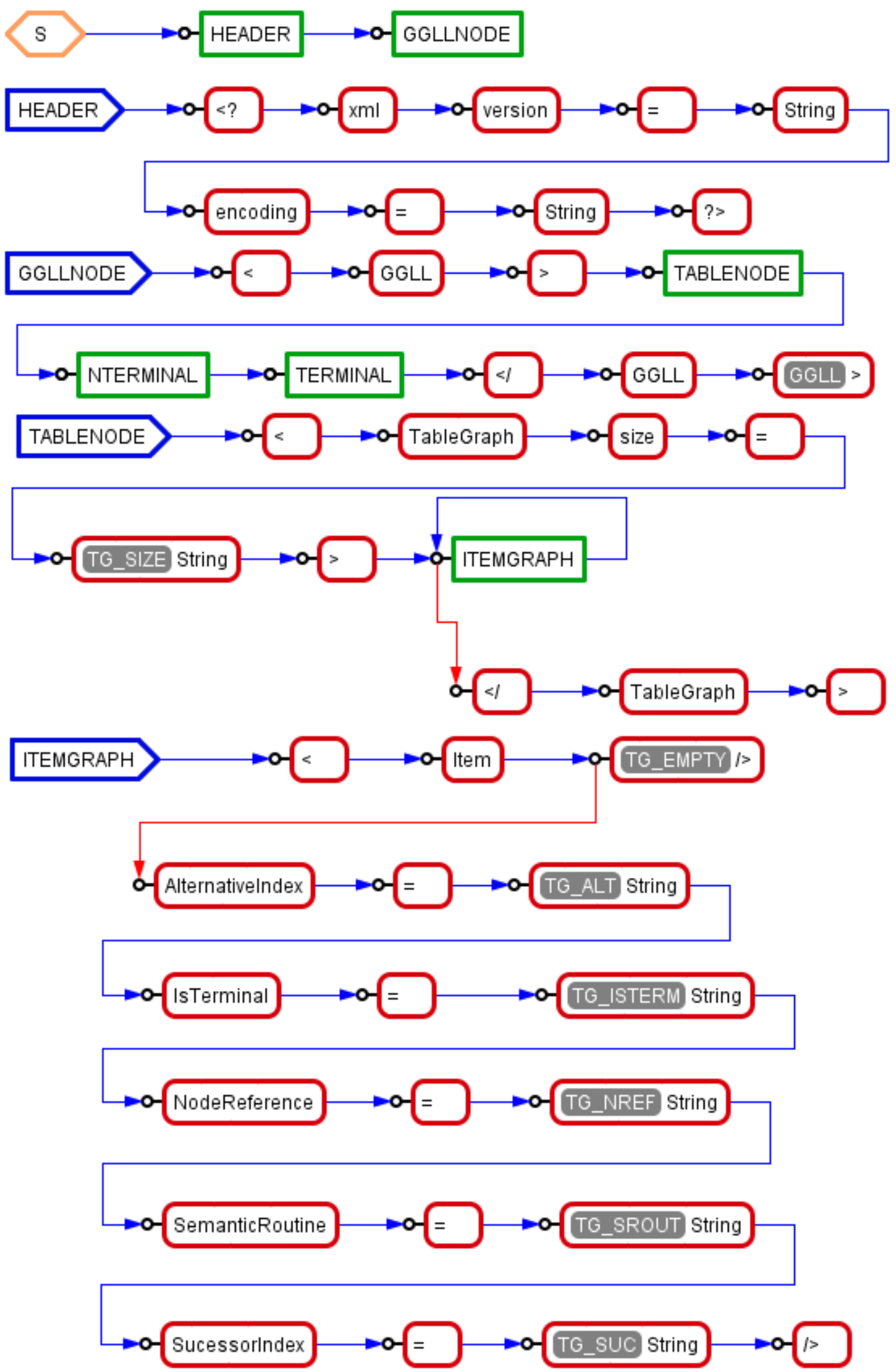

Figura 6.14: Gramática para o analisador do XML de entrada do GGLL.Core - 1 


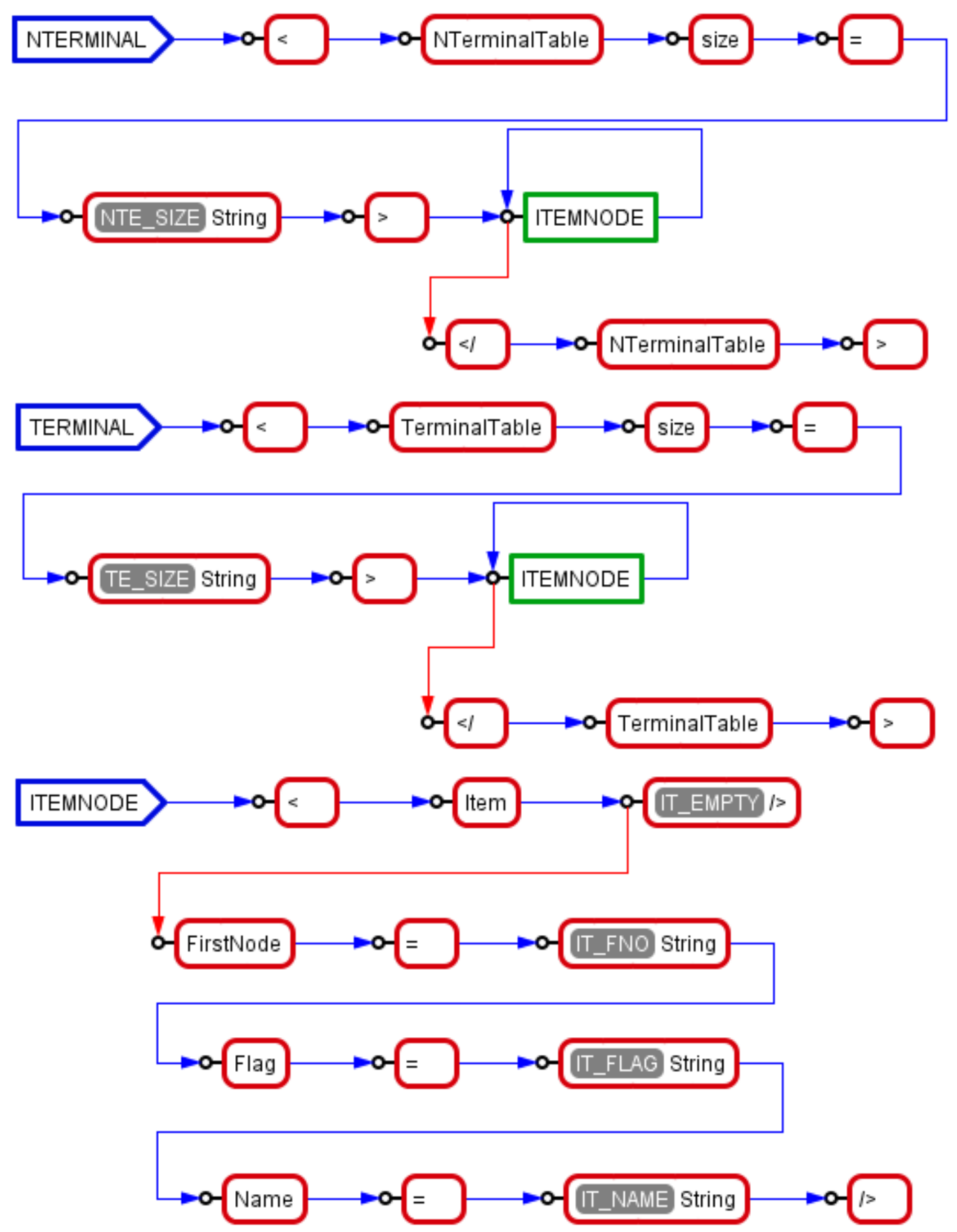

Figura 6.15: Gramática para o analisador do XML de entrada do GGLL.Core - 2

A gramática 6.14 e 6.15 é representada como definido no item 2.11.5. Além disso também foram definidas rotinas semânticas a serem executadas. Essas rotinas são representadas graficamente com um nome em branco em uma caixa de fundo cinza, por exemplo, a rotina semântica IT_NAME — um dos nós terminais String da figura 6.15.

\section{Pacote syntax}

Este pacote é dividido em três outros pacotes: 
- Model: neste pacote estão as classes de objetos utilizadas pelo algoritmo GGLL. As classes TableGraphNode e TableNode (ver item 6.5.1) são utilizadas para representar os objetos criados no gráfico sintático. Também são encontradas classes como ParseStack, NTerminalStack e GGLLStack, que são classes em que serão armazenadas as pilhas utilizadas pelo algoritmo GGLL.

- Error: neste pacote são encontradas as classes para a recuperação automática de erros (ver item 6.6).

- Parser: neste pacote são encontradas as classes responsáveis pela execução do algoritmo GGLL. Dentro da classe Parser está a implementação desse algoritmo, que será detalhado adiante.

\subsubsection{Entrada de dados}

A entrada de dados do GGLL.Core consiste de três arquivos gerados pelo GGLL.UI:

- Arquivo léxico: arquivo em código Java contendo o analisador léxico gerado pelo JLex; esse arquivo possui a extensão ".lex".

- Arquivo semântico: arquivo em código Java, contendo a classe que possui as rotinas semânticas que serão executadas pelo GGLL; esse arquivo possui a extensão “.java”.

- Arquivo sintático: arquivo XML, contendo a especificação sintática da gramática; esse arquivo possui a extensão ".ggll".

Além disso, o GGLL.Core recebe como entrada uma cadeia de caracteres para ser analisada. Para mais informações de como utilizar esses três arquivos em conjunto com o GGLL.Core, vide o apêndice $A$.

\subsubsection{Saída de dados}

O GGLL.Core tem como saída de dados o resultado da execução do algoritmo GGLL. Esse algoritmo retorna o resultado da análise sintática da cadeia de caracteres de entrada. Esse resultado pode ser sucesso ou erro; caso seja erro, podem ser listados os erros da análise e as mensagens de recuperação de erros.

\subsubsection{APIs utilizadas}

O GGLL.Core utiliza o JLex para gerar o analisador léxico.

\subsubsection{Desafios}

Os principais desafios encontrados no desenvolvimento do GGLL.Core foram a organização estrutural do código-fonte, a definição das classes e a implementação dos algoritmos. 
- Estrutura do código-fonte: para esse problema, foi feita uma análise das classes presentes no sistema e foi verificada a melhor estrutura para cada classe. Também foram utilizados conceitos de POO (programação orientada a objeto) para facilitar a manutenção do códigofonte. Dessa maneira, obteve-se um código mais claro e de fácil entendimento.

- Implementação dos algoritmos: o principal desafio na implementação dos algoritmos foi a estrutura de dados, que foi projetada prevendo melhorias e alterações futuras. Também foram inseridos padrões de projetos como citado anteriormente e tratamento de exceções. 


\section{Capítulo 7}

\section{Resultados}

\subsection{Utilização didática}

O sistema GGLL pode ser utilizado para auxiliar o ensino de gramáticas formais e compiladores, uma vez que a interface gráfica facilita o entendimento de como funciona uma gramática livre de contexto, tanto para a geração de uma linguagem como para a análise sintática. Normalmente, o ensino desse tipo de gramática é dado por meio de teorias e exemplos em notação BNF, a qual não é tão simples quanto a representação gráfica. Em termos de análise sintática, a indicação gráfica de qual nó está sendo analisado na análise passo a passo serve para ilustrar o processo de análise.

Outro ponto positivo em relação à utilização didática é a possibilidade de examinar o conteúdo das pilhas sintática e semântica durante a análise e a geração de código, mostrando quando as rotinas semânticas são executadas.

\subsection{Testes com usuários}

Devido à falta de tempo, não foi possível testar o uso do GGLL com muitas pessoas, a fim de avaliar a dificuldade em aprender a usar o sistema. Foram feitos três testes com pessoas de níveis diferentes de conhecimento de computação e de análise sintática.

- Usuário sem experiência com programação.

- Usuário com conhecimentos básicos de programação e pouco conhecimento sobre compiladores e análise sintática.

- Usuário experiente com bons conhecimentos em programação, em compiladores e em análise sintática.

\subsubsection{Primeiro cenário}

A usuária Katarina Romero Barcellos, 24 anos, formada em Publicidade e Propaganda, sem conhecimentos em programação ou compilação, testou o sistema. Para isso, foi-lhe fornecida uma imagem de um gráfico sintático de uma calculadora simples para que ele fosse desenhado no sistema. Os resultados foram os seguintes: 
- A usuária reconheceu que a interface é bastante intuitiva e fácil de usar, porém sentiu necessidade de expandir automaticamente as dimensões da tela, conforme o seu espaço foi sendo utilizado, para facilitar a navegabilidade do programa.

- A usuária apreciou o fato de todos os elementos necessários para a elaboração da gramática, sua aplicação (teste) e a recuperação de erros estarem contidos em uma mesma área de trabalho, o que facilita a visualização de todo o conjunto de elementos do analisador sintático ao mesmo tempo.

- A usuária valorizou a aplicação da recuperação de erros na análise sintática, que informa se a cadeia a ser analisada está correta ou incorreta e ainda sugere termos para a correção da expressão que apresentou erro.

\subsubsection{Segundo cenário}

O usuário Hector Kikuchi Martins, 27 anos, formado em Ciência da Computação, com conhecimentos de programação, porém com poucos conhecimentos de linguagens formais ou compiladores, testou o sistema. Para isso foram fornecidos diversos exemplos em notação BNF de gramáticas simples e de uma calculadora com as operações de adição e multiplicação. Foi pedido que elaborasse uma calculadora mais complexa, com as operações de subtração e divisão, usando o GGLL. Os resultados foram os seguintes:

- No início houve uma dificuldade para entender a lógica das gramáticas formais, porém após esse entendimento o usuário conseguiu elaborar uma calculadora com as quatro operações básicas e ainda incrementou essa calculadora com parênteses.

- Ele relatou que o sistema é de muito simples utilização e que a curva de aprendizado é muito pequena e rápida, bastando alguns exemplos para conseguir elaborar gramáticas mais complexas.

\subsubsection{Terceiro cenário}

O usuário Ígor Bonadio, 27 anos, mestre em Ciência da Computação, com ótimos conhecimentos em programação e compilação, testou o sistema. Foi-lhe pedido para construir uma gramática para uma calculadora simples e os resultados foram os seguintes:

- Após esses resultados, o usuário relatou os lados positivos: interface gráfica que possibilita a visualização da gramática facilitando assim, para pessoas que não têm muitos conhecimentos na área, criar uma nova linguagem. Ígor destacou também a possibilidade de poder executar a análise da gramática passo a passo e com isso poder ver o estado das pilhas sintáticas e semânticas em cada passo da análise.

- O usuário relatou alguns pontos negativos: por se tratar de um programador experiente, particularmente gosta de trabalhar com o teclado e muito pouco com o mouse. Então, se fosse possível definir a gramática digitando e depois visualizar graficamente (principalmente na hora de executar passo a passo) seria ótimo. 


\section{Capítulo 8}

\section{Conclusões}

Nesse trabalho pode-se concluir que o sistema GGLL facilita a criação de novas gramáticas, pois possui uma interface gráfica que auxilia e simplifica essa criação. Além disso pode-se afirmar que um usuário com poucos conhecimentos em linguagens e em gramáticas formais conseguirá criar um analisador sintático utilizando o GGLL, porém será necessária mais experiência para ele programar as rotinas semânticas.

A interface gráfica mostra-se muito importante para os usuários iniciantes, porém para usuário mais avançados torna-se apenas uma opção. Provavelmente pessoas que usam geradores como o Yacc e o AntLR, acostumadas a definir uma gramática em forma de texto, precisarão usar o GGLL para se conscientizarem das vantagens da visualização gráfica da gramática. A validação da gramática e execução da análise em conjunto com a interface gráfica são ferramentas muito úteis e interessantes para se encontrar erros na gramática.

Comparado com outros geradores de analisadores sintáticos, o GGLL possui a facilidade da definição da gramática por meio de interface gráfica. Nenhum dos outros quatro sistemas comparados possui essa facilidade. Uma outra vantagem é a validação da gramática desenhada e a indicação clara dos pontos de erro, com a facilidade de se perceber a causa dos erros e como corrigi-los. Ele ainda possui uma recuperação automática de erros; isso não ocorre nos sistemas baseados em métodos bottom-up como o Yacc e o SableCC, e apresenta uma estratégia a mais (busca de delimitadores) do que, por exemplo, o AntLR. O GGLL ainda necessita ser testado em diversos ambientes porem é um sistema que merece ser ampliado (por exemplo, com uma linguagem para substituir ao máximo as rotinas semânticas) por possuir um grande potencial de se tornar uma alternativa vantajosa de gerador de analisadores sintáticos. 


\section{Capítulo 9}

\section{Trabalhos Futuros}

Neste trabalho de mestrado foi desenvolvido um gerador de analisadores sintáticos para gramáticas gráficas. Esse sistema auxilia a criação de novas gramáticas pela facilidade da interface gráfica, e pela recuperação automática de erros. O sistema foi desenvolvido em Java, escolhida por sua universalidade e popularidade e não necessita de nenhum ambiente de programação. A dependência de um desses ambientes poderia tornar o sistema inoperante se o ambiente tivesse atualizações posteriores. As rotinas semânticas também devem ser programadas em linguagem Java. Uma sugestão para trabalhos futuros é a implementação de uma linguagem de scripts para descrever as rotinas semânticas, evitando-se assim uma boa parte da programação de um compilador. Para isso, deveria ser utilizado o próprio GGLL para facilitar o desenvolvimento.

Outra sugestão é utilizar o GGLL.UI para se projetar gramáticas para outros geradores de analisadores sintáticos que utilizem gramáticas LL, como é o caso do AntLR. Ele também pode ser usado para projetar gramáticas de outros tipos, mas nesse caso seria conveniente poder-se desativar as rotinas de validação.

Finalmente, um desenvolvimento que tornaria o GGLL um sistema muito prático e com enormes vantagens sobre os outros geradores de analisadores existentes seria uma implementação para se trabalhar diretamente pela internet, para desenhar o grafo sintático e para usar todas as outras funcionalidades. 
68

TRABALHOS FUTUROS 


\section{Apêndice A}

\section{Algoritmos}

\section{A.1 $\quad F I R S T_{T}$ e $F I R S T_{N}$}

Definição: $F \operatorname{IRS} T_{T}(\alpha)=\left\{t \in V_{T} \mid \alpha \stackrel{*}{\Rightarrow} t \beta, \beta \in V^{*}\right\}$.

Seja $N$ um nó não terminal, $F I R S T_{T}(N)$ é o conjunto $C_{T}$ de símbolos de nós terminais pertencentes à cadeia de alternativas que começa no sucessor do nó inicial de $N$. Se nessa cadeia houver um nó não terminal $M$, inclui-se $F I R S T_{T}(M)$ em $C_{T}$.

Seja $t$ um nó terminal. FIRST $T_{T}(t)$ é o conjunto $C_{T}$ de símbolos de nós terminais da cadeia de alternativas iniciando em $t$, unido com os conjuntos $F I R S T_{T}(N)$ onde $\mathrm{N}$ é um nó não terminal da cadeia de alternativas de $t$

Definição: $F I R S T_{N}(\alpha)=\left\{N \in V_{N} \mid \alpha \stackrel{*}{\Rightarrow} N \beta, \beta \in V^{*}\right\}$.

Seja $M$ um nó não terminal. $F I R S T_{N}(M)$ é o conjunto $C_{N}=\left\{M_{1}, M_{2}, \ldots, M_{k} \mid M_{i} \in V_{N}\right\}$ de símbolos não terminais da cadeia de alternativas de $M$, unido com $F \operatorname{IRST} T_{N}\left(m_{1}\right), F I R S T_{N}\left(m_{2}\right)$, $\ldots, F I R S T_{N}\left(m_{k}\right)$, onde $m_{1}, m_{2}, \ldots, m_{k}$ são os sucessores dos nós iniciais de $M_{1}, M_{2}, \ldots, M_{k}$

\section{A.2 Eliminação de recursão à esquerda}

O algoritmo do quadro A.1 transforma uma gramática com recursão à esquerda em uma equivalente sem recursão à esquerda.

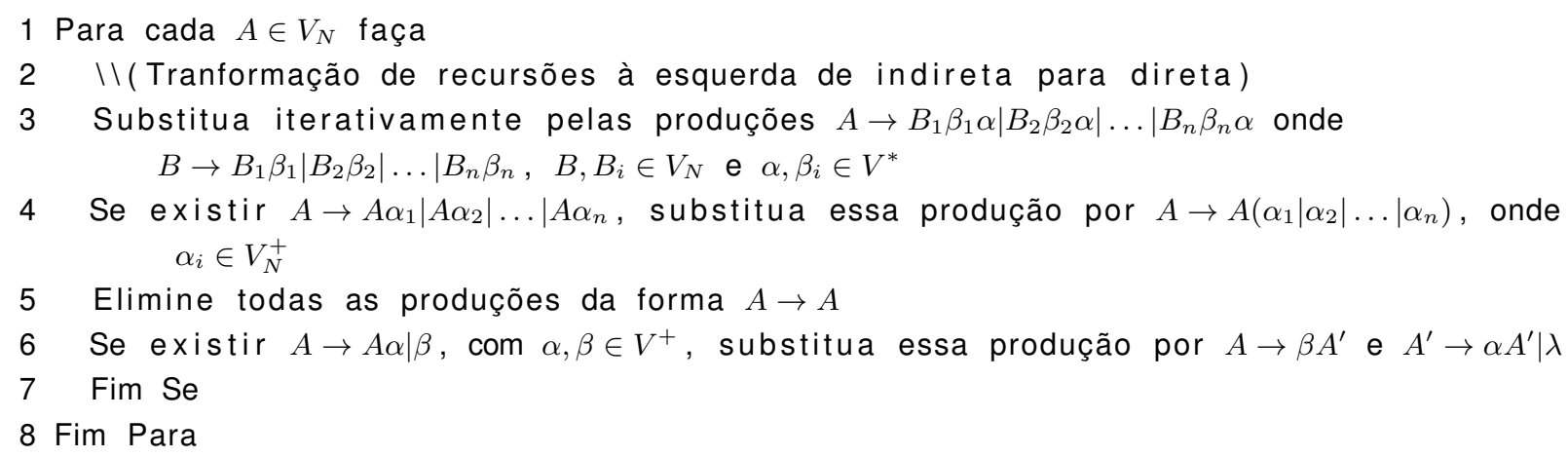

Quadro A.1: Algoritmo para detecção de recursão à esquerda 
APÊNDICE A 


\section{Apêndice B}

\section{Padrões de Projeto}

Neste apêndice são apresentados alguns padrões de projetos (design patterns), utilizando técnicas de orientação a objeto que foram empregadas no desenvolvimento deste trabalho.

\section{B.1 Visitor}

O padrão de projeto Visitor [GJHV06] é um padrão comportamental de objeto, ou seja, ele atua sobre a estrutura de um objeto. $O$ Visitor permite que sejam criadas novas operações sobre um objeto sem que esse seja modificada a classe sobre o qual o objeto opera.

Na figura B.1 é apresentado o diagrama estrutural desse padrão.
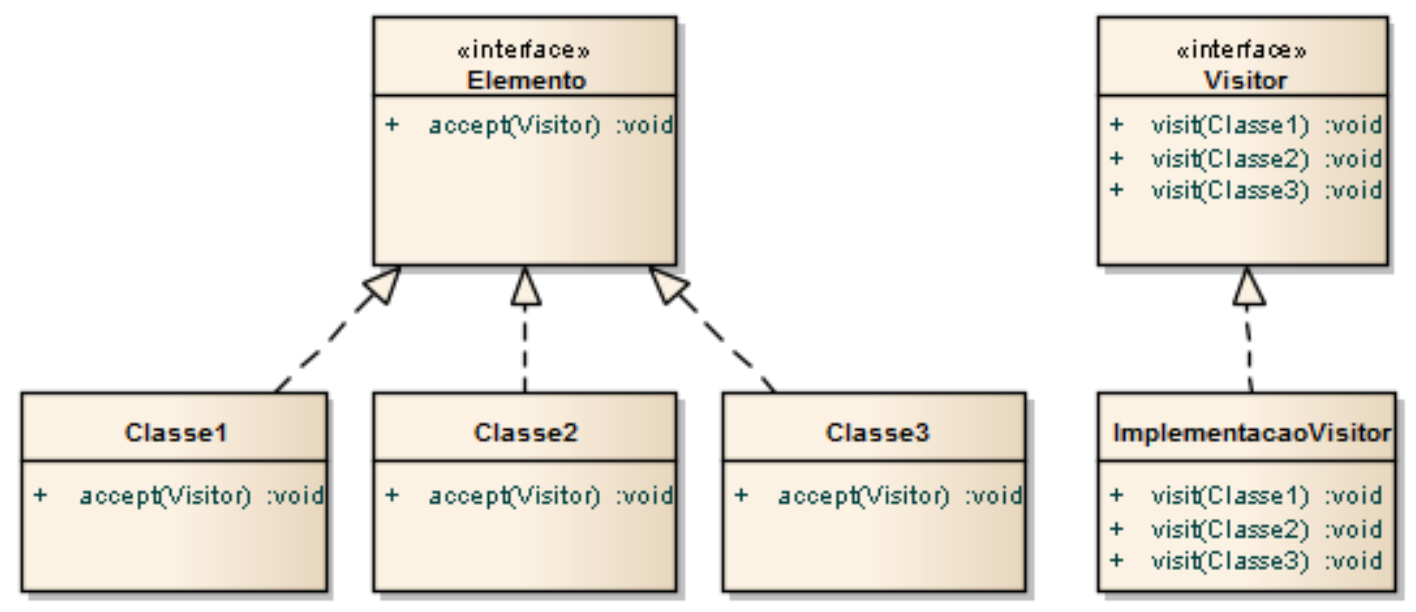

Figura B.1: Diagrama estrutural Visitor

O padrão Visitor cria duas interfaces. A primeira interface, denominada de Elemento no diagrama define todos os elementos que serão visitados. A segunda interface, denominada de Visitor no diagrama, define a classe que irá conter as operações sobre as classes que implementarem a interface Elemento.

As classes concretas a serem visitadas devem implementar a interface Elemento, como é o caso de Classe1, Classe2 e Classe3. Essas classes terão um método accept que irá receber como parâmetro a interface Visitor. Esse método irá invocar o método visit da interface Visitor passando como parâmetro a sua própria classe. 
A classe concreta do Visitor, denominada ImplemetacaoVisitor, implementa a interface Visitor. Nessa classe concreta são definidos os métodos visit. Há um método visit para cada classe concreta da interface Elemento. Nesses métodos são realizadas as operações sobre essas classes concretas.

No quadro B.1 é apresentado um código em Java para a implementação do padrão Visitor.

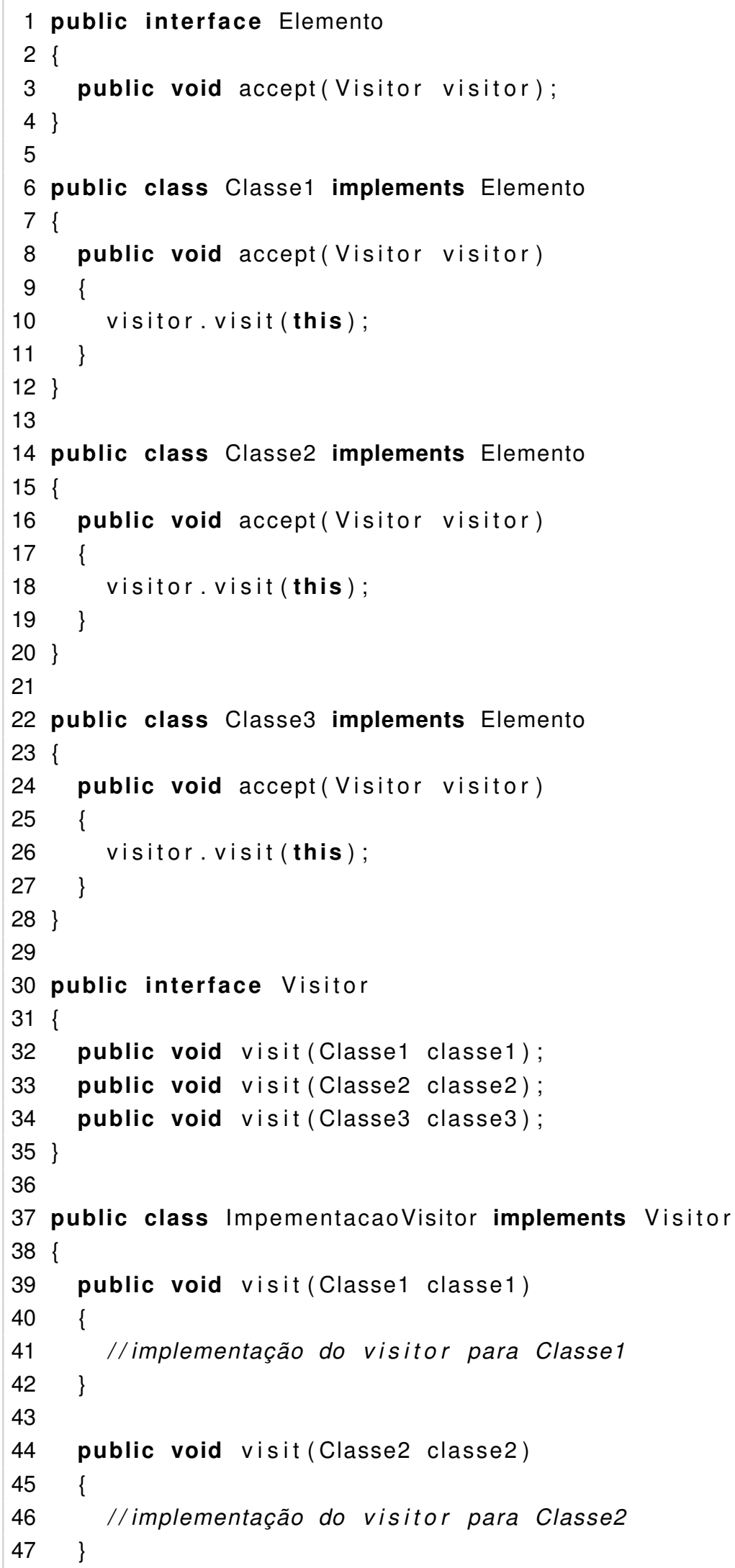




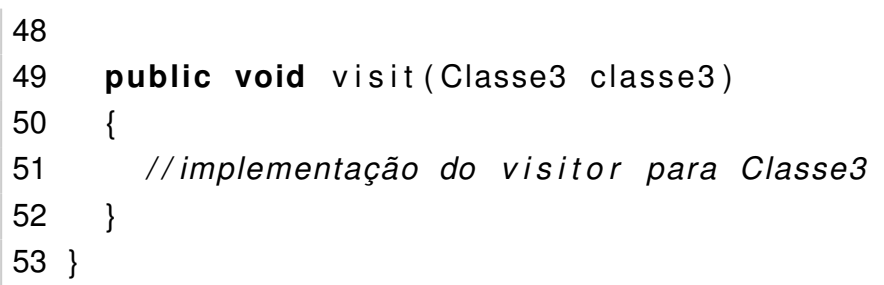

Quadro B.1: Exemplo de implementação do padrão de projeto Visitor

\section{B.2 Singleton}

Este padrão de projeto garante que exista apenas uma instância de um objeto presente no sistema. Ele também fornece um ponto comum de acesso a essa instância [GJHV06].

Este padrão é indicado quando se deve garantir que haja apenas uma instância de uma classe no sistema e que não haja a possibilidade de se criar outra instância dessa classe.

Na figura B.2 é apresentado o diagrama estrutural desse padrão.

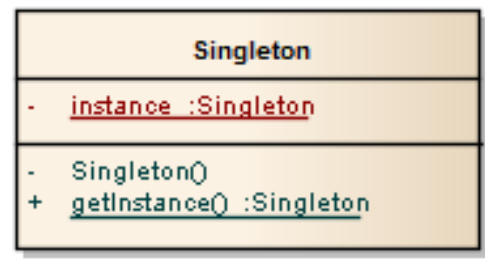

Figura B.2: Diagrama estrutural Singleton

A implementação desse padrão de projeto consiste de uma classe com um construtor privado, ou seja, que não pode ser acessado por outras classes. Na classe que usará o padrão Singleton deve estar presente uma propriedade estática do mesmo tipo da classe e um método denominado getInstance. Esse método é o responsável por retornar apenas uma instância da classe.

No quadro B.2 é apresentado um código em Java para a implementação do padrão Singleton.

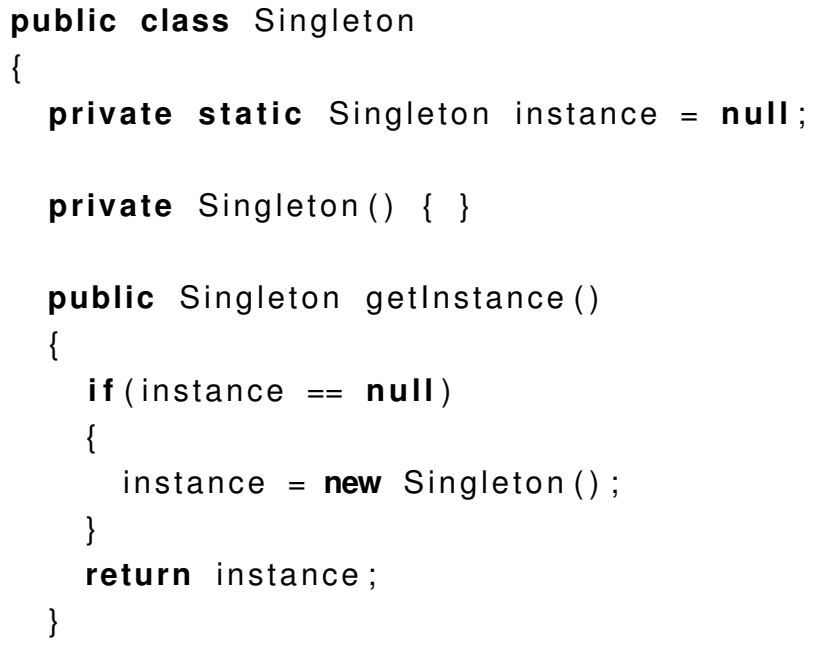

Quadro B.2: Exemplo de implementação do padrão de projeto Singleton 


\section{B.3 Factory Method}

Este padrão de projeto consiste em criar um conjunto de classes relacionadas tendo uma interface em comum e uma outra classe que decide qual tipo de classe instanciar [GJHV06].

Este padrão é indicado quando se possui um conjunto de classes com características comuns e que possam ser agrupadas. Para isso cria-se uma nova classe que irá decidir qual classe seria criada de acordo com a necessidade do sistema.

Na figura B.3 é apresentado o diagrama estrutural desse padrão.

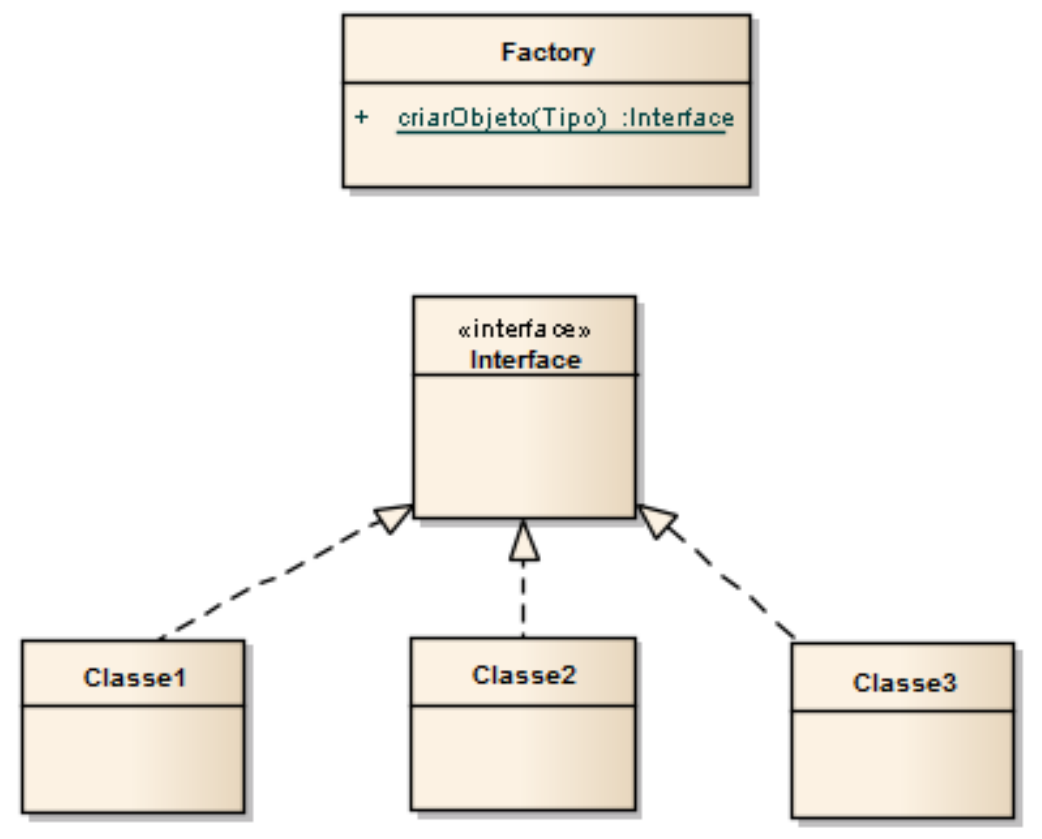

Figura B.3: Diagrama estrutural Factory Method

A implementação do Factory Method consiste em uma interface comum para todos as classes que serão geradas pela classe Factory. A classe Factory possui um método criarObjeto que recebe como parâmetro o tipo do objeto a ser instanciado e retorna um novo objeto do tipo informado. Desse modo, caso haja uma alteração na criação ou alteração do objeto, essa alteração terá impacto apenas em um ponto do sistema e não em vários pontos do sistema como ocorreria caso não fosse utilizado o padrão Factory Method.

No quadro B.3 é apresentado o código em Java de um exemplo de implementação desse padrão de projeto.

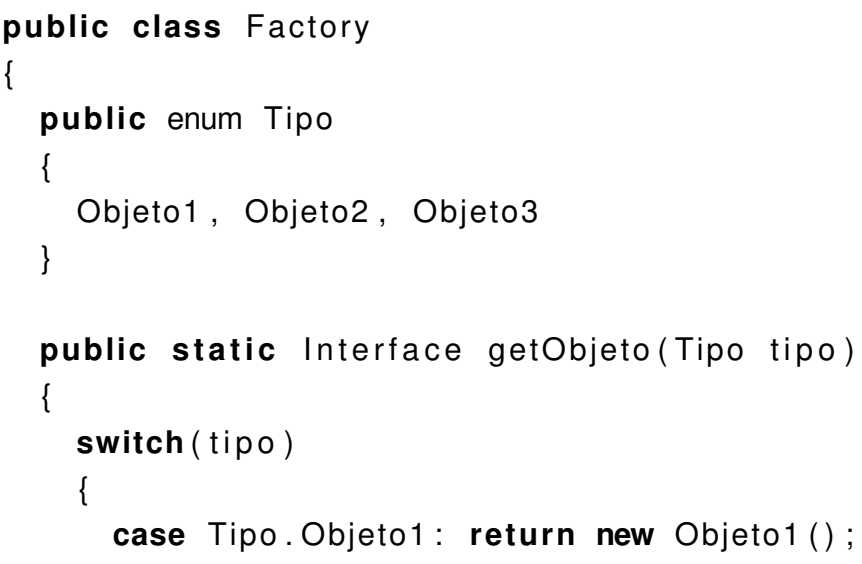




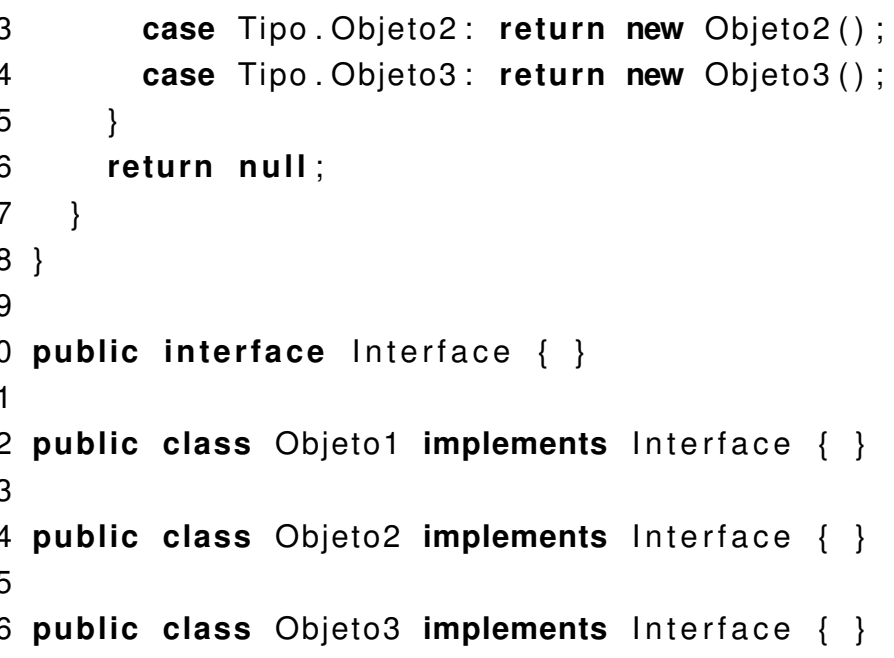

Quadro B.3: Exemplo de implementação do padrão de projeto Factory Method

\section{B.4 Facade}

O padrão de projeto Facade [GJHV06] define uma interface unificada para um conjunto de interfaces de uma parte do sistema. O Facade define uma interface para tornar essa parte do sistema mais fácil de ser utilizada.

Esse padrão é utilizado quando a estrutura do sistema é muito complexa e deseja-se facilitar o seu uso. É então criada uma interface que reúne as principais classes e métodos e essa interface é exposta para o sistema a fim de ser utilizada por todas as demais classes.

Na figura B.4 é apresentado o diagrama estrutural desse padrão.

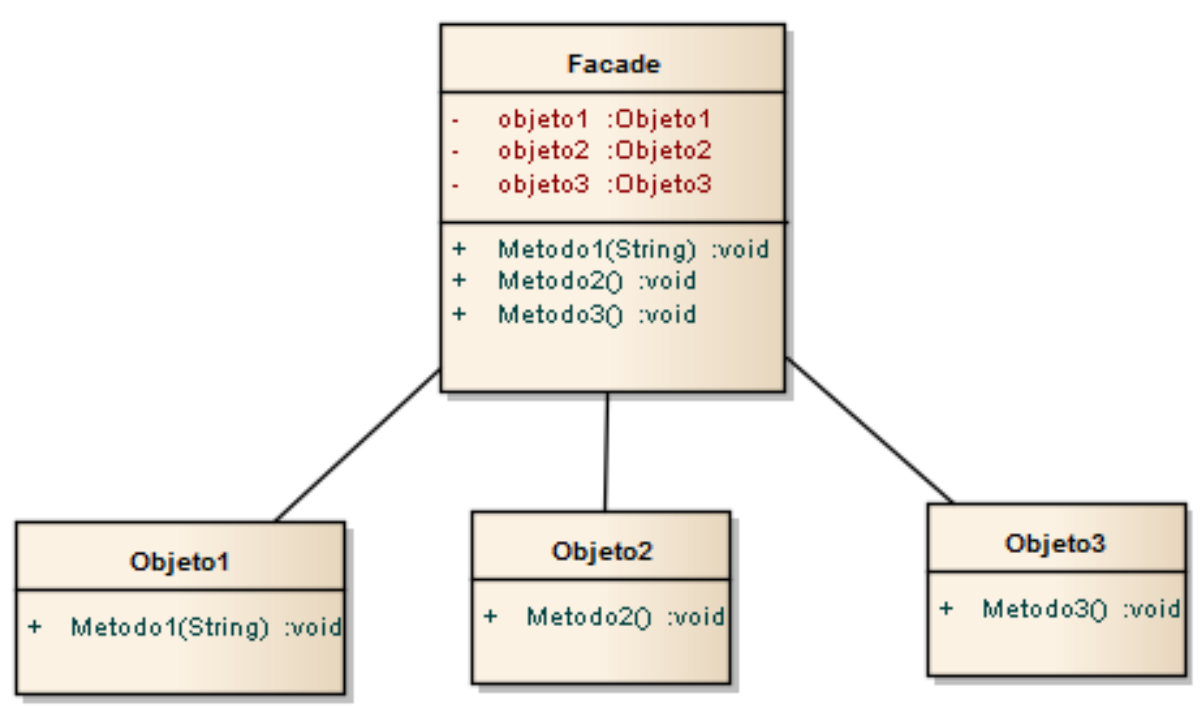

Figura B.4: Diagrama estrutural Facade

No quadro B.4 é apresetando o código em Java de um exemplo de implementação desse padrão de projeto. 


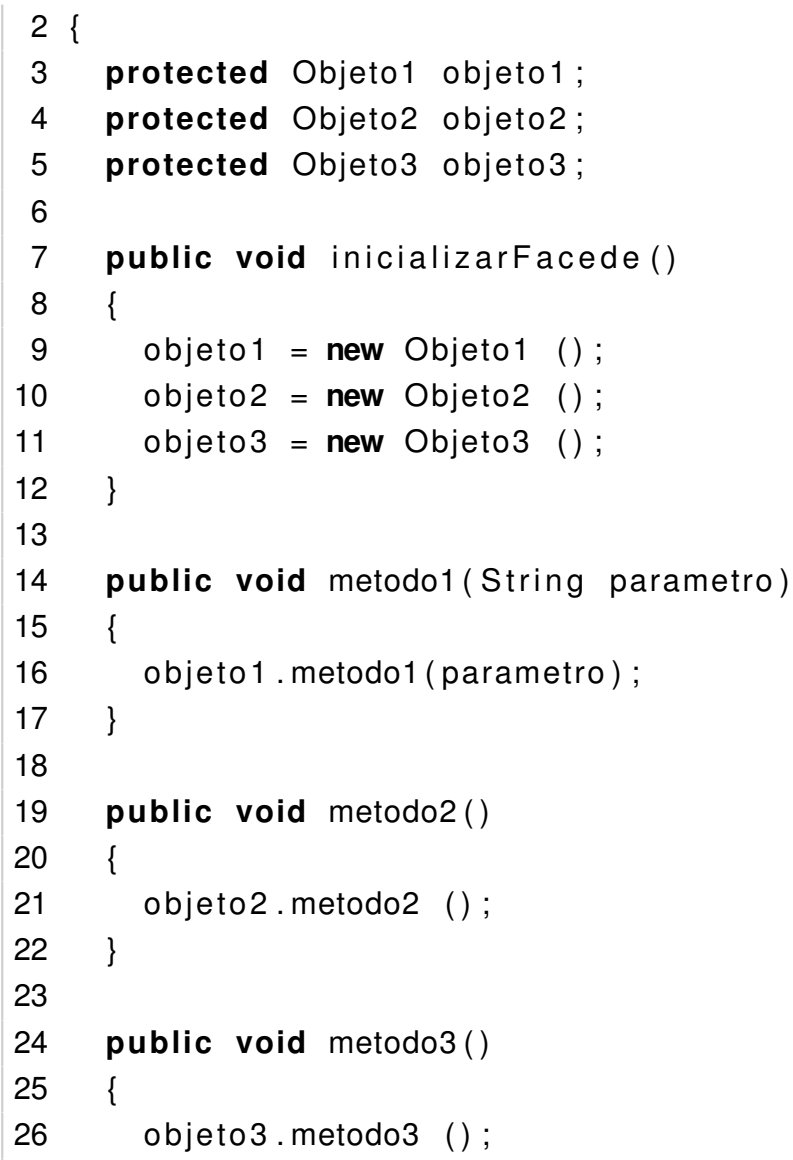

Quadro B.4: Exemplo de implementação do padrão de projeto Facade 


\section{Apêndice C}

\section{Manual de utilização do GGLL}

\section{C.1 Prefácio}

O GGLL é um sistema gerador de analisadores sintáticos, para auxiliar a construção de um compilador ou interpretador. Para isso o sistema utiliza como entrada uma gramática gráfica do tipo LL(1). O sistema foi desenvolvido para utilização de profissionais de computação que desejam desenvolver um compilador ou interpretador para uma nova linguagem de computação, além de poder ser utilizado como ferramenta de ensino de compiladores. O sistema pode ser encontrado no site www.ggll.com.br.

Este manual de usuário explica as funções do GGLL e fornece detalhes sobre:

- Configuração do GGLL;

- Criação de uma nova gramática;

- Utilização da gramática criada em um sistema independente.

\section{C.2 Acordo de Licença}

Copyright (c) 2014

Permission is hereby granted, free of charge, to any person obtaining a copy of this software and associated documentation files (the "Software"), to deal in the Software without restriction, including without limitation the rights to use, copy, modify, merge, publish, distribute, sublicense, and/or sell copies of the Software, and to permit persons to whom the Software is furnished to do so, subject to the following conditions:

The above copyright notice and this permission notice shall be included in all copies or substantial portions of the Software.

THE SOFTWARE IS PROVIDED "AS IS", WITHOUT WARRANTY OF ANY KIND, EXPRESS OR IMPLIED, INCLUDING BUT NOT LIMITED TO THE WARRANTIES OF MERCHANTABILITY, FITNESS FOR A PARTICULAR PURPOSE AND NONINFRINGEMENT. IN NO EVENT SHALL THE AUTHORS OR COPYRIGHT HOLDERS BE LIABLE FOR ANY CLAIM, DAMAGES OR OTHER LIABILITY, WHETHER IN AN ACTION OF CONTRACT, TORT OR OTHERWISE, ARISING FROM, OUT OF OR IN CONNECTION WITH THE SOFTWARE OR THE USE OR OTHER DEALINGS IN THE SOFTWARE. 


\section{C.3 Introdução ao Sistema}

O sistema GGLL é composto por dois módulos distintos:

- GGLL.UI: responsável pela criação de uma gramática. Nesse módulo é possível realizar a criação gráfica da gramática, realizar validações para verificar se a gramática desenhada é uma gramática do tipo LL(1), além de realizar testes na gramática criada. Ainda no GGLL é especificado o arquivo para a geração do analisador léxico e as rotinas semânticas.

- GGLL.Core: responsável pela execução do algoritmo GGLL sobre a gramática criada. Nesse módulo também está presente o tratamento de erros da análise sintática de uma cadeia a ser analisada pelo compilador ou interpretador.

\section{C.4 Pré-requisitos}

O GGLL.UI é um sistema desenvolvido em Java e por esse motivo necessita da máquina virtual Java, também conhecida como JVM (Java Virtual Machine) para sua utilização. A JVM pode ser encontrada no endereço http://java.com/getjava. Também é necessário para a utilização do sistema o JDK (Java Developer Kit), pois o sistema realiza compilações em tempo real de alguns arquivos. O JDK pode ser encontrado no endereço http://www.oracle.com/technetwork/pt/ java/javase/downloads/.

\section{C.5 Configuração do GGLL.UI}

O primeiro passo que deve ser feito antes de executar o GGLL.Ul é ajustar o arquivo de configuração "ggll.properties" que se encontra na pasta raiz do GGLL.UI. Nesse arquivo deve ser informado o caminho do local, onde foi realizada a instalação do Java JDK. Para isso deve-se localizar a linha <entry key='jdk_path'></entry > e preencher com o caminho do JDK, por exemplo: <entry key='jdk_path'>C:Program Files\Javaljdk1.7.0_05</entry>. Feito isso, o sistema estará pronto para ser executado.

\section{C.6 Execução do GGLL.UI}

Para executar o GGLL.UI deve-se digitar no prompt de comando a sequência "java -jar GGLL.UI". Após a execução do comando, será apresentada a interface da figura C.1. 




Figura C.1: GGLL.UI - Seleção de Workspace

Nessa tela, será necessário escolher um diretório (workspace) onde serão armazenados os arquivos do projeto da nova gramática a ser criada. Esse diretório deve estar vazio para se criar um novo projeto ou ainda escolher um diretório com uma gramática já existente.

Após escolhido o diretório deve-se clicar no botão OK. Caso uma nova gramática esteja sendo criada, nesse diretório serão então criados três arquivos:

- Arquivo da gramática (.gram): nesse arquivo estará presente a gramática gerada pelo sistema. Os arquivos .gram são arquivos que contém a representação gráfica da gramática. $O$ arquivo possui o mesmo nome do projeto criado.

- Arquivo léxico (.lex): nesse arquivo estará presente a especificação do analisador léxico a ser gerado. Essa especificação segue o padrão Lex e será detalhada no tópico Análise Léxica. $\mathrm{O}$ arquivo possui o mesmo nome do projeto criado.

- Arquivo semântico (.java): nesse arquivo estarão presentes as rotinas semânticas que deverão ser chamadas pela gramática criada. Essas rotinas devem ser programadas em linguagem Java e serão detalhadas no tópico análise semântica (ver item C.10). O arquivo possui o mesmo nome do projeto criado.

\section{C.7 Interface do Sistema}

Após a seleção da área de trabalho ou workspace, será aberta a tela principal do sistema com o arquivo da gramática pronto para ser editado, conforme a figura C.2. 


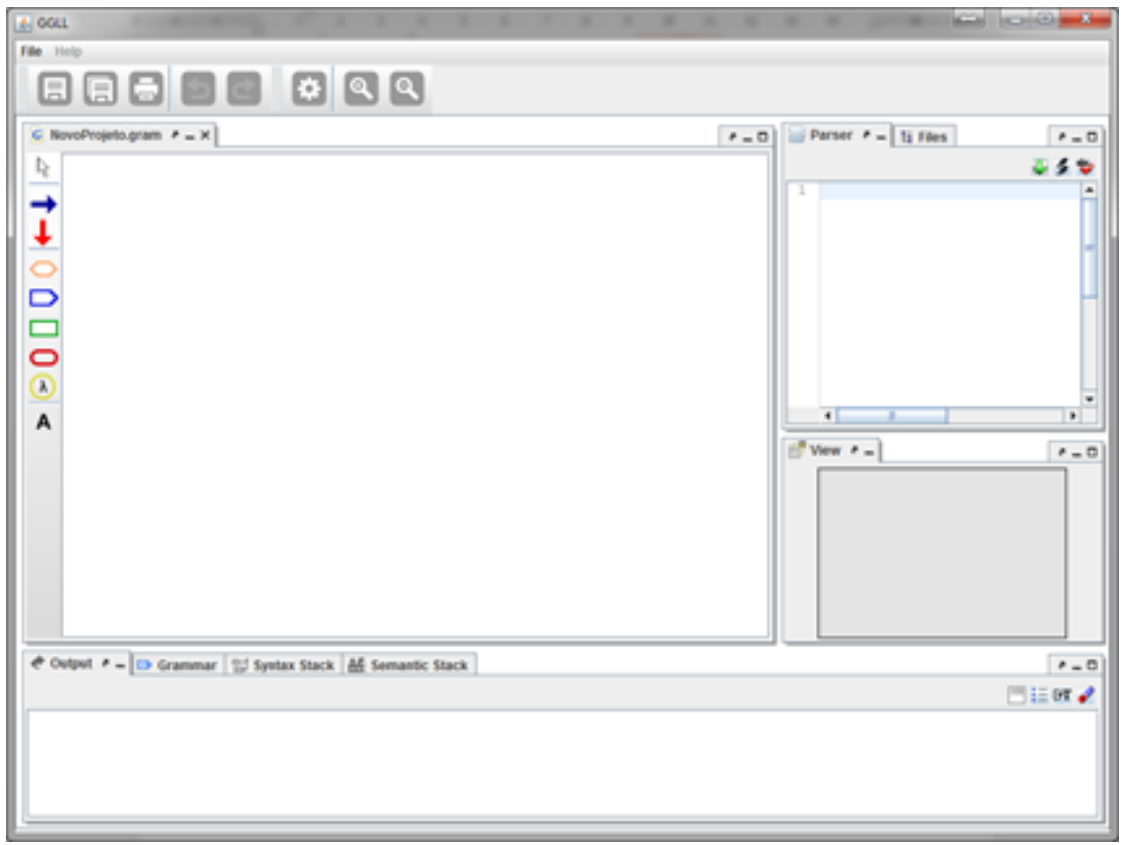

Figura C.2: GGLL.UI - tela principal

O GGLL.UI permite editar diversos tipos de arquivos (arquivo da gramática, arquivo léxico e arquivo semântico). Para cada tipo de arquivo a interface do sistema é modificada. A seguir serão descritos todos os elementos da interface do GGLL.UI, e em cada elemento será especificado em qual tipo arquivo esse elemento será mostrado.

\section{C.7.1 Menu superior}

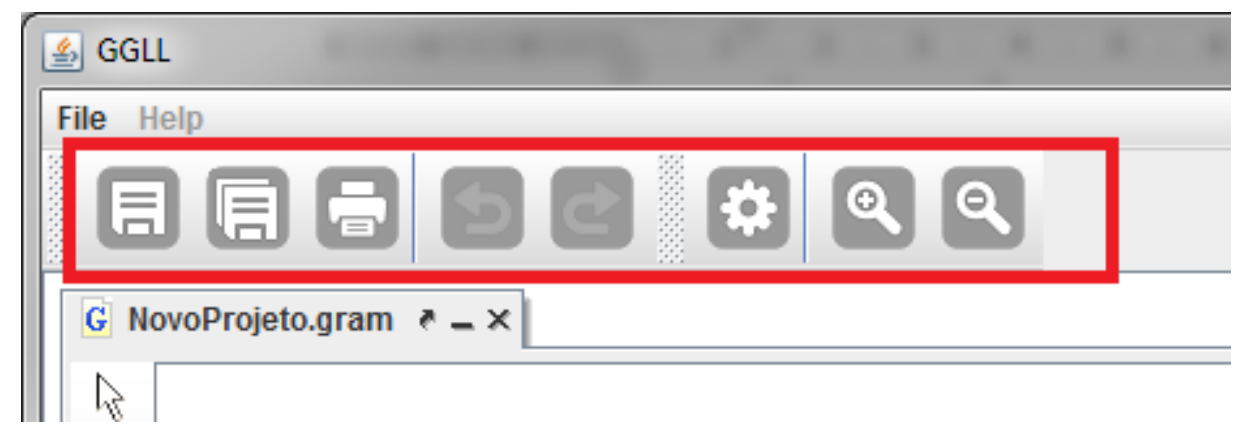

Figura C.3: GGLL.UI - Menu superior

Essa interface está presente em todos os tipos de arquivo; colocando-se o cursor sobre um ícone, aparece como "hint" o comando correspondente. Nessa tela é possível executar os comandos da tabela C.1: 


\begin{tabular}{|c|c|c|}
\hline Ícone & Comando & Descrição \\
\hline$\overline{\bar{n}}$ & Save & Salva no disco as alterações do arquivo atual \\
\hline 辰 & Save All & Salva no disco todos os arquivos abertos \\
\hline 回 & Print & Imprime 0 arquivo atual \\
\hline & Undo & Desfaz a última operação executada no arquivo atual \\
\hline & Redo & Refaz a última operação desfeita \\
\hline$\hat{\varepsilon}$ & Build & $\begin{array}{l}\text { Executa a validação da gramática e gera as tabelas do } \\
\text { GGLL. Essas tabelas são usadas pelo GGLL para fazer } \\
\text { uma análise sintática segundo a gramática gráfica dada } \\
\text { (ver 6.5.1) }\end{array}$ \\
\hline (9) & Zoom in & $\begin{array}{l}\text { Este comando está presente apenas na edição de arquivos } \\
\text { de gramática e amplia a visualização do gráfico da gramá- } \\
\text { tica }\end{array}$ \\
\hline & Zoom out & $\begin{array}{l}\text { Este comando está presente apenas na edição de arquivos } \\
\text { de gramática e diminui a visualização do gráfico da gramá- } \\
\text { tica }\end{array}$ \\
\hline
\end{tabular}

Tabela C.1: GGLL.UI - Comandos Menu Superior

\section{C.7.2 Parser (menu lateral direito)}

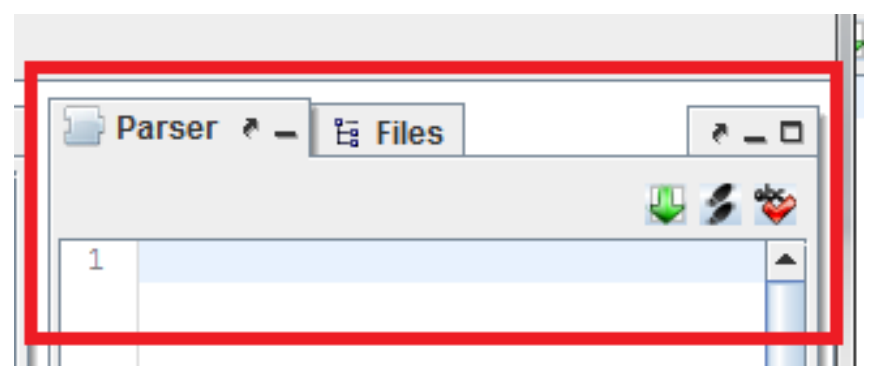

Figura C.4: GGLL.UI - Parser

Esta aba está presente em todos os tipos de arquivo. Nela é possível usar a gramática criada para fazer uma análise sintática de uma cadeia de entrada. Para isso, deve-se digitar uma expressão (uma cadeia de entrada) na área de texto presente nessa aba. Com isso é possível testar a gramática assim que desenhada, agilizando o processo de criação. Nela é possível executar um dos seguintes comandos da tabela C.2. 


\begin{tabular}{|c|c|c|}
\hline Ícone & Comando & Descrição \\
\hline 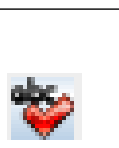 & $\begin{array}{l}\text { Parse } \\
\text { Expression }\end{array}$ & $\begin{array}{l}\text { Realizar a análise sintática da cadeia digitada na área de } \\
\text { texto }\end{array}$ \\
\hline 8 & $\begin{array}{l}\text { Parse Next } \\
\text { Step }\end{array}$ & $\begin{array}{l}\text { Realizar a análise passo a passo da expressão digitada na } \\
\text { área de texto }\end{array}$ \\
\hline 5 & $\begin{array}{l}\text { Open } \\
\text { File With } \\
\text { Expression }\end{array}$ & $\begin{array}{l}\text { Carregar um arquivo de texto para a área de texto; esse } \\
\text { arquivo texto será utilizado como cadeia de entrada }\end{array}$ \\
\hline
\end{tabular}

Tabela C.2: GGLL.UI - Comandos da aba Parser

\section{C.7.3 Files}

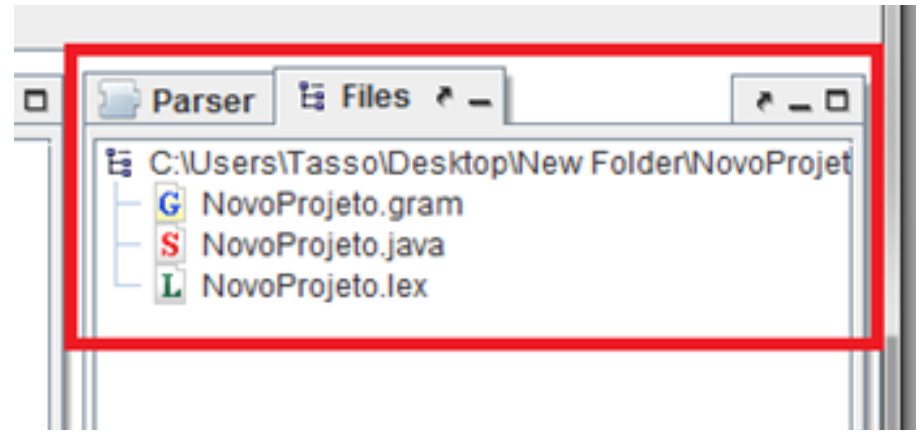

Figura C.5: GGLL.UI - aba Files

Essa aba está presente em todos os tipos de arquivo. Nela são apresentados todos os arquivos que fazem parte do projeto da nova gramática. Ao acionar duas vezes um item, ele é aberto para a área principal, onde poderá ser editado. Caso o arquivo acionado tenha a extensão .gram, será aberta a interface como demonstrada na figura C.1. Caso seja do tipo com a extensão .lex ou .java, será aberta a interface Editor de Texto apresentada no item C.7.10. 


\section{C.7.4 Menu lateral esquerdo}

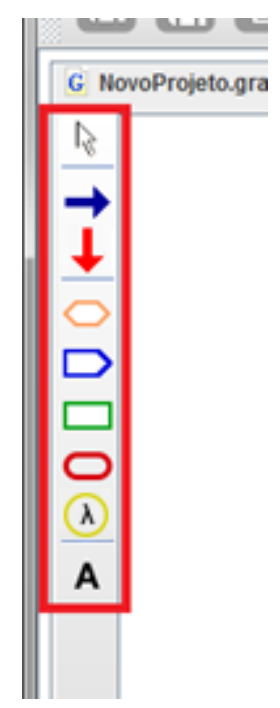

Figura C.6: GGLL.UI - Menu lateral esquerdo

Esse menu é apresentado apenas quando um arquivo de gramática está sendo criado ou modificado. Com ele podem-se selecionar os elementos gráficos que serão desenhados. Hints (balões) exibindo o nome de cada elemento gráfico aparecem ao se posicionar o cursor do mouse sobre o elemento.

Os gráficos que podem ser desenhados são apresentados na tabela C.3.

\begin{tabular}{l|l}
\hline Ícone & Descrição \\
\hline$\square$ & Nó inicial da gramática \\
\hline$\square$ & Nó não terminal \\
\hline$\square$ & Nó terminal \\
\hline$\square$ & Nó lambda ou vazio \\
\hline$\square$ & Lado esquerdo de uma produção \\
\hline$\rightarrow$ & Aponta para o sucessor de um nó \\
\hline$\square$ & Aponta para a alternativa de um nó \\
\hline$\square$ & $\begin{array}{l}\text { Seleciona elementos do gráfico, permitindo } \\
\text { movê-los mantendo as ligações }\end{array}$ \\
\hline
\end{tabular}

Tabela C.3: GGLL.UI - Menu lateral esquerdo

\section{C.7.5 Área de trabalho para criação de gramática}

Esta área é apresentada apenas para os arquivos de gramática, e é utilizada para desenhar os elementos da gramática gráfica. Para isso basta selecionar o elemento a ser desenhado no menu lateral esquerdo e clicar onde se deseja que o elemento seja desenhado na tela. Depois disso os 
elementos podem ser selecionados e movidos para outro local usando-se o botão esquerdo do mouse.

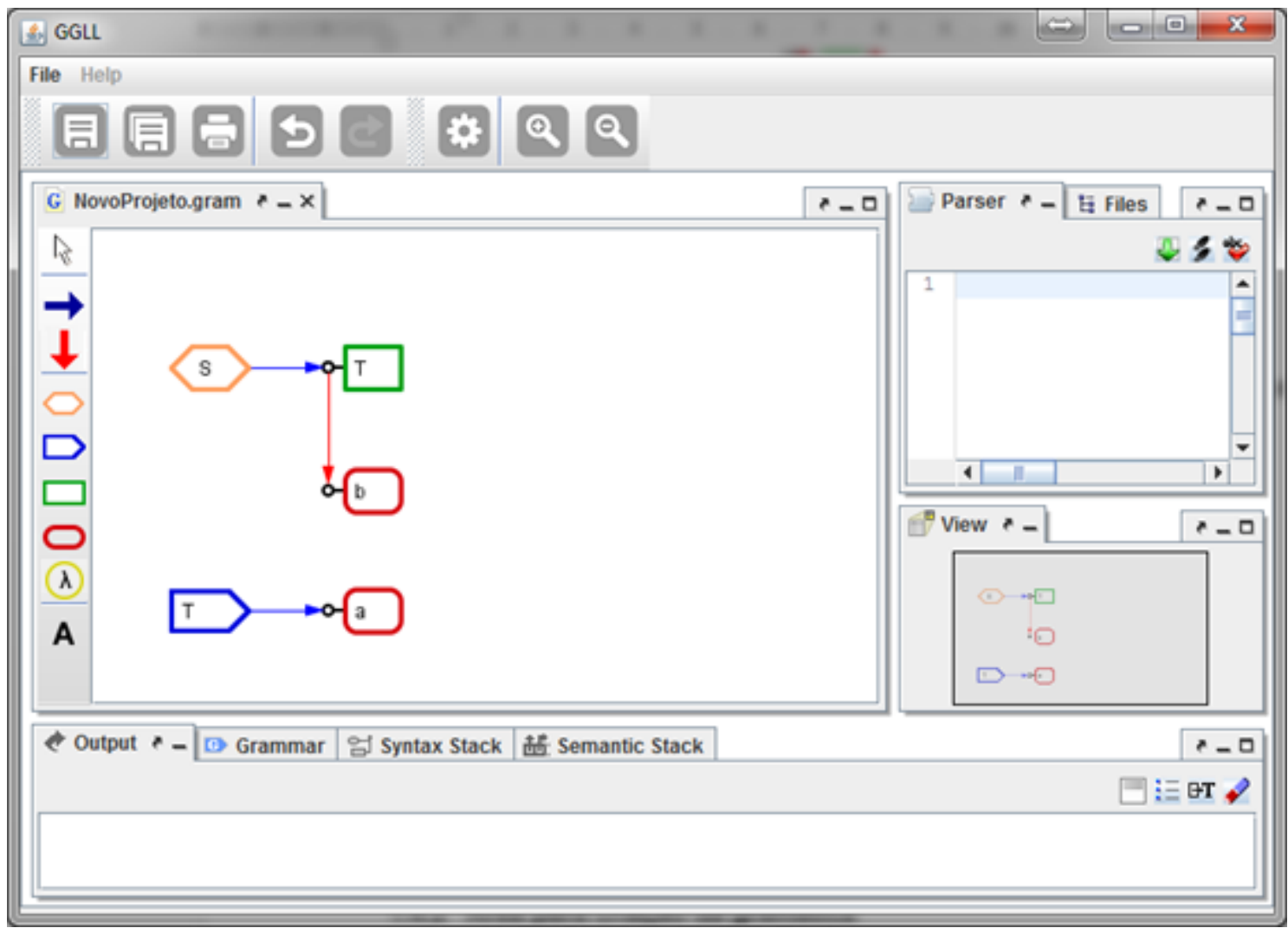

Figura C.7: GGLL.UI - Exemplo de criação de gramática

\section{C.7.6 Aba Output}

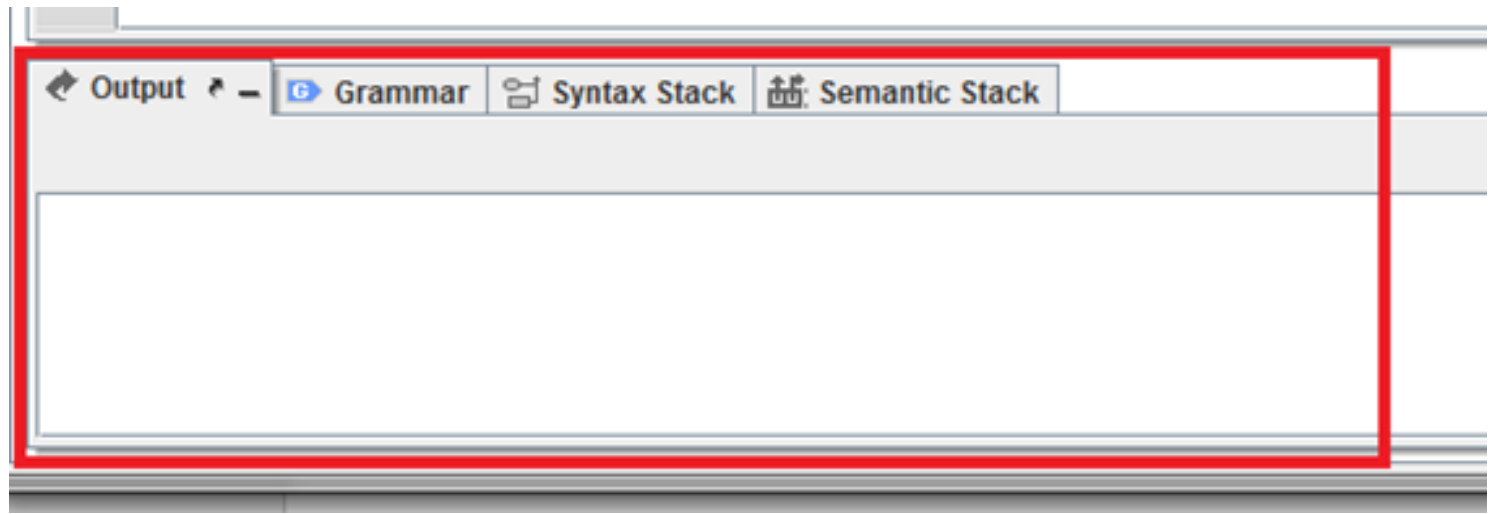

Figura C.8: GGLL.UI - Output

Essa aba está presente em todos os tipos de arquivo. Nela serão apresentadas as saídas do programa, como mensagens de erro ou sucesso de análise de uma cadeia segundo a gramática, mensagens sobre a geração das tabelas do GGLL e mensagens de recuperação de erro. 


\section{C.7.7 Aba Grammar}

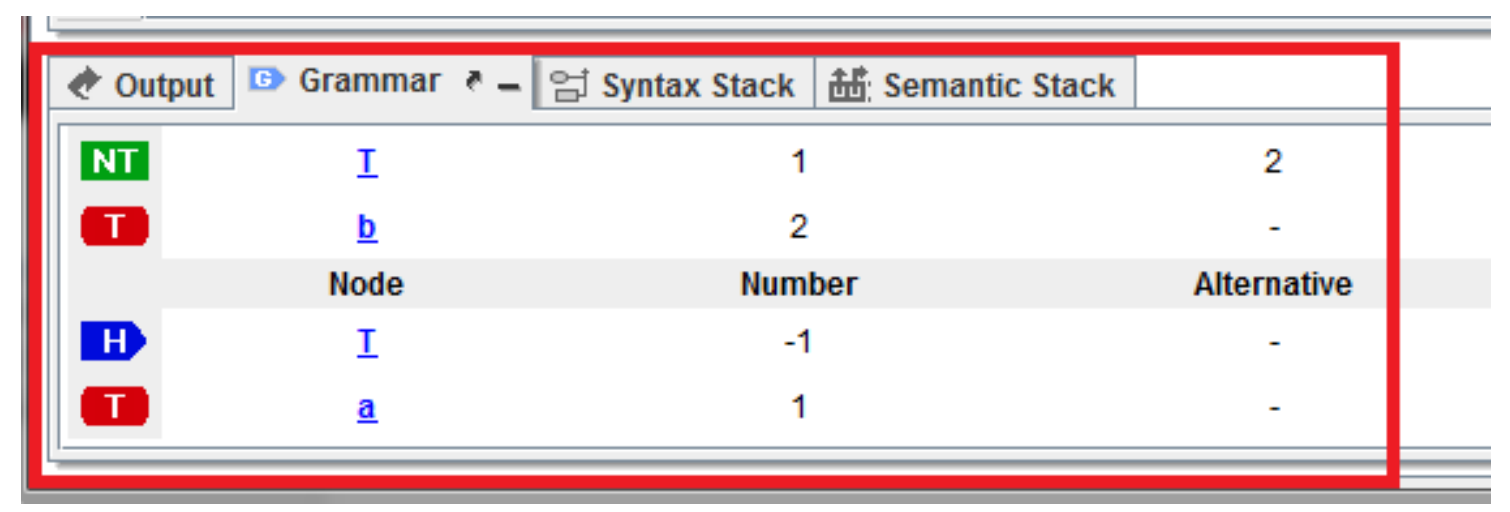

Figura C.9: GGLL.UI - Grammar

Após acionar Build (ver tabela C.1) no menu superior, serão criadas tabelas para executar o algoritmo do GGLL. Essas tabelas são representadas na aba Grammar, na qual é possível ver todas as produções com os terminais, não terminais e nós vazios (lambdas). Na primeira coluna à esquerda está o tipo do símbolo: NT para não terminal; T para terminal; $\mathrm{H}$ (de header) para não terminal à esquerda de uma produção e $S$ (de start) para o símbolo inicial. Na segunda coluna estão os nomes dos nós, na terceira coluna o índice do nó alternativo e na quarta coluna o índice do nó sucessor. Se o nó for um lambda aparece na primeira coluna o símbolo $\lambda$.

\section{C.7.8 Aba Syntax Stack}

Esta aba está presente em todos os tipos de arquivo. Nela é apresentada a pilha sintática da análise, que é montada de acordo com a cadeia de entrada inserida na área Parser.

\section{C.7.9 Aba Semantic Stack}

Esta aba está presente em todos os tipos de arquivo e exibe a pilha semântica da análise. Essa pilha é apresentada de acordo com a cadeia de entrada inserida na área Parser. 


\section{C.7.10 Editor de Texto}

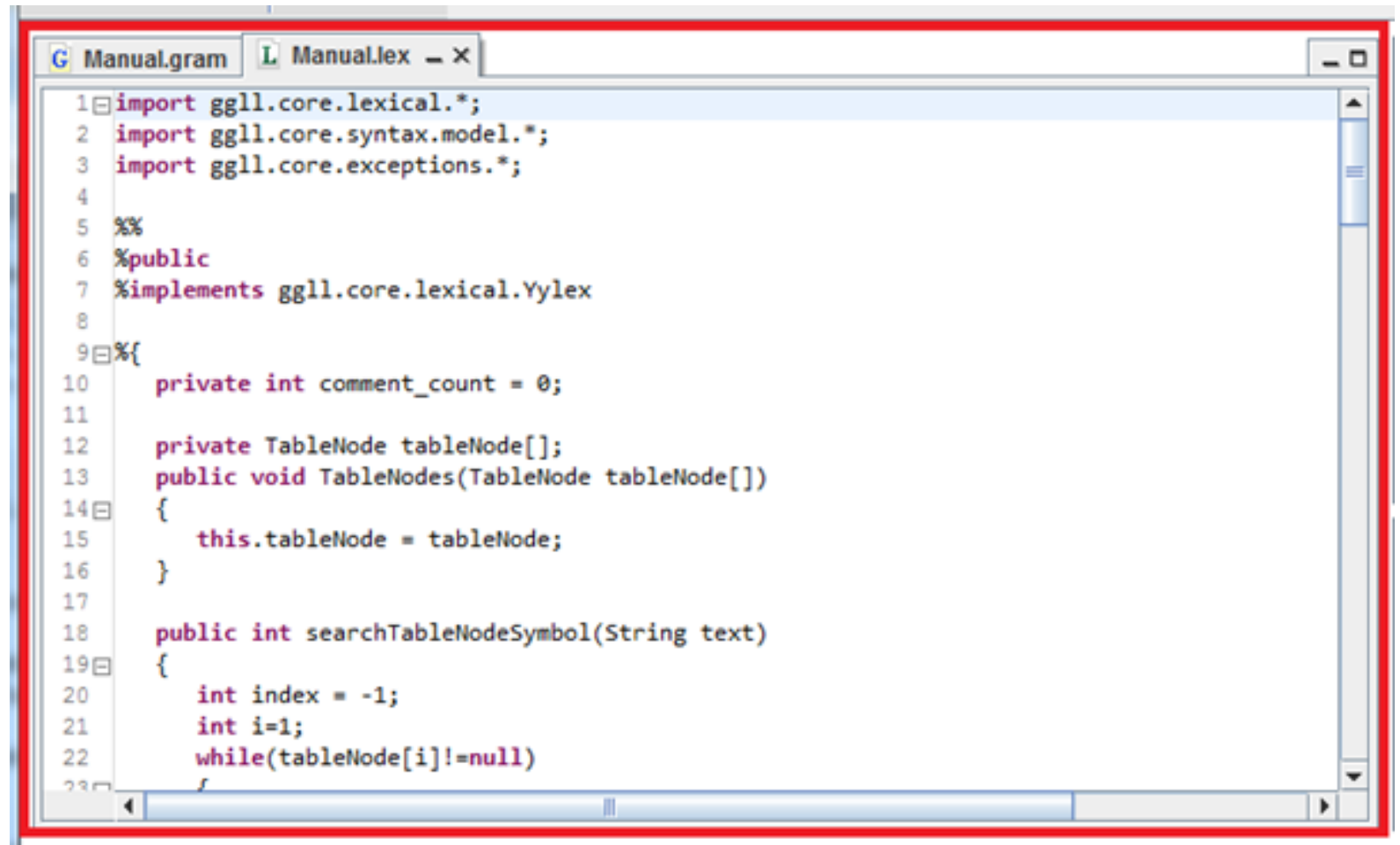

Figura C.10: GGLL.UI - Editor de Texto

Esta interface é apresentada apenas no arquivo léxico ou no arquivo semântico, e é utilizada para editar arquivos de texto.

\section{C.8 Execução passo a passo (debug)}

O GGLL.UI permite a execução da análise sintática passo a passo ou seja, toda vez que um terminal é reconhecido, a análise é interrompida e são apresentadas as pilhas sintática e semântica atualizadas. Essa função é muito utilizada por programadores para encontrar problemas em códigos e no caso do GGLL pode ser utilizado para se encontrar problemas nas gramáticas geradas ou auxiliar na compreensão desta.

Para se realizar a execução passo a passo, deve-se clicar no ícone debug (ver item C.2) até que a análise seja finalizada.

Exemplo: dada a gramática gráfica da figura C.11 e a entrada "accb", tem-se a execução passo a passo nas figuras C.11 até C.16. O terminal reconhecido é marcado na gramática em cada passo. 


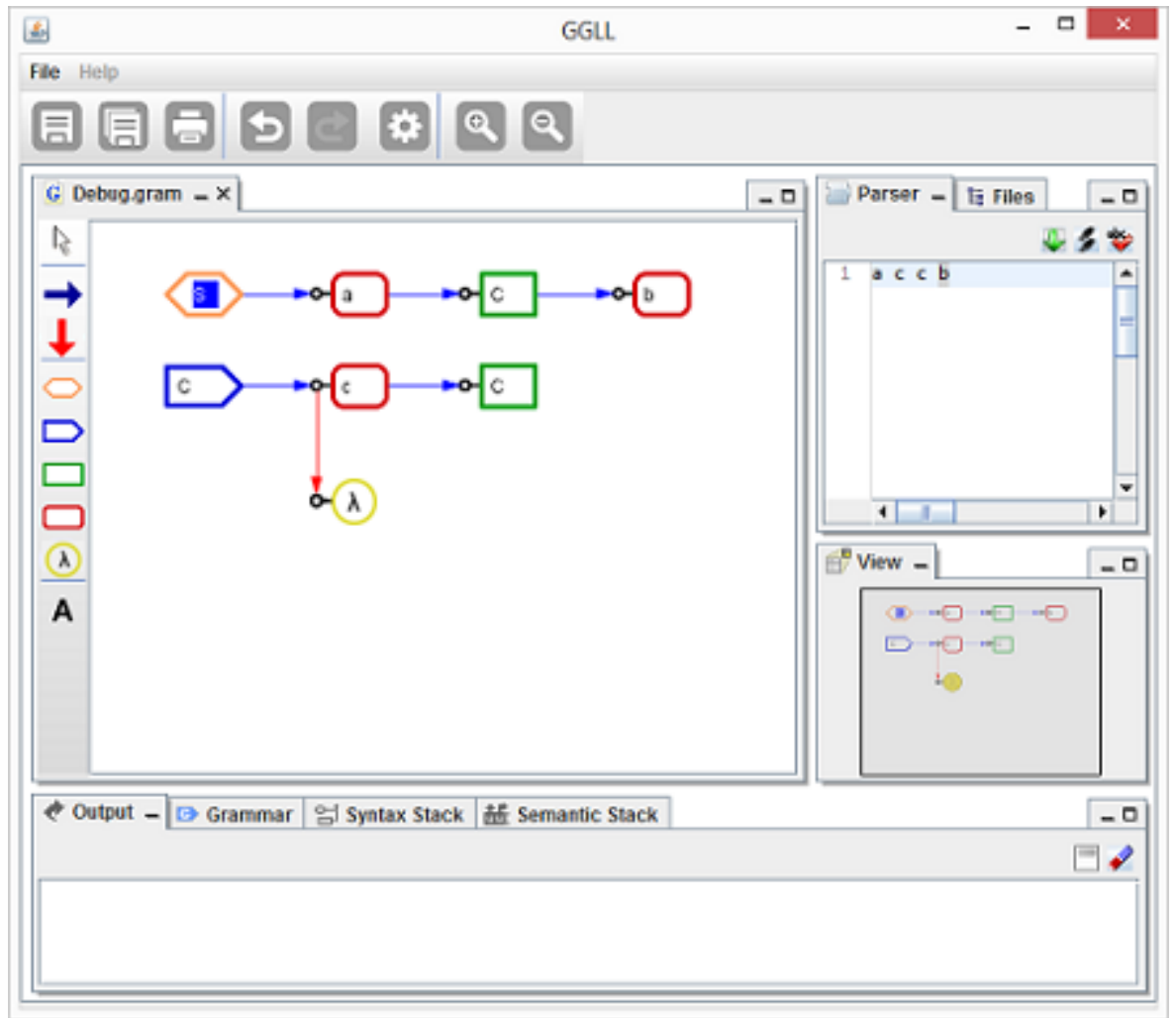

Figura C.11: GGLL.UI - Exemplo de debug - Gramática

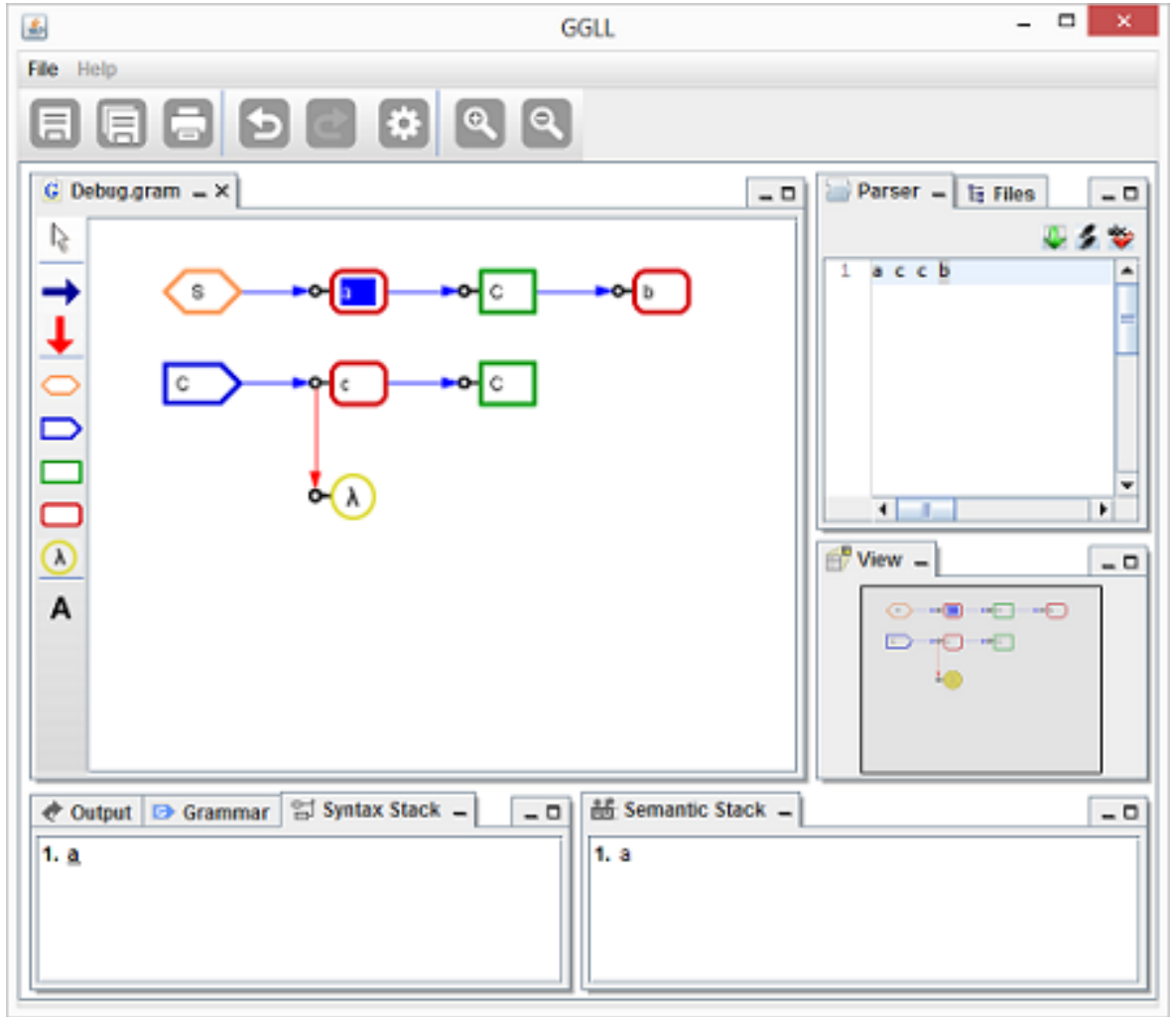

Figura C.12: GGLL.UI - Exemplo de debug - Passo 1 


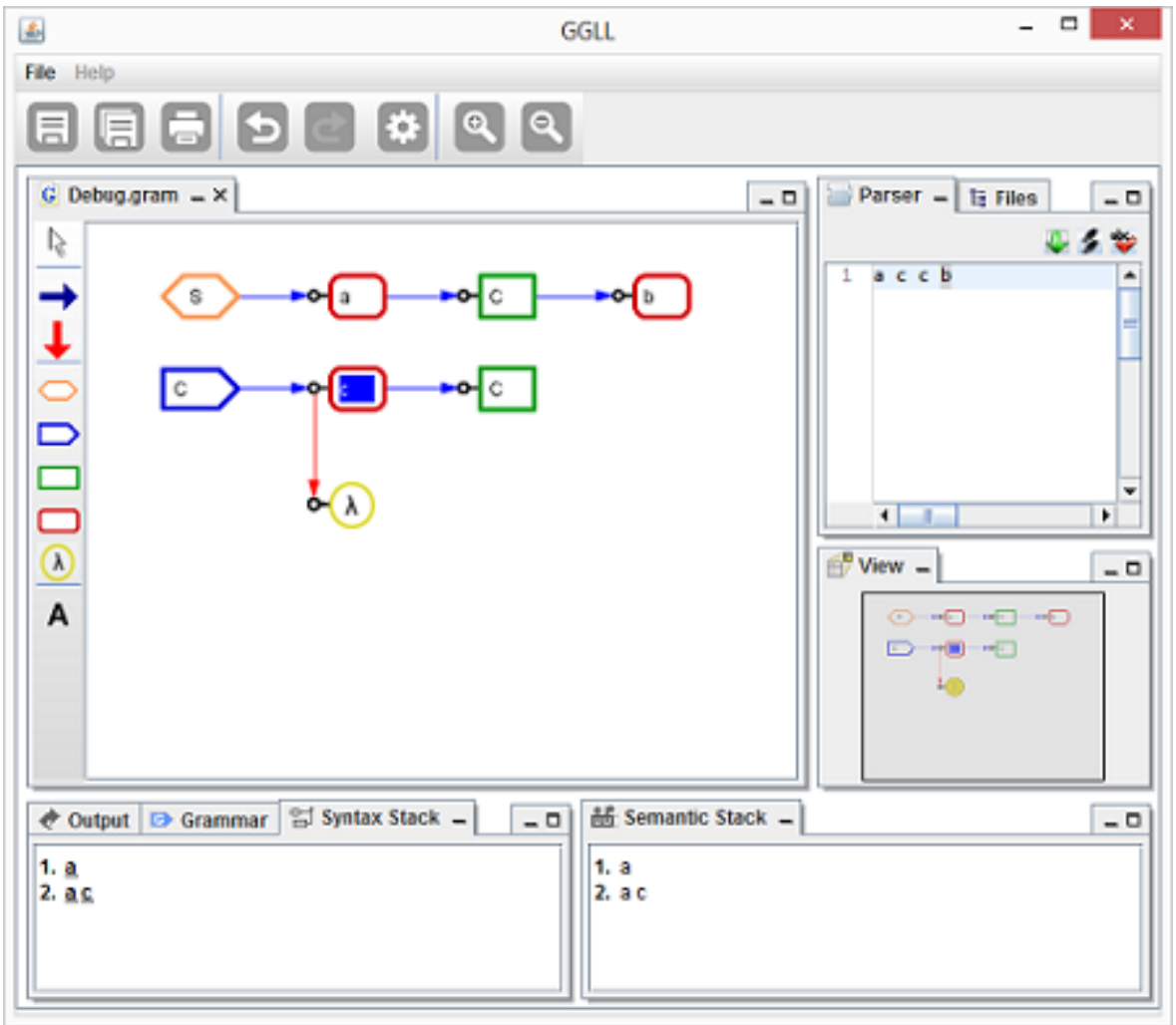

Figura C.13: GGLL.UI - Exemplo de debug - Passo 2

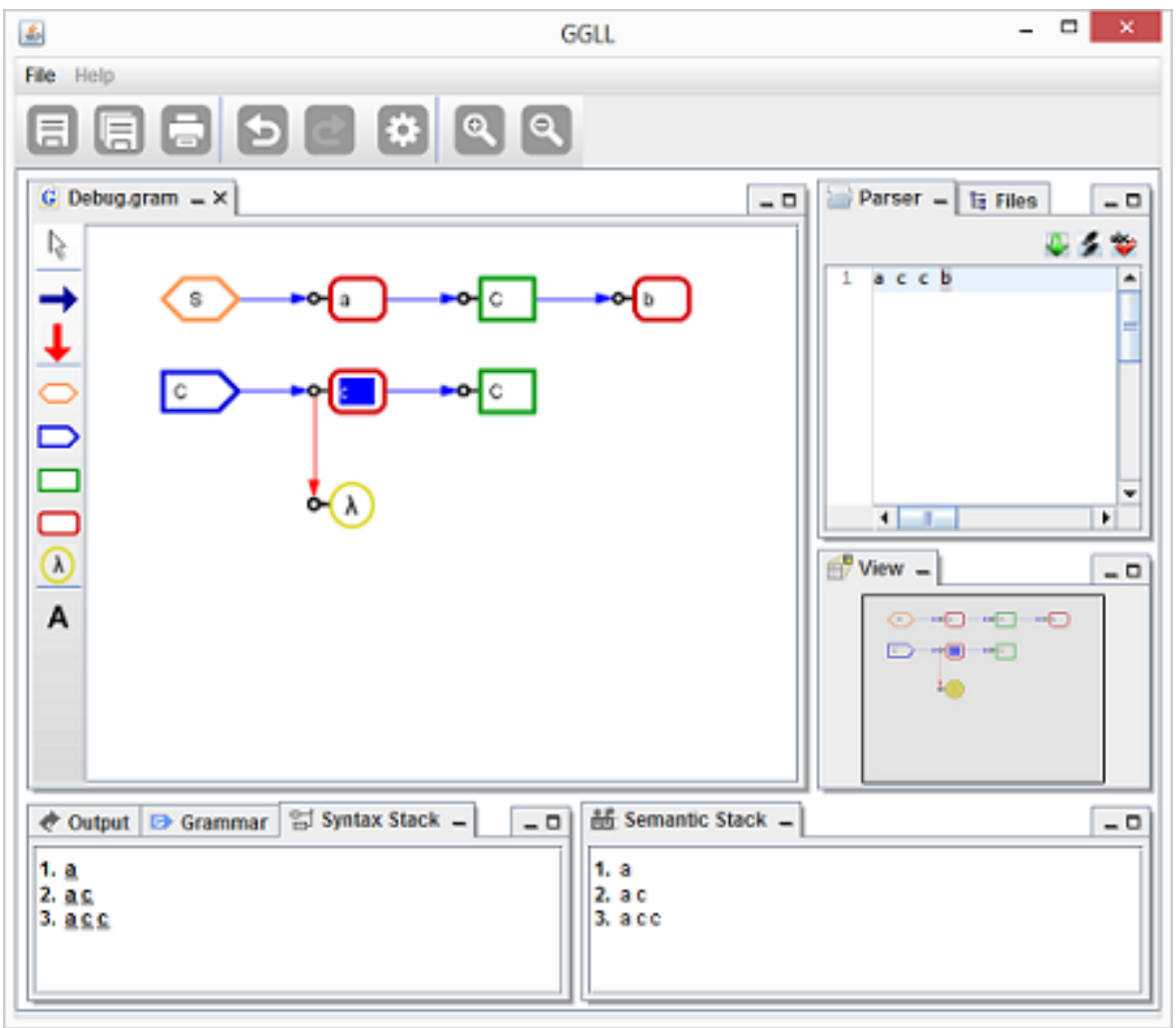

Figura C.14: GGLL.UI - Exemplo de debug - Passo 3 


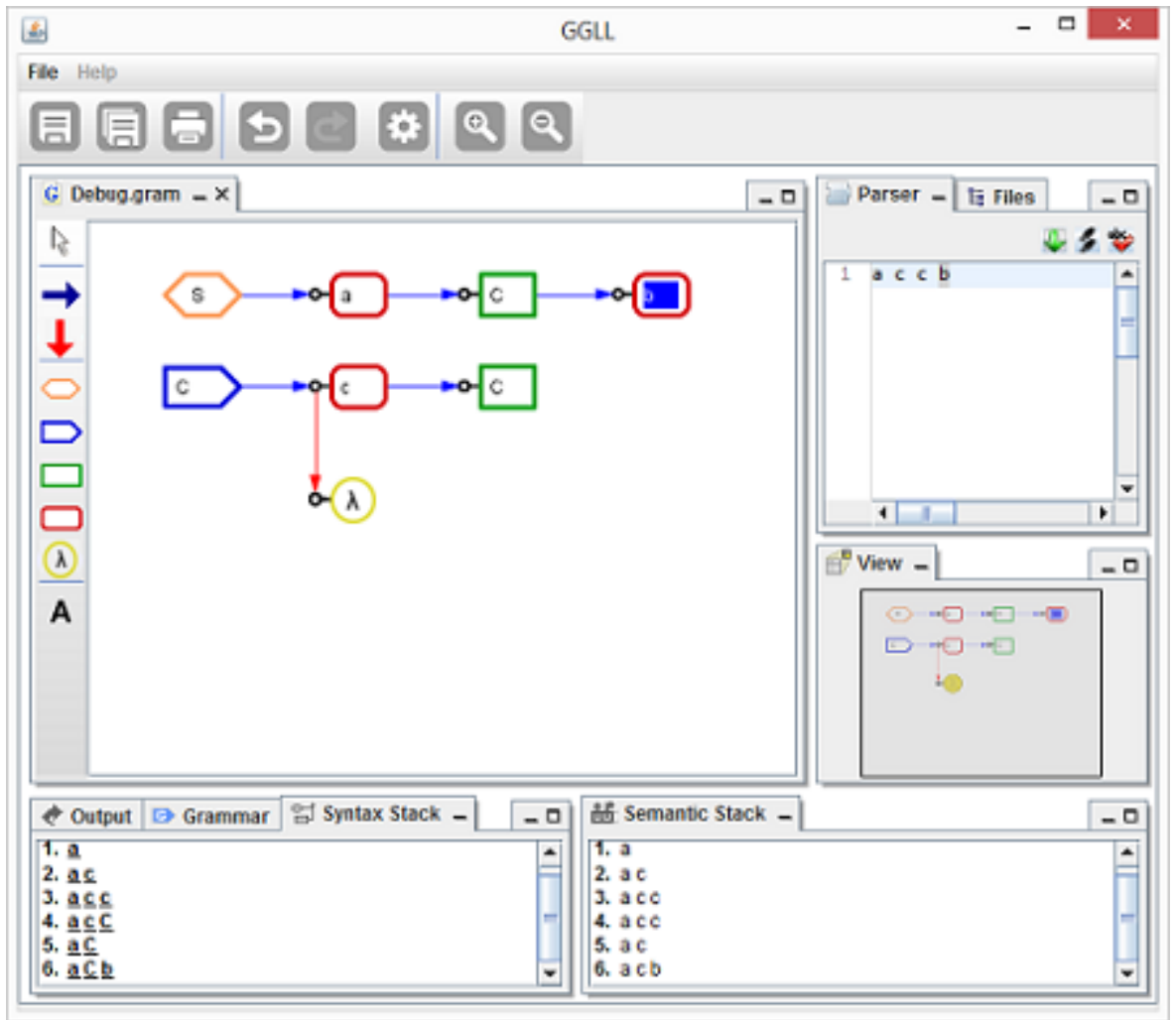

Figura C.15: GGLL.UI - Exemplo de debug - Passo 4

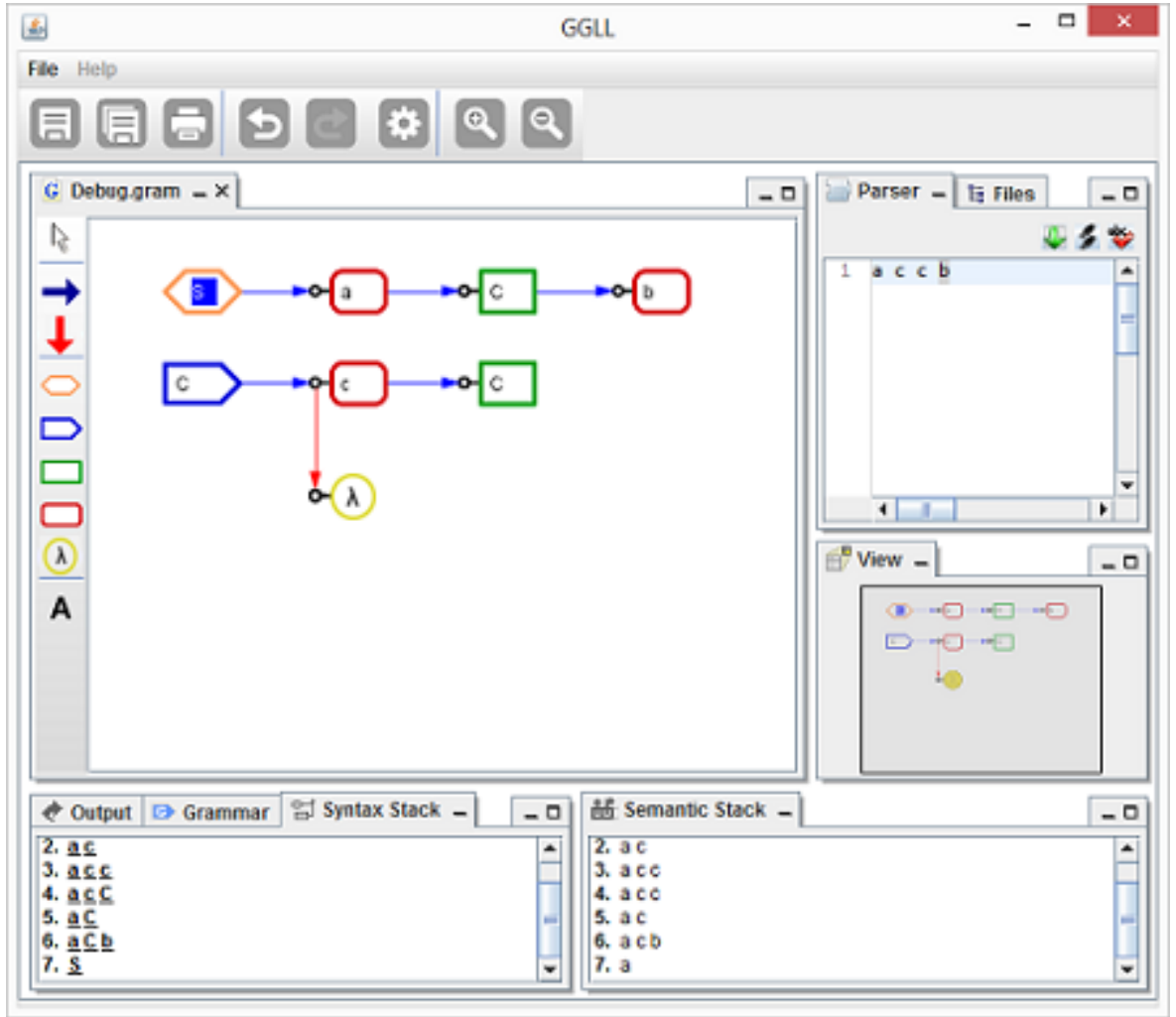

Figura C.16: GGLL.UI - Exemplo de debug - Passo 5 


\section{C.9 Análise Léxica}

O GGLL utiliza o JFlex [Kle09] para se definir e gerar um analisador léxico. O JFlex por sua vez utiliza um arquivo com uma especificação léxica e seu manual pode ser encontrado em http: //jflex.de/manual.html. No momento da criação do projeto de uma gramática o GGLL.UI produz um arquivo contendo um código-fonte Lex padrão que é utilizado para se gerar um analisador léxico por meio do JLex. Esse arquivo pode ser modificado caso haja necessidade.

\section{C.10 Análise Semântica}

O GGLL utiliza uma classe em Java onde podem ser criadas rotinas semânticas especificadas em cada nó da gramática gráfica. Essa classe deve herdar a classe SemanticRoutineClass que irá conter métodos e propriedades que tornam possível a realização das rotinas semânticas. Seus métodos são:

- I(n): retorna um número inteiro que está na posição $n$ da pilha semântica a partir do topo, sendo o topo 0.

- $F(n)$ : retorna um número real que está na posição $n$ da pilha semântica;

- $S(n)$ : retorna uma cadeia de caracteres que está na posição n da pilha semântica;

- N(n): retorna um item semântico que está na posição $n$ da pilha semântica;

- getCurrentToken: retorna o token atual;

- getParserStack: retorna a pilha semântica.

\section{C.11 Exemplo de uma Calculadora com Atribuição}

A seguir é mostrado como construir uma gramática de uma calculadora que contém as operações de atribuição, soma, subtração, multiplicação, divisão e impressão do valor de uma variável (identificador). Para isso começa-se construindo a gramática da figura C.17. 


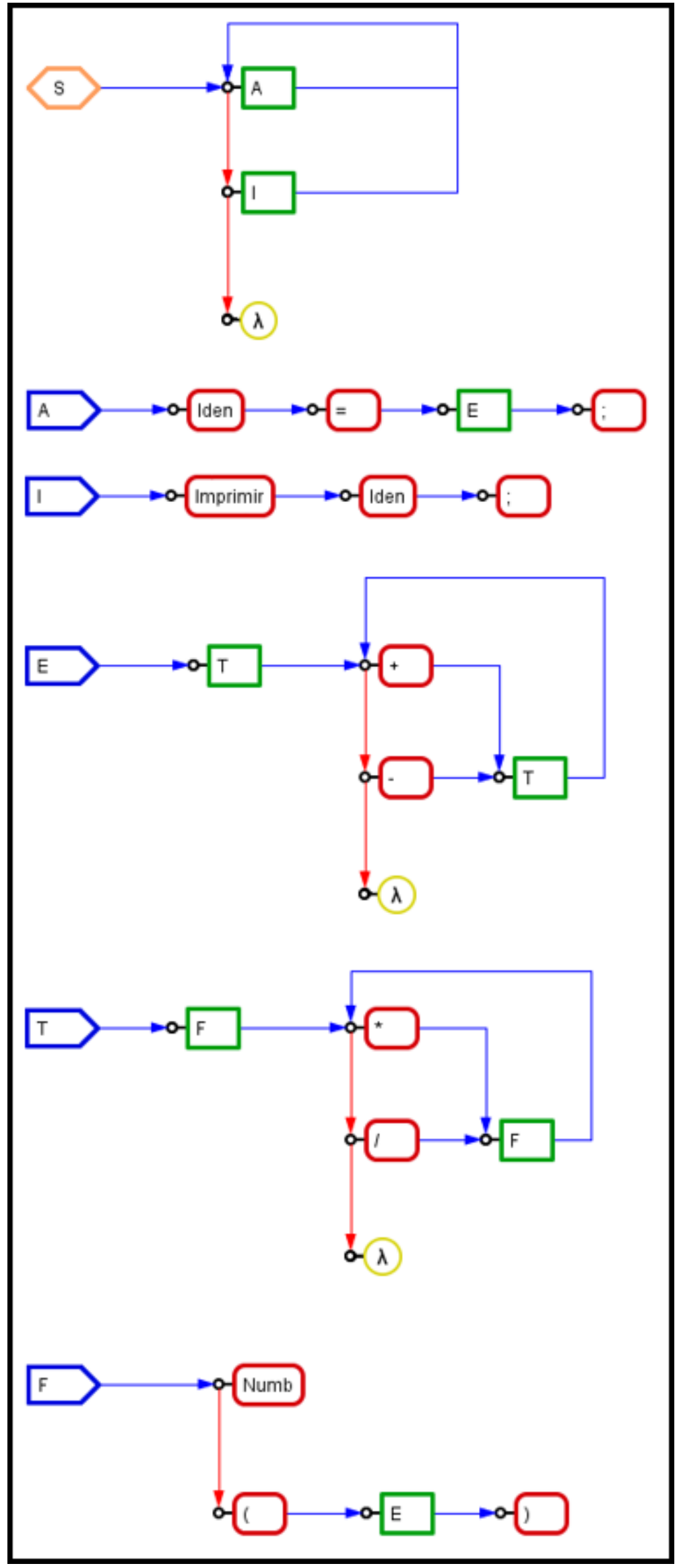

Figura C.17: GGLL.UI - Gramática gráfica de uma calculadora 
Essa gramática gráfica é semelhante à seguinte gramática em notação ENBF, onde os símbolos terminais são representados entre apóstrofes:

$$
\begin{aligned}
& S \rightarrow(A \mid I)^{*} \\
& A \rightarrow \text { Iden }=E \\
& I \rightarrow{ }^{\prime} \text { Imprimir }=\text { Iden } \\
& E \rightarrow T\left(\left({ }^{\prime}+\left.^{\prime}\right|^{\prime}-^{\prime}\right) T\right)^{*} \\
& T \rightarrow F\left(\left(\left.{ }^{\prime} *^{\prime}\right|^{\prime} /{ }^{\prime}\right) F\right)^{*} \\
& \left.F \rightarrow{ }^{\prime} N u m b^{\prime}\right|^{\prime}\left({ }^{\prime} E^{\prime}\right)^{\prime}
\end{aligned}
$$

Clicando em Build (ver tabela C.1), serão criadas as tabelas para a execução da análise sintática. Com isso, pode-se testar algumas expressões como por exemplo: $a=10+20$; que retornará uma mensagem informando que a expressão foi reconhecida com sucesso.

Caso seja inserida uma expressão que contenha um erro sintático, como por exemplo $b 10+20$, faltando assim o símbolo =, o sistema irá identificar essa falha, tentará corrigi-la para que a execução possa continuar, exibindo então uma mensagem informando que encontrou um erro e inseriu um símbolo $=$ entre $b$ e 10.

É possível verificar as pilhas sintática e semântica durante o reconhecimento das cadeias de entrada nas abas Syntax Stack e Semantic Stack (ver itens C.7.8 e C.7.9 respectivamente).

\section{C.12 Adição de rotinas semânticas}

Foi visto acima como criar um analisador sintático para uma gramática gráfica. Porém, não há execução de rotinas semânticas fundamentais para um compilador ou interpretador. Essas rotinas podem ser inseridas na gramática para se obter um compilador ou interpretador completo. Para isso, basta selecionar o nó onde se deseja adicionar uma rotina semântica, acionar nele o botão esquerdo do mouse, selecionar a opção Semantic Routine, em seguida Create New, como indicado na figura C.18.

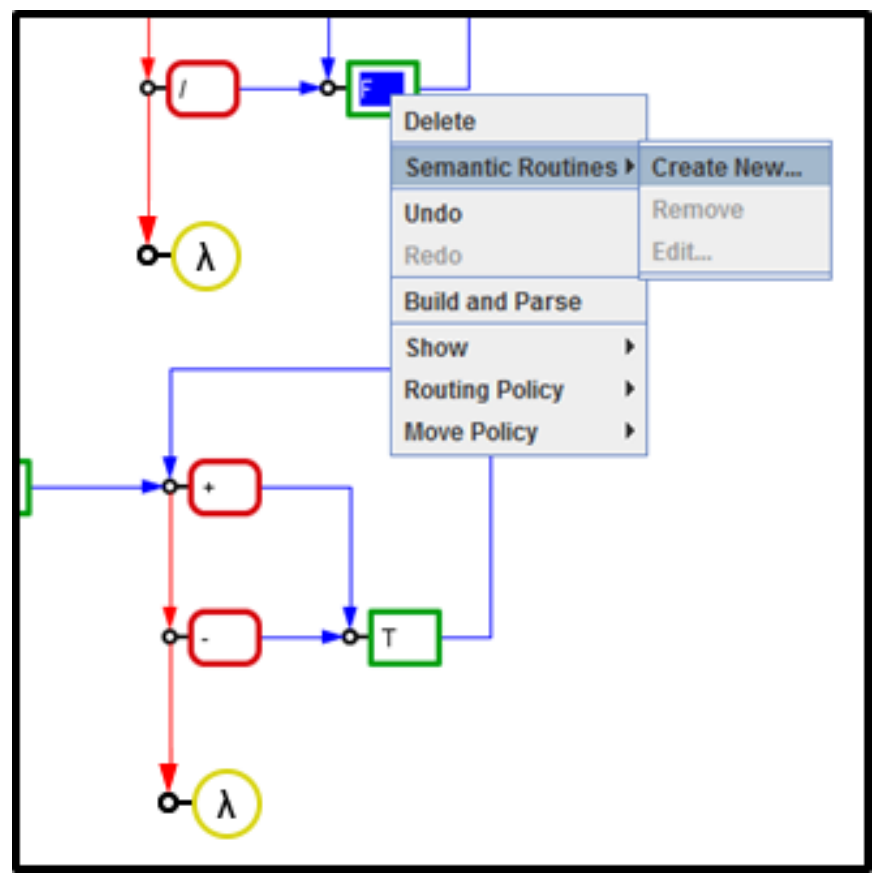

Figura C.18: GGLL.UI - Adição de rotina semântica 
Após iniciar-se assim a criação de uma nova rotina, será apresentada a tela da figura C.19 onde deve ser inserido o nome da rotina semântica, além do código que será executado.

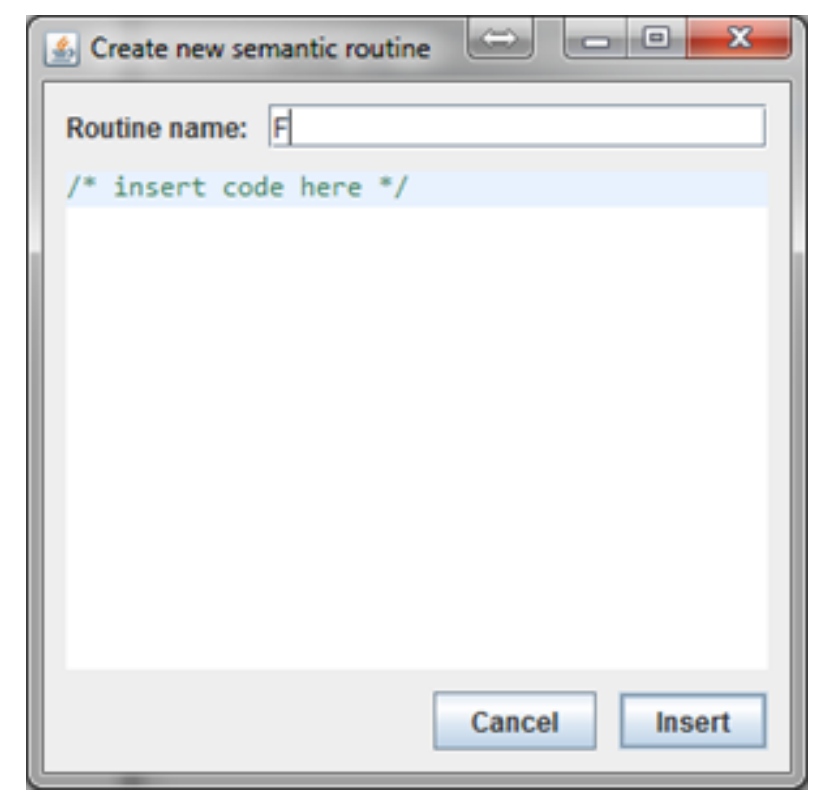

Figura C.19: GGLL.UI - Código da Rotina Semântica

Em nosso exemplo foram adicionadas algumas rotinas semânticas, deixando a gramática conforme a figura C.20. 


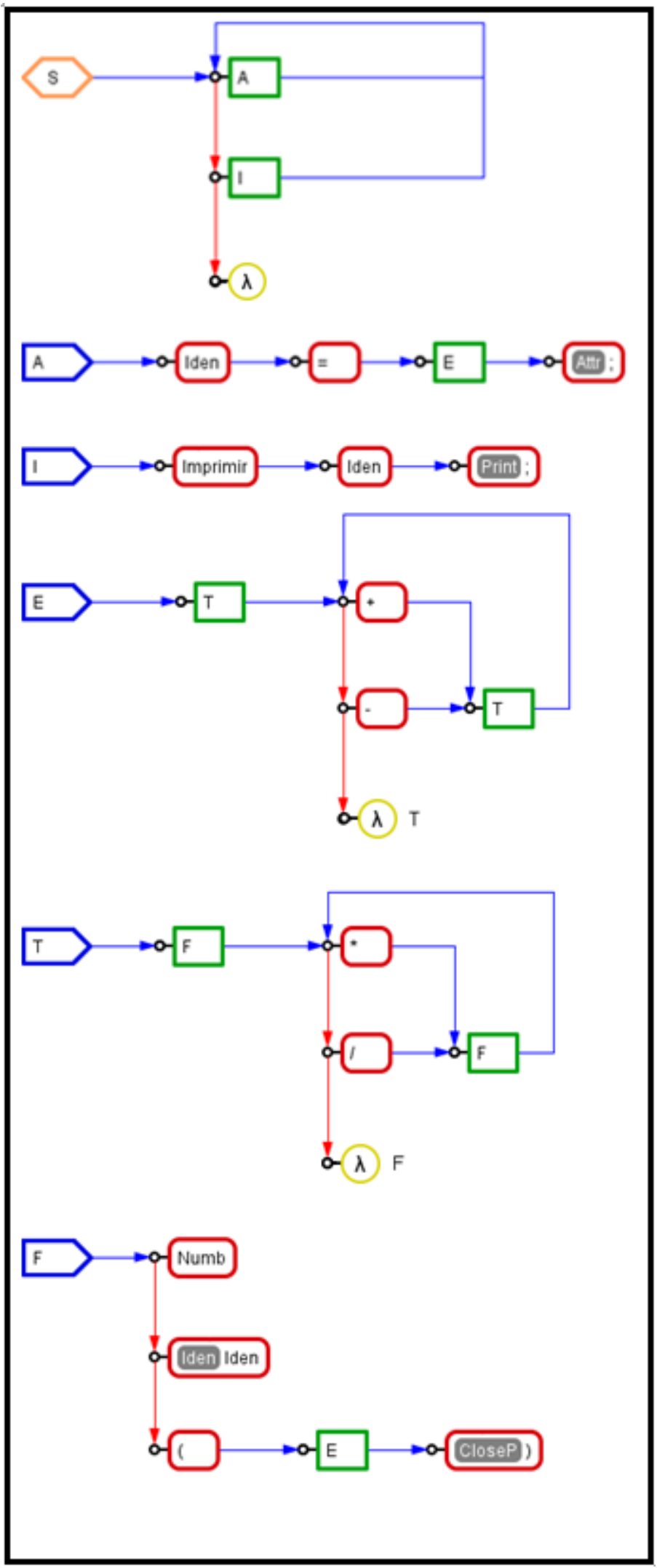

Figura C.20: GGLL.UI - Gramática gráfica de uma calculadora com rotinas semânticas

Cada rotina semântica é detalhada no quadro C.1.

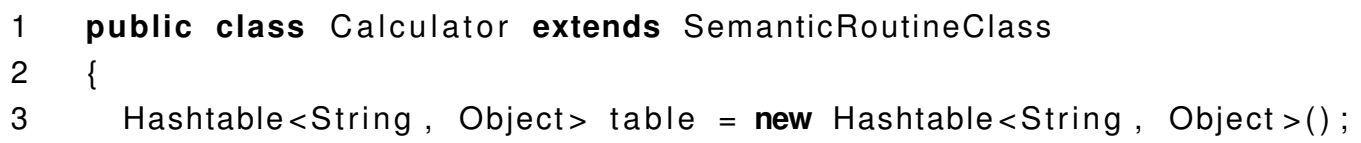


4

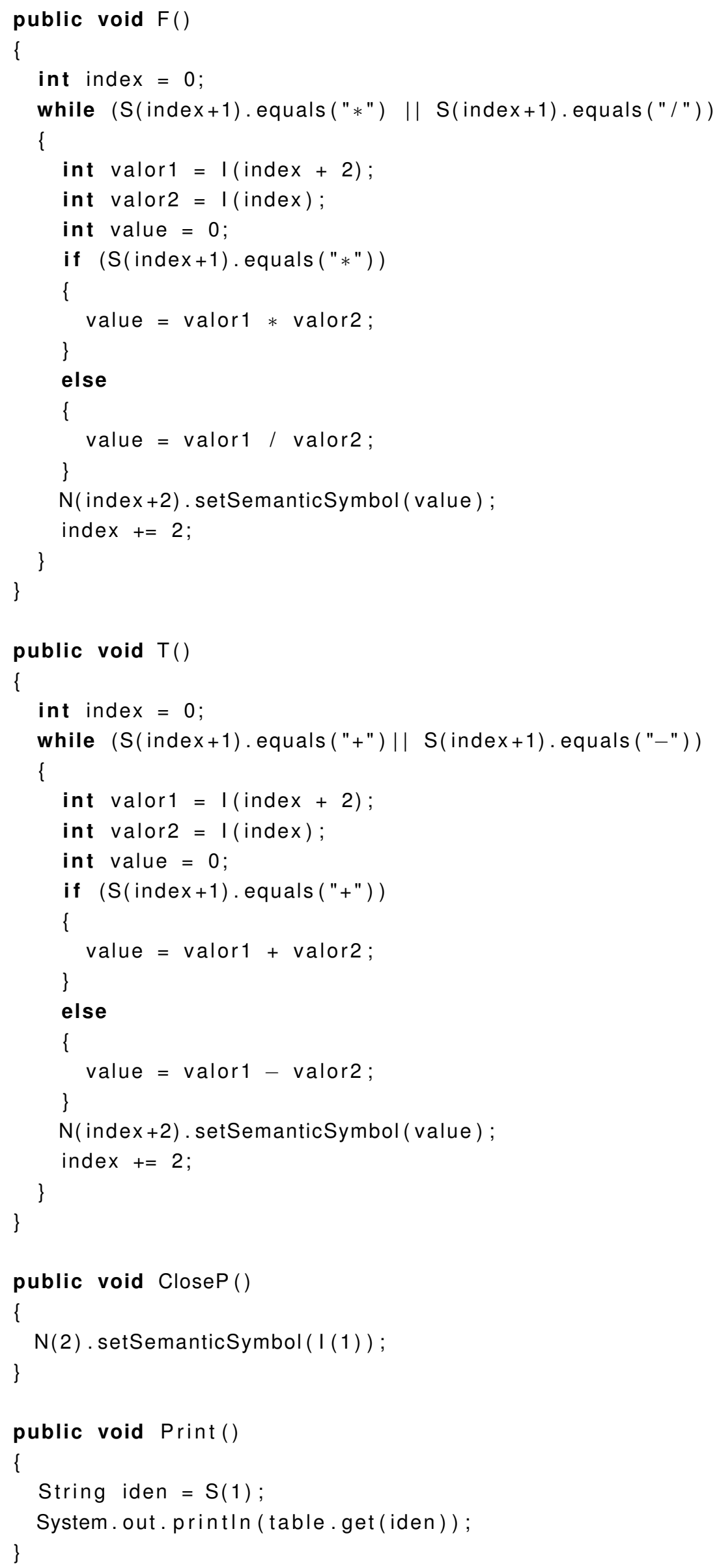




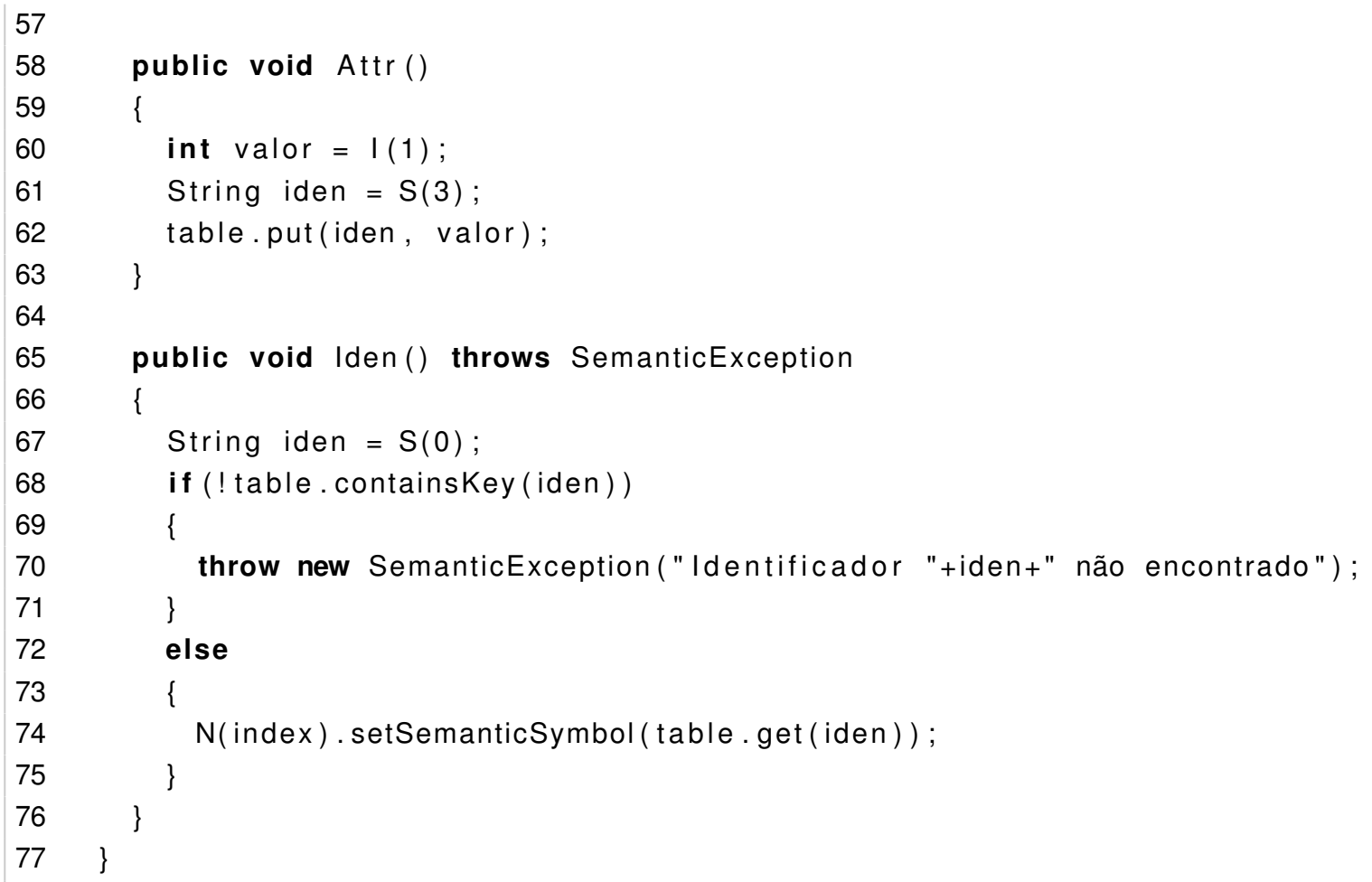

Quadro C.1: Exemplo de rotinas semânticas

\section{C.13 O GGLL.Core}

O GGLL.Core é composto de diversas classes responsáveis por aplicar o algoritmo GGLL nas tabelas geradas pelo GGLL.UI a partir da gramática desenhada. Para isso deve-se primeiro gerar o arquivo com código XML com as tabelas referidas. Após geradas as tabelas do GGLL, e o arquivo léxico e o arquivo semântico pelo GGLL.UI, pode-se utilizá-los em um sistema totalmente independente, apenas referenciando o GGLL.Core. Isso significa que o GGLL.Core é independente de qualquer ambiente de programação. Ele também é independente do GGLL.UI usado para desenhar a gramática. A única dependência é a JVM (Java Virtual Machine). Não há dependência do JDK (Java Development Kit), que é apenas usado pelo GGLL.UI.

\section{C.13.1 Arquivo Léxico}

O GGLL.UI gera por padrão uma classe contendo um analisador léxico utilizando o JLex. Esse arquivo é encontrado no diretório export dentro do diretório do projeto da gramática. Esse arquivo tem o nome de Yylex.java.

\section{C.13.2 Arquivo Semântico}

O GGLL.UI gera uma classe com as rotinas semânticas criadas na especificação da gramática. Esse arquivo tem o nome de [Nome do Projeto].java. 


\section{C.13.3 Arquivo Sintático}

O arquivo sintático é um arquivo contendo código XML gerado pelo GGLL.UI, para as tabelas de nós, de terminais e de não terminais. O schema [SM14] do XML, que define as regras de validação da gramática é apresentado no quadro C.2.

1 <xs:schema xmlns:xs=" http://uww.w3.org/2001/XMLSchema">

$2<x$ s:element name="GGLL">

$3<x$ :complextype $>$

$4<x$ :sequence $>$

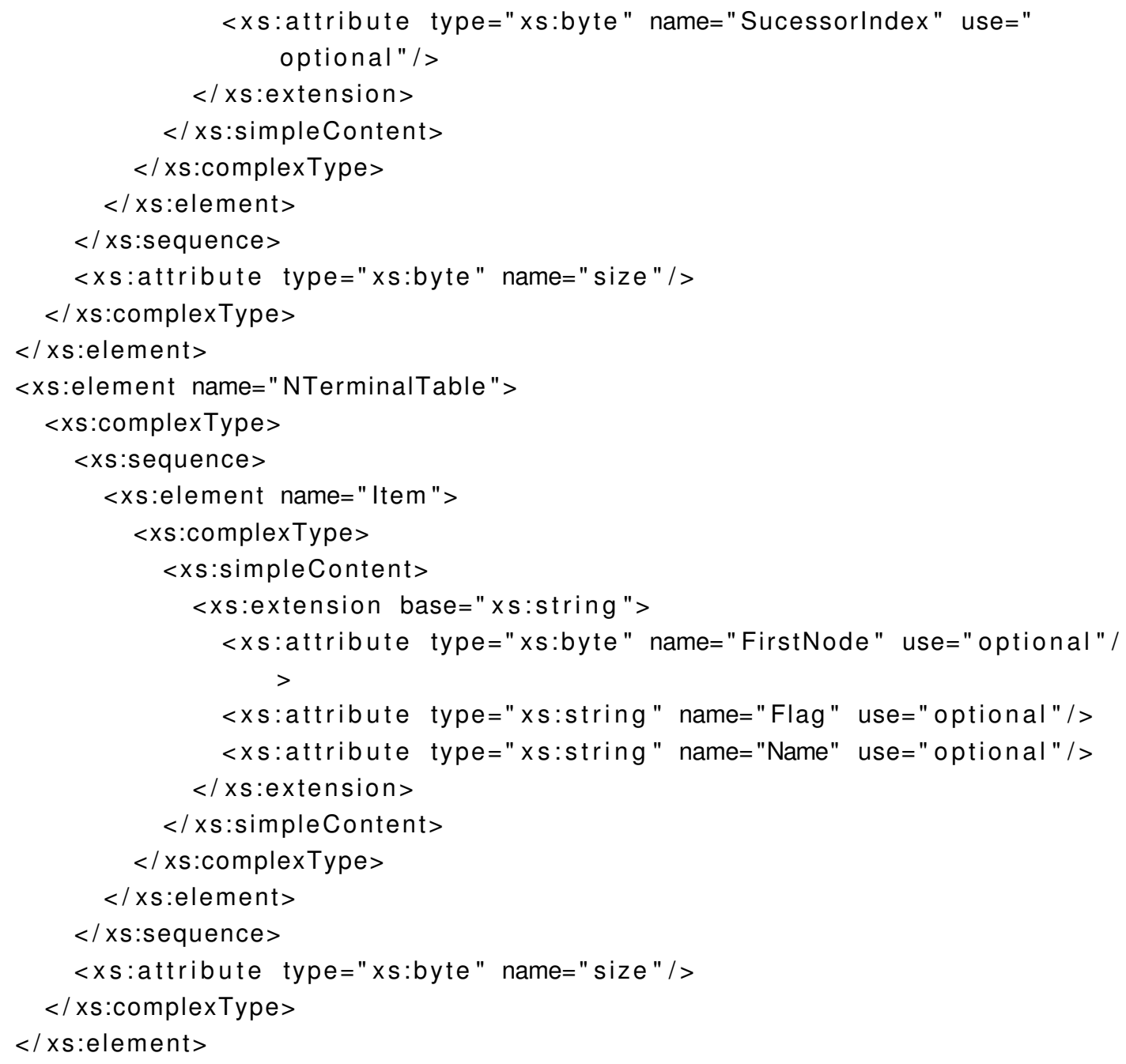




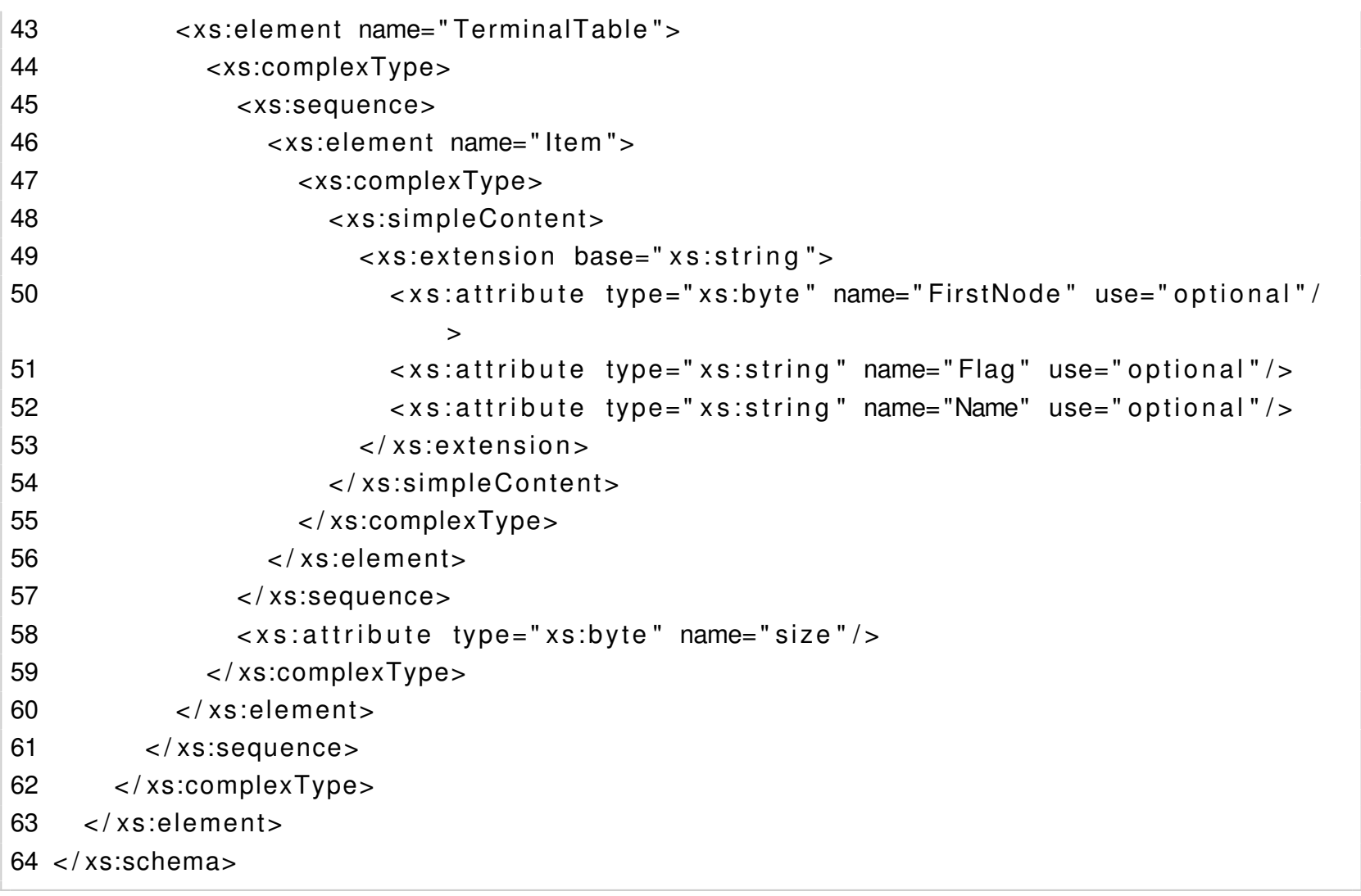

Quadro C.2: Schema XML Gramática

\section{C.13.4 Execução do GGLL.Core}

Há duas maneiras de executar o GGLL. A primeira é usar apenas o GGLL.UI, desenhando uma gramática e imediatamente validando-a e testando-a com cadeias de entrada fornecidas na tela do sistema. A segunda é usar o GGLL.Core, que emprega as tabelas geradas pelo GGLL.UI. Dessa maneira fica-se totalmente independente do GGLL.UI. O projeto assim gerado pode ser usado em outro projeto. A seguir é dado o exemplo da execução do GGLL.Core.

Para executar o GGLL.Core, deve-se chamar a classe Parser passando como parâmetro o analisador léxico, a classe com as rotinas semânticas e as tabelas geradas pelo GGLL.UI. O quadro C.3 apresenta um código dessa execução.

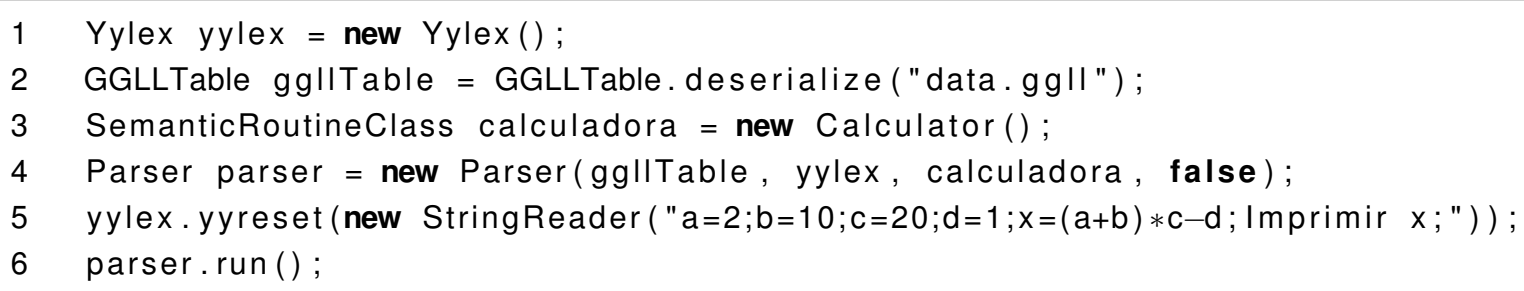

Quadro C.3: Exemplo de execução do GGLL.Core

Na linha 10 analisador léxico é instanciado. Na linha 20 arquivo XML contendo as tabelas do GGLL é convertido para o objeto GGLLTable. Na linha 3 é instanciada a classe "Calculadora" contendo as rotinas semânticas. Na linha 4 o objeto Parser é criado passando-se como argumentos as tabelas do GGLL, o analisador léxico, a instância das rotinas semânticas e o parâmetro false. Esse último indica, no exemplo, que o analisador não (false) irá operar em modo debug, isto é 
passo a passo. Na linha 5 a cadeia de entrada a ser analisada pelo Parser $(a=2 ; b=10 ; c=20$; $d=1 ; x=(a+b) * c-d$; Imprimir $x$;) é definida por meio do método yyreset do analisador léxico. Finalmente, na linha 6 é chamado o método run do Parser que irá executar o GGLL.

Após a execução do método run da classe Parser, executando-se o método isSuccess dessa classe obtém-se o valor true para sucesso na análise sintática ou false caso ocorra um erro na análise sintática. Além disso pode-se executar o método getErrorList que retorna a lista de erros que ocorreram ao executar a análise sintática. 
APÊNDICE C 


\section{Referências Bibliográficas}

[ALSU08] Alfredo V. Aho, Monica S. Lam, Ravi Sethi e Jeffrey D. Ullman. Compiladores Princípios, técnicas e ferramentas. Pearson, São Paulo, SP, Brasil, 2008. xv, 7, 8, $16,19,20$

[BBG $\left.{ }^{+} 63\right]$ J. W. Backus, F. L. Bauer, J. Green, C. Katz, J. McCarthy, A. J. Perlis, H. Rutishauser, K. Samelson, B. Vauquois, J. H. Wegstein, A. van Wijngaarden e M. Woodger. Revised report on the algorithm language algol 60. Commun. $A C M, 6(1): 1-17$, Janeiro 1963. 2

[BPSM ${ }^{+}$08] Tim Bray, Jean Paoli, C. Michael Sperberg-McQueen, Eve Maler e François Yergeau. Extensible markup language $(\mathrm{xml}) 1.0$ (fifth edition). http://www.w3.org/TR/REC-xml/, 2008. Último acesso em 03/04/2014. 54

[Bra09] G. H. Braga. Asin user manual. Dissertação de Mestrado, USP, 2009. 1, 33

[Cho59] Noam Chomsky. On certain formal properties of grammars. Information and Control, 2(2):137-167, June 1959. 9

[Del04] M. Delamaro. Como Construir um Compilador Utilizando Ferramentas Java. Novatec, 2004. 15, 17

[Der69] F. L. Deremer. Practical translators for Ir(k) languages. Relatório técnico, Massachusetts Institute of Technology, Cambridge, MA, USA, 1969. 20

[DeR71] Franklin L. DeRemer. Simple Ir(k) grammars. Commun. ACM, 14(7):453-460, Julho 1971. 20

[Dij97] Edsger Wybe Dijkstra. A Discipline of Programming. Prentice Hall PTR, 1997. 2

[Ear70] Jay Earley. An efficient context-free parsing algorithm. Commun. ACM, 13(2):94102, Fevereiro 1970. 17

[GH98a] Etienne M. Gagnon e Laurie J. Hendren. Sablecc, an object-oriented compiler framework. Em Proceedings of the Technology of Object-Oriented Languages and Systems, TOOLS '98, páginas 140-, Washington, DC, USA, 1998. IEEE Computer Society. 1

[GH98b] Etienne M. Gagnon e Laurie J. Hendren. Sablecc, an object-oriented compiler framework. Em Proceedings of the Technology of Object-Oriented Languages and Systems, TOOLS '98, páginas 140-, Washington, DC, USA, 1998. IEEE Computer Society. 27

[GJHV06] E. Gamma, R. Johnson, R. Helm e J. Vlissides. Padrões de Projetos: Soluções Reutilizáveis. BOOKMAN COMPANHIA ED, 2006. 31, 52, 56, 71, 73, 74, 75

[Har13] Sam Harwell. Antlrworks 2 | tunnel vision laboratories. http://tunnelvisionlabs.com/ products/demo/antlrworks, 2013. Último acesso em 08/03/2014. 30, 32 
[HU69] John E. Hopcroft e Jeffrey D. Ullman. Formal Languages and Their Relation to Automata. Addison-Wesley Longman Publishing Co., Inc., Boston, MA, USA, 1969. 6

[Inf09] InfoNode. Infonode. http://www.infonode.se/, 2009. Último acesso em 04/01/2014. 54

[Jav14] Java. Como posso começar a desenvolver programas java com o java development kit (jdk)? https://www.java.com/pt_BR/download/faq/develop.xml, 2014. Último acesso em 03/04/2014. 55

[Joh78] S.C. Johnson. Yacc: Yet Another Compiler-compiler. Computing science technical report. Bell Laboratories, 1978. 23

[Joh79] Stephen C. Johnson. Yacc: Yet another compiler-compiler. Relatório técnico, AT\&T Bell Laboratories, Murray Hill, New Jersey 07974, 1979. 3

[Kas65] T. Kasami. An efficient recognition and syntax analysis algorithm for context free languages. 1965. 17

[Kle09] Gerwin Klein. Jflex. http://jflex.de/, 2009. Último acesso em 01/04/2014. 54, 90

[Kle14] Gerwin Klein. Jflex - the fast scanner generator for java. http://jflex.de/, 2014. Último acesso em 03/04/2014. 56

[Knu68] DonaldE. Knuth. Semantics of context-free languages. Mathematical systems theory, 2(2):127-145, 1968. 20, 29

[Kor69] A. J. Korenjak. A practical method for constructing Ir (k) processors. Commun. ACM, 12(11):613-623, Novembro 1969. 20

[Kow10a] T. Kowaltowski. Análise sintática ascendente. http://www.ic.unicamp.br/ tomasz/ mo403/restrito/transp_ho_071_090.pdf, 2010. Último acesso em 04/03/2014. 20

[Kow10b] T. Kowaltowski. Análise sintática descendente. http://www.ic.unicamp.br/ tomasz/ mo403/restrito/transp_ho_053_070.pdf, 2010. Último acesso em 04/03/2014. 21

[Lan74] Bernard Lang. Deterministic techniques for efficient non-deterministic parsers. Em Proceedings of the 2Nd Colloquium on Automata, Languages and Programming, páginas 255-269, London, UK, UK, 1974. Springer-Verlag. 26

[Lan13] LangPop. Programming language popularity. http://www.langpop.com, 2013. Último acesso em 03/03/2014. 3

[LS75] M. E. Lesk e E. Schmidt. Lex - a Lexical Analyzer Generator. Relatório técnico, Bell Laboratories, 1975. CS Technical Report No. 39. 24

[LS90] M. E. Lesk e E. Schmidt. Unix vol. ii. chapter Lex - Lexical Analyzer Generator, páginas 375-387. W. B. Saunders Company, Philadelphia, PA, USA, 1990. 2

[MC13] Jesús Mena-Chalco. Arquivos latex de exemplo de dissertação / tese. http://www. vision.ime.usp.br/ jmena/stuff/tese-exemplo, 2013. Último acesso em 27/12/2014. 2

[Ora13] Oracle. Netbeans visual library. https://platform.netbeans.org/graph/, 2013. Último acesso em 04/01/2013. 54

[Osw06] Derrick Oswald. Html parser | free development software downloads at sourceforge.net. http://sourceforge.net/projects/htmlparser/, 2006. Último acesso em 04/01/2014. 54 
[Par13] Terence Parr. The Definitive ANTLR 4 Reference. Pragmatic Bookshelf, 2nd edição, 2013. 2

[Per04] L. F. Pereira. Grview - um gerador gráfico de analisadores sintáticos. Relatório técnico, USP, 2004. 33

[PQ95] T. J. Parr e R. W. Quong. Antlr: A predicated-II(k) parser generator. Softw. Pract. Exper., 25(7):789-810, Julho 1995. 30

[RM89] P. Rechenberg e H. Mössenböck. A Compiler Generator for Microcomputers. Prentice Hall, 1989. 29

[SDM83] V. W. Setzer e I. S. H. De Melo. A Construcao de um Compilador. Campos, $3^{a}$ edição, 1983. 1, 3, 10, 15, 17, 18, 33, 39, 42, 47, 51

[Set79] V. W. Setzer. Non-recursive top-down syntax analysis. Software-Practice and Experience, 9:237-245, 1979. 1, 33

[SM14] Henry Sperberg-McQueen, C. M.; Thompson. W3c xml schema. http://www.w3.org/ XML/Schema/, 2014. Último acesso em 16/04/2014. 97

[W3C14] W3C. Html tutorial. http://www.w3schools.com/html, 2014. Último acesso em 04/03/2014. 2

[Wir66] Niklaus Wirth. A programming language for the 360 computers. Relatório técnico, Stanford University, Stanford, CA, USA, 1966. 51

[Wir78] Niklaus Wirth. Algorithms + Data Structures $=$ Programs. Prentice Hall PTR, Upper Saddle River, NJ, USA, 1978. 31

[You66] Daniel H. Younger. Context-free language processing in time n3. Em Proceedings of the 7th Annual Symposium on Switching and Automata Theory (Swat 1966), SWAT '66, páginas 7-20, Washington, DC, USA, 1966. IEEE Computer Society. 17 